ALBERTO MITSUO OYAMA

ELIMINAÇÃO DE ARTEFATOS DE ESTÍMULO EM POTENCIAIS EVOCADOS SOMATOSSENSITIVOS 
ALBERTO MITSUO OYAMA

\section{ELIMINAÇÃO DE ARTEFATOS DE ESTÍMULO EM POTENCIAIS EVOCADOS SOMATOSSENSITIVOS}

Dissertação apresentada à Escola Politécnica da Universidade de São Paulo para obtenção do título de Mestre em Engenharia.

Área de Concentração:

Sistemas Eletrônicos

Opção:

Engenharia Biomédica

Orientadora:

Cinthia Itiki 
FICHA CATALOGRÁFICA

Oyama, Alberto Mitsuo

Eliminação de artefatos de estímulo em potenciais evocados somatossensitivos / A.M. Oyama. -- São Paulo, 2010.

$79 \mathrm{p}$.

Dissertação (Mestrado) - Escola Politécnica da Universidade de São Paulo. Departamento de Engenharia de Telecomunicações e Controle.

1. Processamento de sinais biomédicos 2. Potenciais evo cados I. Universidade de São Paulo. Escola Politécnica. Departamento de Engenharia de Telecomunicações e Controle II. t. 
OYAMA, A.O. Eliminação de artefatos de estímulo em potenciais evocados somatossensitivos. 2010. 79p. Dissertação de mestrado - Escola Politécnica da Universidade de São Paulo, São Paulo, 2010.

\section{Errata}

Folha Linha

$\begin{array}{ccc} & & \text { SEP } \\ \text { SEPs } \\ 14 & 3 & \text { SEPs, do inglês Sensory Evoked } \\ 14 & 8 & \text { Potentials } \\ 32 & 7 & \text { SEPS } \\ 32 & 8 & \text {, somatimulação sensitiva. } \\ 32 & 9 & \text { São mais sensíveis } \\ 33 & 17 & \text { fossa superior } \\ 38 & 4 & \text { estimulação do dedo médio } \\ 38 & 10 & \text { estimulação no punho. } \\ & & \end{array}$

$49 \quad 1$

$66 \quad 4$

$67 \quad 7$

$67 \quad 15$

$68 \quad 3$

$68 \quad 5$

$70 \quad 6$

$70 \quad 8$

$70 \quad 10$

$70 \quad 11$

\section{Gaussiano} neurologicamente normal, após seu consentimento escrito.

$$
-0,05 s \leq t \leq 0,10 s
$$

$$
0,10 s \leq t \leq 0,20 s
$$$$
0,20 s \leq t \leq 0,60 s
$$$$
0,60 s \leq t \leq 1,50 s
$$$$
0,00 s \leq t \leq 0,20 s
$$$$
0,20 s \leq t \leq 0,35 s
$$$$
0,35 s \leq t \leq 0,50 s
$$$$
0,50 s \leq t \leq 2,35 s
$$

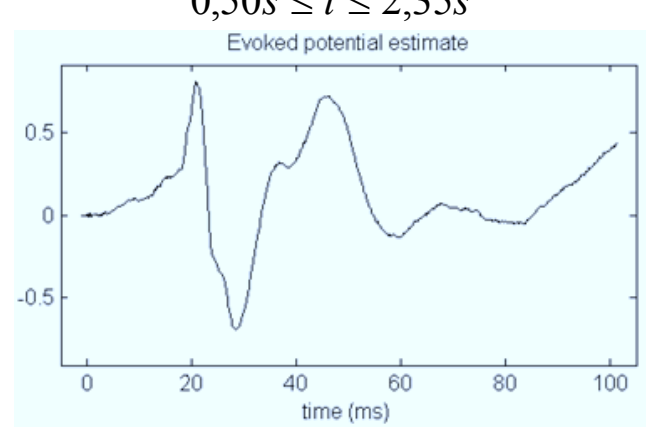

essa exclusão provavelmente forneceria amplitudes grandes grande amplitude
Leia-se

SSEP

SSEPs

SSEPs, do inglês SomatoSensory Evoked Potentials

SSEPs

estimulação sensorial externa. e somatossensitivo.

Os potenciais evocados corticais são mais sensíveis fossa posterior estimulação dos dedos o posicionamento do eletrodo para estimulação do nervo mediano no punho.

$t_{2}=1,6 \mathrm{~ms}$. $\mathrm{O}$ ajuste desses valores foi visual e empírico. gaussiano branco

neurologicamente normal.

$$
\begin{gathered}
-0,05 \mathrm{~ms} \leq t \leq 0,10 \mathrm{~ms} \\
0,10 \mathrm{~ms} \leq t \leq 0,20 \mathrm{~ms} \\
0,20 \mathrm{~ms} \leq t \leq 0,60 \mathrm{~ms} \\
0,60 \mathrm{~ms} \leq t \leq 1,50 \mathrm{~ms} \\
0,00 \mathrm{~ms} \leq t \leq 0,20 \mathrm{~ms} \\
0,20 \mathrm{~ms} \leq t \leq 0,35 \mathrm{~ms} \\
0,35 \mathrm{~ms} \leq t \leq 0,50 \mathrm{~ms} \\
0,50 \mathrm{~ms} \leq t \leq 2,35 \mathrm{~ms}
\end{gathered}
$$

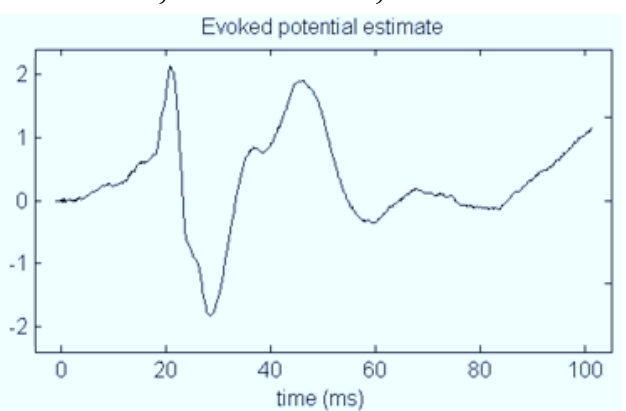

essa exclusão forneceria pequena amplitude pequena amplitude 
Aos meus pais, pela minha vida e incentivo aos estudos.

À Karin, pelo seu amor, paciência e companheirismo. Ao meu filho Rafael, pela alegria e bom humor. Ao meu irmão Sergio, pelo apoio e amizade. 


\section{Agradecimentos}

À Profa. Cinthia Itiki pela paciência, compreensão, orientação, apoio e pela oportunidade de aprendizado, desenvolvimento e crescimento acadêmico.

Aos meus familiares e à minha esposa pelo convívio, incentivo e apoio em todos os momentos.

Aos professores André F. Kohn, Sérgio S. Furuie e Henrique T. Moriya pelas sugestões ao desenvolvimento desta dissertação.

A todos os professores e integrantes do Laboratório de Engenharia Biomédica pela oportunidade de desenvolvimento e crescimento acadêmico.

A todos professores da EPUSP, fundamentais à minha formação acadêmica.

Aos gerentes da empresa em que trabalho, que proporcionaram o tempo para a realização do mestrado.

Aos meus amigos e colegas, pelo incentivo e apoio. 


\section{Resumo}

Os potenciais evocados têm uma consagrada utilização em clínica. Sua obtenção é dificultada pela presença de outros sinais biológicos, de artefatos de movimento, de ruído eletrônico, de interferência da rede elétrica e de artefatos de estímulo. A média síncrona ou promediação é um método que elimina os sinais que não estejam sincronizados com a estimulação, incluindo os outros sinais biológicos, os artefatos de movimento, o ruído e a interferência. No entanto, esse método não consegue eliminar os artefatos de estímulo. Outros métodos devem ser usados para essa tarefa. Para esses métodos, a eliminação do artefato de estímulo é bem sucedida quando o artefato não se sobrepõe ao potencial evocado. Porém, para uma captação próxima ao local de estimulação, a sobreposição ocorre e dificulta a eliminação do artefato de estímulo. O objetivo deste trabalho foi o de estudar a variação da amplitude e latência do pico do potencial evocado e sua influência nas estimativas da amplitude, da latência e do erro quadrático médio. Para potenciais evocados em que houve sobreposição com o artefato, o erro médio quadrático sempre foi reduzido com a remoção do artefato de estímulo. O erro de medição da latência foi reduzido a praticamente zero, independentemente da amplitude do potencial evocado. Por outro lado, o método inseriu erro na medição da amplitude de potenciais evocados grandes. Por isso, nesse caso específico de atraso pequeno e amplitude grande, a medição da amplitude deve ser feita diretamente no sinal antes da remoção do artefato de estímulo. Comparando a ocorrência de sobreposição com os locais de captação do potencial evocado, pode-se afirmar que, para o modelo de artefato de estímulo usado neste trabalho, a necessidade de se aplicar o procedimento de remoção de artefato se restringiu aos potenciais evocados captados no cotovelo, para estimulação do nervo mediano tanto no punho quanto na mão.

Palavras-chave: Potenciais evocados somatossensitivos. Artefato de estímulo. Ajuste de curvas. 


\begin{abstract}
Evoked potentials have been used in clinics. Their measurement is hindered by the presence of other biological signals, movement artifacts, electronic noise, power-line interference, and stimulus artifacts. Synchronous averaging is a method that eliminates the signals that are not synchronized with the stimulation, including other biological signals, movement artifacts, noise and interference. However, this method fails to eliminate stimulus artifacts. Other methods must be used in this task. Using these methods, one can obtain success in the stimulus artifact elimination, whenever the artifact does not superimpose with the evoked potential. Nevertheless, for a measurement close to the stimulation site, the superimposition is a fact that hinders the elimination of the stimulus artifact. The objective of this Master's thesis was to study the variation of the amplitude and latency of an evoked potential and verify their influence on the amplitude and latency estimates, as well as on the mean square error. For evoked potentials in which there was superposition, the mean square error was always reduced by the removal of the stimulus artifact. Latency measurement errors were reduced to zero, regardless of the evoked potential amplitude. However, this method inserted amplitude measurement errors for large evoked potentials. So, in the case of short delays and large amplitudes, amplitude measurements should be performed directly on the signal, before stimulus artifact removal. By comparing the presence of superposition with the evoked potential recording sites, one may state that, for the stimulus artifact model used in this work, the need to apply the artifact removal procedure was restricted to the evoked potentials recorded on the elbow, for median nerve stimulation both on wrist and hand.
\end{abstract}

Key-words: Somatosensory evoked potentials. Stimulus artifact. Curve fitting. 


\section{Lista de Figuras}

Figura 1.1 - Sinais captados: a) respostas a um único estímulo e b) potencial evocado obtido pela média síncrona de 2.000 respostas.

Figura 1.2 - Potenciais evocados somatossensitivos calculados pela média síncrona de 1000 respostas captadas por eletrodos de superfície localizados a) no escalpo (C4' - Fpz'), b) na vértebra $\mathrm{C} 5, \mathrm{c}$ ) no ombro (ponto de Erb) e d) no cotovelo. Para cada posição há 5 médias síncronas. Os estímulos de corrente tinham duração de $0,2 m s$ e amplitude equivalente a 1 vez e meia do limiar motor. Foram aplicados no punho esquerdo à taxa de estimulação foi de $3 \mathrm{~Hz}$. Os sinais foram captados com eletrodos de superfície em indivíduo neurologicamente normal e sadio, no Laboratório de Engenharia Biomédica da EPUSP.

Figura 1.3 - Remoção de artefato de estímulo de polaridade positiva pelo algoritmo de O'Kleefe

Figura 1.4 - Descontinuidade resultante do método de O'Kleefe. Sinal remanescente após a remoção do artefato de estímulo. 22

Figura 1.5 - Artefato médio deslocado a) de $0,050 \mathrm{~ms}$ e b) de $0,005 \mathrm{~ms}$. 23

Figura 1.6 - (A) Artefato de estímulo. As setas $\mathrm{p}_{0}, \mathrm{p}_{1}, \mathrm{p}_{2}, \mathrm{p}_{3}$ indicam a separação dos segmentos. (B) Primeiro segmento. (C) Segundo segmento. (D) Terceiro segmento. (E) Componente adicional.

Figura 1.7 - Remoção de artefato de estímulo pelo método de Harding. 26

Figura 1.8 - (A) Potencial evocado contaminado com artefato de estímulo $c(t)$ e os pontos determinados para delimitação dos trechos. (B) Potencial evocado após a aplicação do algoritmo.

Figura 2.1 - Efeito da inversão da posição dos eletrodos de captação em um EP. .35

Figura 2.2 - Latência de pico (L1) e latência entre picos (L2). 36

Figura 2.3 - Amplitude de pico (A1) e amplitude pico a pico (A2). 37

Figura 2.4 - Possíveis medições de amplitude na presença de pico duplo: a) amplitude do pico mais proeminente, $b$ ) amplitude do primeiro pico, c) média entre os picos, d) intersecção das retas tangenciais. 
Figura 2.5 - Eletrodos de estimulação fixados ao pulso de um voluntário. Ambos os eletrodos (o catodo e o anodo) estão fixos à peça plástica preta. 38

Figura 2.6 - Localização do nervo mediano nos membros superiores. 39

Figura 2.7 -O sistema internacional 10-20 nas vistas a) lateral esquerda e b) superior da cabeça. Os símbolos indicam $\mathrm{A}=$ lóbulo auricular, $\mathrm{C}=$ central, $\mathrm{Pg}=$ nasofaríngeo, $\mathrm{P}=$ parietal, $\mathrm{F}=$ frontal, $\mathrm{F} p=$ frontal polar, $\mathrm{O}=$ occipital.

Figura 2.8 - Localização e nomenclatura dos eletrodos intermediários (10\%).

Figura 2.9 - Tipos de artefatos de estímulo: a) bifásico de polaridade negativa; b) bifásico de polaridade positiva; c) monofásico de polaridade negativa; d) monofásico de polaridade positiva. Os picos negativos são indicados para cima 42

Figura 3.1 - (A) Dois ciclos completos de senóide de amplitude unitária e freqüência de $666,67 \mathrm{~Hz}$ com início em 6ms. (B) Co-seno de amplitude 0,5 e freqüência de $333,33 \mathrm{~Hz}$ somado a um nível DC (offset) de 0,5. (C) Modelo do SEP, resultante da multiplicação dos sinais anteriores.

Figura 3.2 - Modelo de potencial evocado com os parâmetros atraso $(D)$, latência $(L)$ e amplitude pico a pico (App). 46

Figura 3.3 - Potencial evocado somato-sensitivo captado na fossa antecubital em resposta à estimulação do nervo mediano (punho). 46

Figura 3.4 - Modelo do potencial evocado com duração de $3 \mathrm{~ms}$, atraso $D$ de $1 \mathrm{~ms}$ e parâmetro $A$ unitário (amplitude de pico de 0,83 ) que foi ajustado para uma comparação visual com o potencial evocado da Figura 3.3.

Figura 3.5 - Um pulso bipolar retangular e três segmentos exponenciais do modelo de artefato de estímulo. 48

Figura 3.6 - Sinal composto pelo artefato de estímulo, resposta evocada e ruído. As flechas indicam os pontos que demarcam o início e o fim do segundo segmento exponencial.

Figura 3.7 - Medição da amplitude pico-a-pico $\left(A_{p p}\right)$ no sinal original $s(t)$. 52

Figura 3.8 - Medição da amplitude pico-a-pico $\left(A_{p p}\right)$ na estimativa do potencial evocado $\hat{x}(t)$. 
Figura 3.9 - Medida de latência. O cruzamento do zero do sinal diferencial define o pico pequeno da estimativa da resposta evocada (antes da remoção do artefato).

Figura 3.10 - Medida de latência. O cruzamento do zero do sinal diferencial define o pico da estimativa da resposta evocada (depois da remoção do artefato)

Figura 4.1 - Estimativa da resposta evocada

Figura 4.2 - Raiz quadrada do erro médio quadrático para diversos atrasos fixos, como função do parâmetro $A$. 56

Figura 4.3 - Raiz quadrada do erro médio quadrático para diversas amplitudes fixas, como função do atraso $D$ variando de $2 \mathrm{~ms}$ a $4 \mathrm{~ms}$

Figura 4.4 - Raiz quadrada do erro médio quadrático, em função do parâmetro $A$ (de 0,00 a 1,00 ) e do atraso $D$ (de $2 \mathrm{~ms}$ a $20 \mathrm{~ms}$ ), após remoção do artefato de estímulo.

Figura 4.5 - Diferença entre os erros médios quadráticos antes e depois da remoção do artefato de estímulo, em função do parâmetro $A$ (de 0,00 a 1,00) e do atraso $D$ (de $2 \mathrm{~ms}$ a $20 \mathrm{~ms})$.

Figura 4.6 - Erro de amplitude calculado antes (linha tracejada) e após remoção de artefato (linha contínua), representado como função do parâmetro $A$, para o atraso $D$ de $4 \mathrm{~ms}$.

Figura 4.7 - Erro de amplitude calculado antes (linha tracejada) e após remoção de artefato (linha contínua), representado como função do atraso $D$, para o parâmetro $A$ de 0,15 .

Figura 4.8 - Erro da amplitude pico-a-pico, em função do parâmetro $A$ (de 0,00 a 1,00) e do atraso $D$ (de $2 \mathrm{~ms}$ a $20 \mathrm{~ms}$ ), após remoção do artefato de estímulo.

Figura 4.9 - Diferença entre os erros absolutos da amplitude pico-a-pico medida antes e depois da remoção do artefato de estímulo, em função do parâmetro $A$ (de 0,00 a 1,00) e do atraso $D$ (de $2 \mathrm{~ms}$ a $20 \mathrm{~ms})$.

Figura 4.10 - Erro de latência (em ms) calculado antes (linha tracejada) e depois (linha contínua) da remoção do artefato, como função do parâmetro $A$, para um atraso $D$ de $4 \mathrm{~ms}$. 
Figura 4.11 - Erro de latência (em ms) calculado antes (linha tracejada) e depois (linha contínua) da remoção do artefato como função do atraso $D$, para um parâmetro $A$ de 0,15

Figura 4.12 - Erro da latência (em ms), em função do parâmetro $A$ (de 0,00 a 1,00) e do atraso $D$ (de $2 \mathrm{~ms}$ a $20 \mathrm{~ms}$ ), após remoção do artefato de estímulo

Figura 4.13 - Diferença (em ms) entre os erros absolutos da latência medida antes e depois da remoção do artefato de estímulo, em função do parâmetro $A$ (de 0,00 a 1,00 ) e do atraso $D$ (de $2 \mathrm{~ms}$ a $20 \mathrm{~ms})$. 66

Figura 4.14 - Potencial evocado somatossensitivo captado no cotovelo de uma voluntária neurologicamente normal e artefato de estímulo.

Figura 4.15 - Estimativa do potencial evocado, após remoção do artefato de estímulo 68

Figura 4.16 - Sinais antes da remoção (em linha tracejada) e após a remoção (em linha contínua) do artefato de estímulo

Figura 4.17 - Potencial evocado somatossensitivo captado no escalpo de um voluntário neurologicamente normal e artefato de estímulo.

Figura 4.18 - Estimativa do potencial evocado, após remoção do artefato de estímulo

Figura 4.19 - Sinais antes da remoção (em linha tracejada) e após a remoção (em linha contínua) do artefato de estímulo.... 


\section{Lista de Tabelas}

Tabela 4.1 - Estimativas dos parâmetros das exponenciais para SEP captado no cotovelo.... 68

Tabela 4.2 - Estimativas dos parâmetros das exponenciais para SEP captado no escalpo......71 


\section{Sumário}

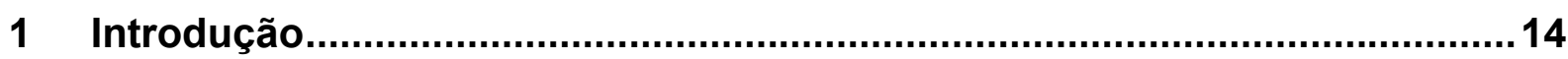

1.1 Técnicas pré-aquisição para remoção do artefato de estímulo.................17

1.1.1 Técnicas clínicas de minimização de artefato de estímulo................................. 18

1.1.2 Métodos de hardware para minimização do artefato de estímulo ....................... 18

1.1.3 Métodos baseados em estímulos adicionais ....................................................... 19

1.2 Técnicas pós-aquisição para remoção do artefato de estímulo .................20

1.2.1 Métodos baseados na delimitação do trecho com artefato de estímulo...............20

1.2.2 Métodos baseados na estimação e subtração do artefato de estímulo .................22

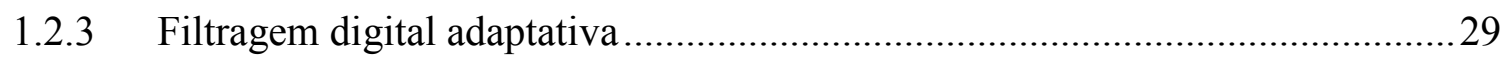

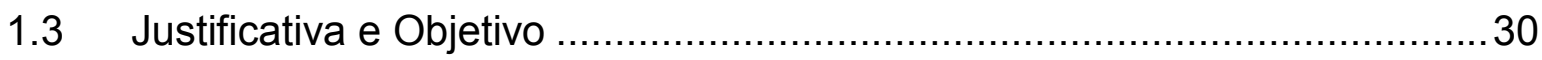

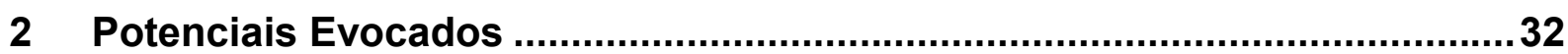

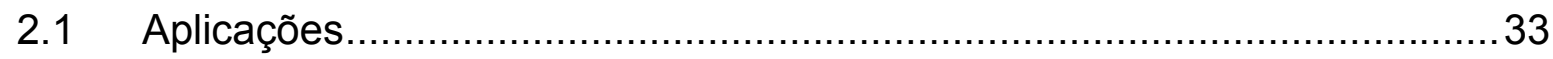

2.2 Os picos do potencial evocado .............................................. 34

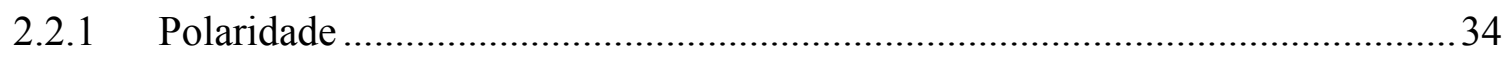

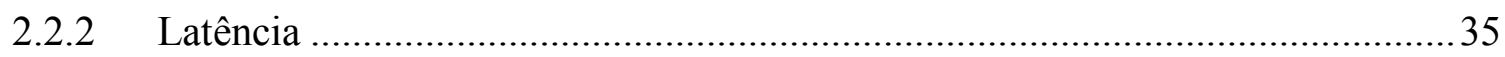

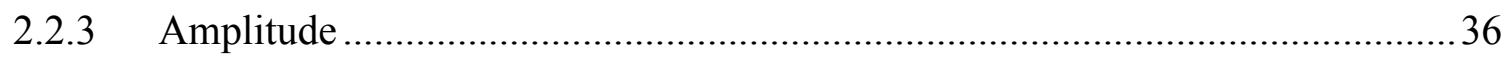

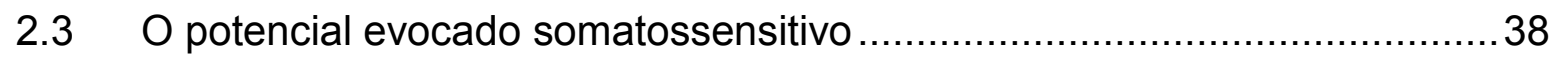

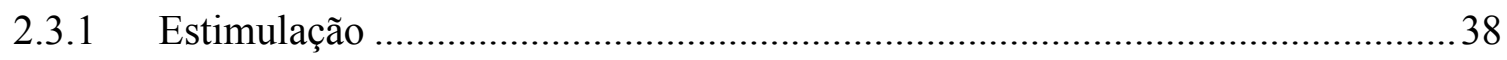

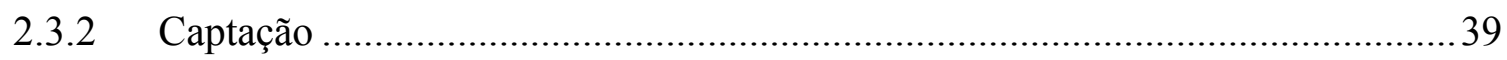

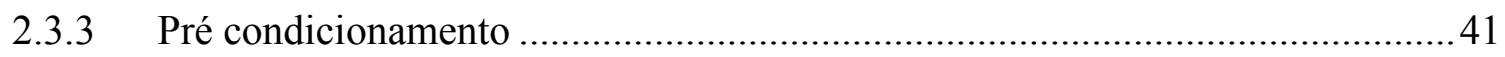

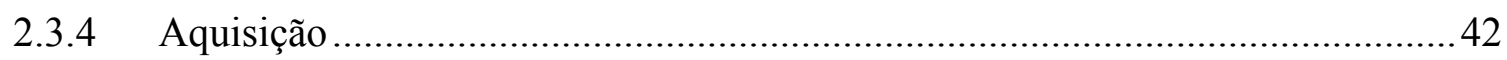

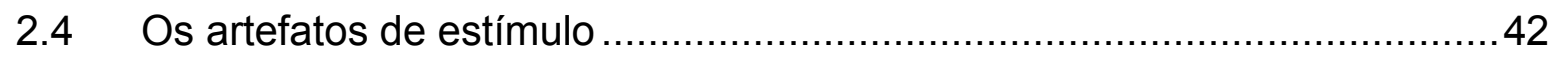

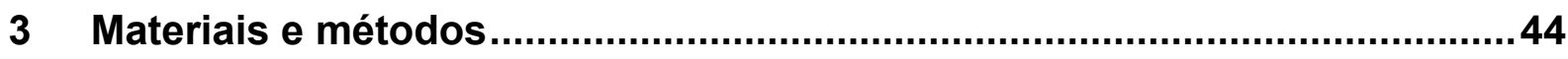

3.1 Descrição do modelo de potencial evocado.....................................44

3.2 Descrição do modelo de artefato de estímulo ...................................47

3.3 Descrição do sinal com ruído ..................................................... 49

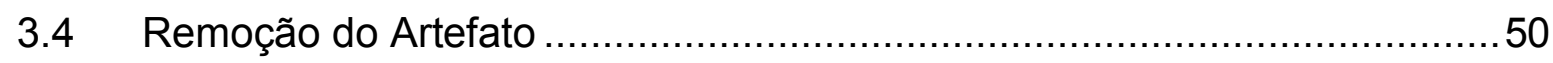

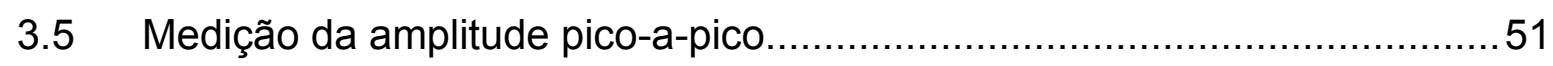

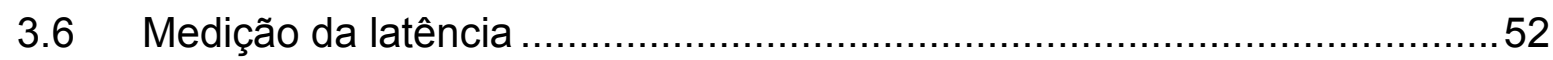

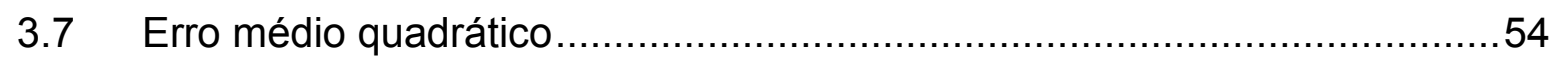


4.1 Remoção do artefato de estímulo ..................................................... 55

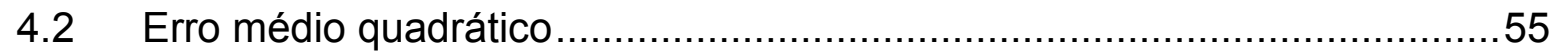

4.2.1 O erro médio quadrático como função do parâmetro A …....................................56

4.2.2 O erro médio quadrático como função do atraso D...........................................56

4.2.3 O erro médio quadrático como função do atraso D e do parâmetro A ................57

4.2.4 A influência da remoção do artefato de estímulo no erro médio quadrático......58

4.3 O erro da amplitude pico-a-pico ........................................................59

4.3.1 O erro da amplitude pico-a-pico como função do parâmetro A ...........................59

4.3.2 O erro da amplitude pico-a-pico como função do atraso D.................................60

4.3.3 O erro da amplitude pico-a-pico como função do atraso D e do parâmetro A...61

4.3.4 A influência da remoção do artefato de estímulo no erro da amplitude pico-a-

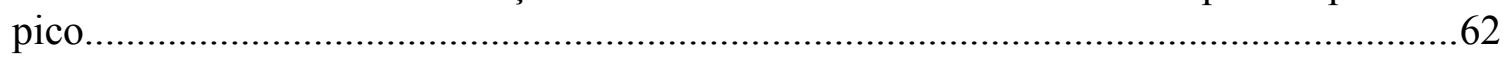

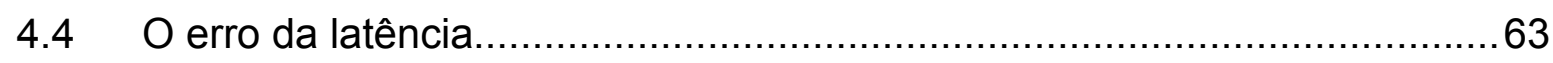

4.4.1 O erro da latência como função do parâmetro A ...................................................63

4.4.2 O erro da latência como função do atraso D .....................................................63

4.4.3 O erro da latência como função do atraso D e do parâmetro A...........................64

4.4.4 A influência da remoção do artefato de estímulo no erro da latência .................65

4.5 Aplicação da técnica de remoção do artefato de estímulo em potenciais evocados somatossensitivos adquiridos ............................................... 66

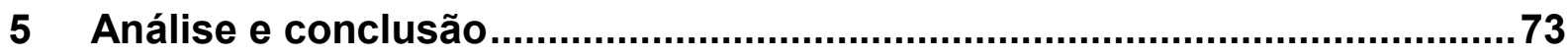

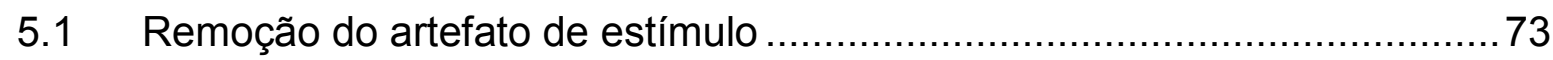

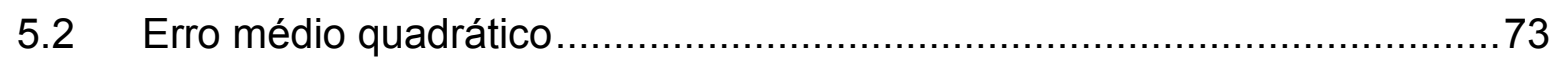

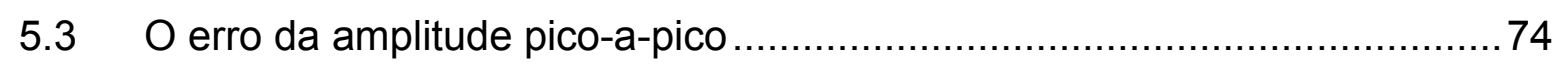

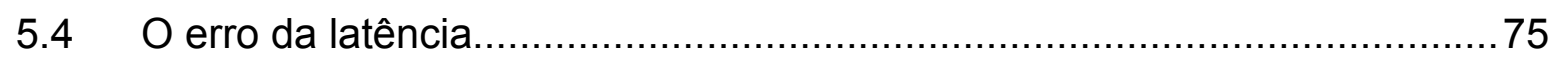

5.5 Aplicação da técnica de remoção do artefato de estímulo em potenciais evocados somatossensitivos adquiridos .............................................. 75

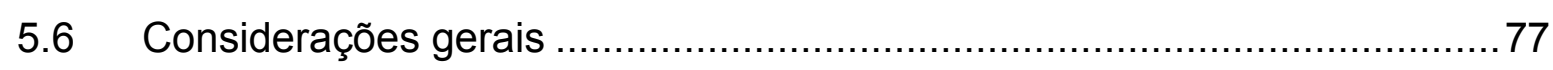

Referências Bibliográficas ......................................................................... 78 


\section{Introdução}

Os potenciais evocados são as respostas do sistema nervoso à estimulação sensorial (visual, auditiva ou elétrica) (MISULIS, 2003). Em particular, as respostas à estimulação elétrica são denominadas potenciais evocados somatossensitivos (SEPs, do inglês Sensory Evoked Potentials). Esses sinais são usados principalmente para testar a condução e localizar lesões nas vias sensoriais. Os SEPs são gerados pela estimulação de nervos específicos e são captados ao longo do sistema nervoso.

No caso dos SEPs captados no escalpo, há um problema na relação sinal-ruído: os SEPS têm amplitude pequena, quando comparados ao sinal de eletrencefalografia (EEG) que, por sua vez, faz o papel de ruído de fundo e dificulta a identificação dos picos dos SEPs. Além disso, a captação dos sinais é dificultada pela presença esporádica de artefatos resultantes de movimentos. Também há dificuldades associadas aos dispositivos eletrônicos envolvidos na amplificação, filtragem e aquisição dos sinais, pois eles introduzem ruído eletrônico. Adicionalmente, a rede elétrica que alimenta os equipamentos eletrônicos produz interferência. E, por fim, a própria estimulação elétrica, que gera o potencial evocado, resulta no artefato de estímulo, presente no trecho inicial do sinal captado.

A natureza do artefato de estímulo é complexa e difícil de determinar. Mas se sabe que há alguns fatores que contribuem para o aparecimento do artefato, incluindo o tipo de estimulador, a interface eletrodo-pele, os tecidos subcutâneos do membro estimulado e as características do amplificador de registro (McGILL at al., 1982; HUA; LOVELY; DORAISWAMI, 2006). O artefato de estímulo seria então resultante da combinação de três componentes: da corrente de estimulação através dos tecidos, da corrente de fuga através dos tecidos e do campo eletromagnético entre os fios de estimulação e registro (SCOTT; Mc LEAN; PARKER, 1997). 
Para melhorar a relação sinal-ruído, a solução tradicional é o cálculo da média síncrona de várias respostas evocadas, tipicamente de 1000 a 2000. Esse processo, também conhecido como promediação, é eficiente para a redução da variância do ruído. Neste trabalho, o termo 'potencial evocado' será usado para especificar o sinal resultante dessa média síncrona, enquanto que o termo 'resposta' irá designar a resposta a um único estímulo.

A Figura 1.1a mostra quatro respostas individuais a estímulos elétricos enquanto que a Figura $1.1 \mathrm{~b}$ mostra o potencial evocado, resultante da média síncrona calculada a partir de 2.000 respostas. Percebe-se que as respostas são corrompidas por um nível muito maior de ruído, tanto de baixa quanto de alta freqüência, em comparação ao potencial evocado.

a)
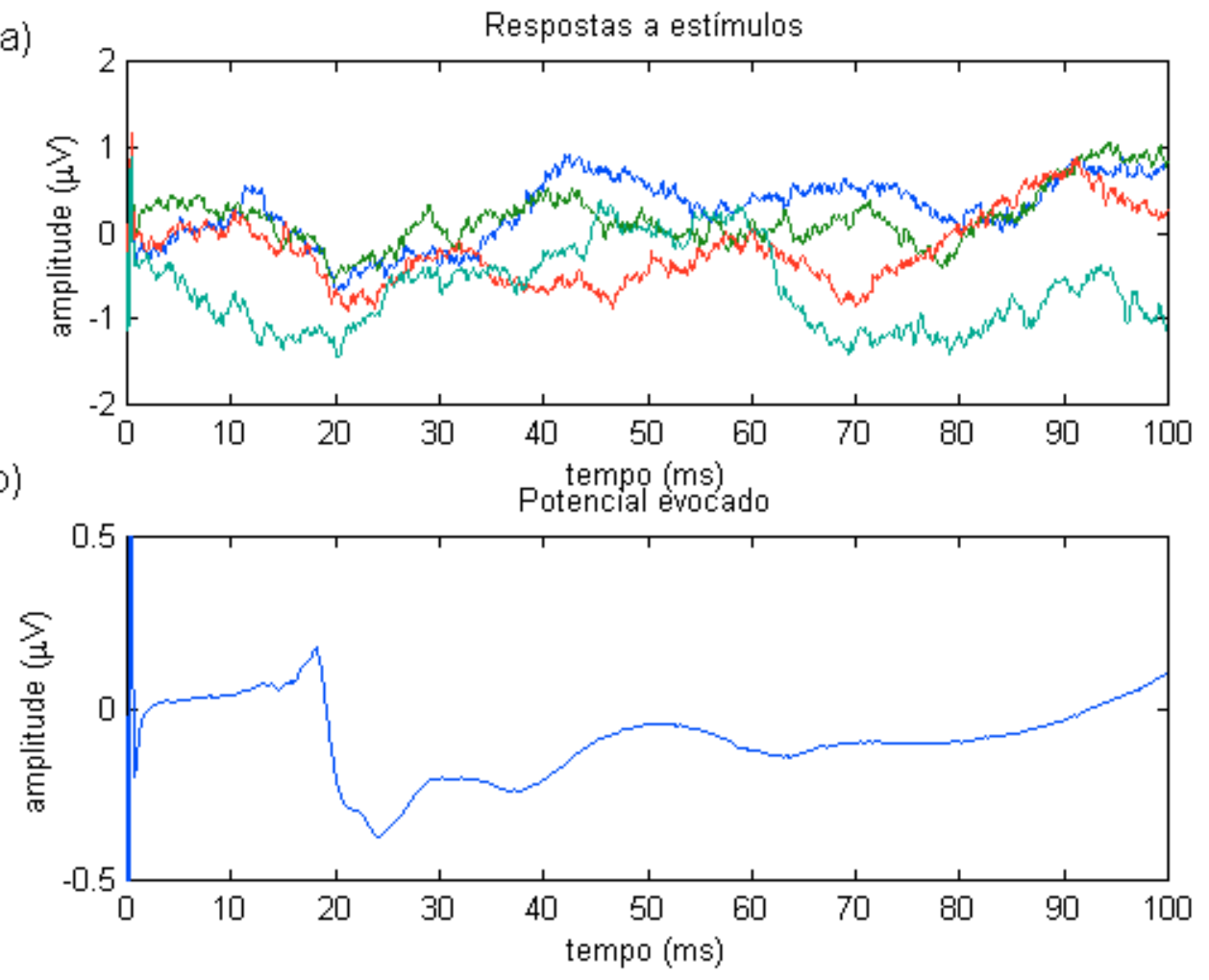

(adaptado de (SHIMIZU, 2005))

Figura 1.1 - Sinais captados: a) respostas a um único estímulo e b) potencial evocado obtido pela média síncrona de 2.000 respostas.

A média síncrona funciona também para eliminar a interferência de rede, desde que a frequência da rede elétrica $(60 \mathrm{~Hz}$, no caso do Brasil) não seja múltipla inteira da taxa de estimulação $(1 \mathrm{~Hz}, 2 \mathrm{~Hz}, 3 \mathrm{~Hz}, 5 \mathrm{~Hz}$, por exemplo). Na prática, equipamentos como o sistema de 
mensuração da marca Nihon Kohden inserem uma variação aleatória (jitter) na taxa de estimulação e acabam alterando levemente a razão entre a frequência da rede e a taxa de estimulação. Dessa forma, a interferência é eliminada com a média síncrona.

No caso dos SEPS, são promediadas as respostas evocadas por 1.000 a 2.000 estímulos elétricos, para que se diminua o efeito do ruído (CHIAPPA, 1997). Usualmente, após a aplicação de técnicas que melhoram a relação sinal-ruído, os picos dos SEPs podem ser identificados, permitindo avaliar se a informação sensorial está sendo conduzida de forma adequada pelo sistema nervoso.

Porém, a média síncrona não funciona para os artefatos de estímulo. Além de, em muitos casos, terem amplitude maior que os SEPs, os artefatos de estímulo não são passíveis de eliminação por meio da média síncrona, já que estão sincronizados ao instante de aplicação do estímulo.

Durante a aplicação do estímulo, o artefato de estímulo apresenta variações abruptas. As bordas de subida e descida do pulso de corrente de estimulação são associadas a grandes transitórios no sinal captado, em função dos filtros analógicos utilizados e do comportamento capacitivo do conjunto pele, gel e eletrodo.

Após a aplicação do estímulo, muitas vezes o sinal captado apresenta um decaimento exponencial. Caso o decaimento do artefato de estímulo seja rápido em comparação à latência do sinal, o potencial evocado não é afetado pelo artefato, conforme ilustrado nas Figuras 1.2a, $1.2 \mathrm{~b}$ e $1.2 \mathrm{c}$. No entanto, existem casos em que o decaimento exponencial do artefato de estímulo é lento. No domínio do tempo, a sobreposição entre o artefato de estímulo e o potencial evocado encobre parcial ou completamente o sinal de interesse, conforme ilustrado na Figura 1.2d. Nesses casos, é essencial que se elimine o artefato de estímulo. 
a)

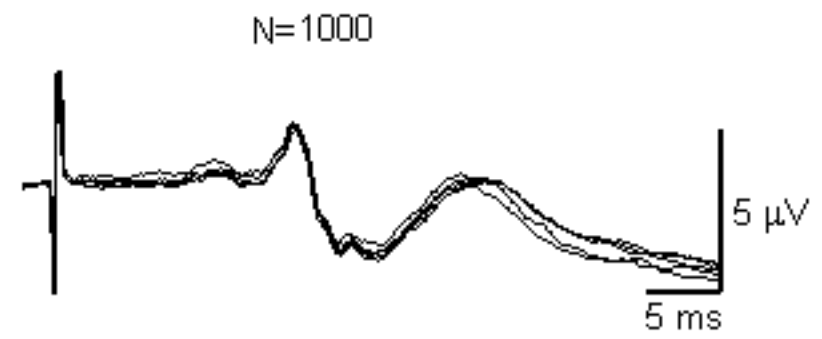

b)

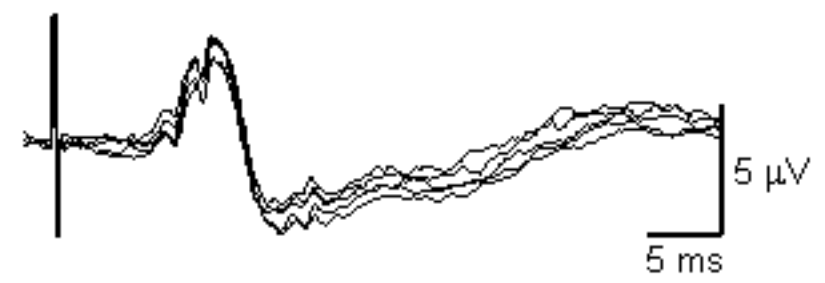

c)

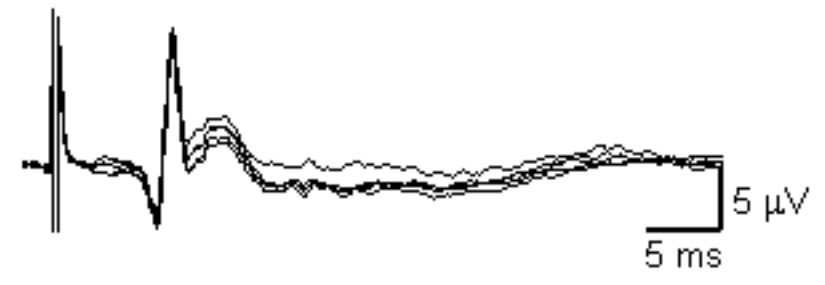

d)

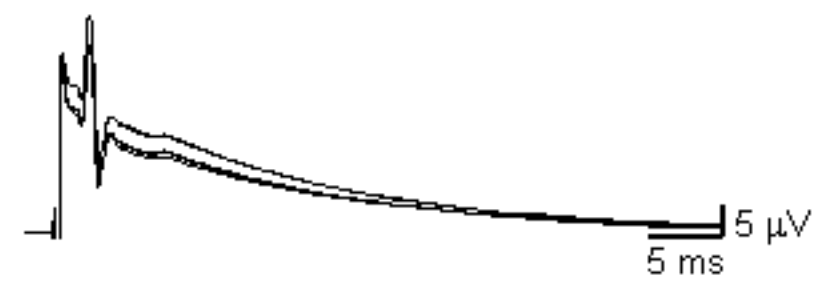

Figura 1.2 - Potenciais evocados somatossensitivos calculados pela média síncrona de 1000 respostas captadas por eletrodos de superfície localizados a) no escalpo (C4' - Fpz'), b) na vértebra $\mathrm{C} 5, \mathrm{c}$ ) no ombro (ponto de Erb) e d) no cotovelo. Para cada posição há 5 médias síncronas. Os estímulos de corrente tinham duração de $0,2 m s$ e amplitude equivalente a 1 vez e meia do limiar motor. Foram aplicados no punho esquerdo à taxa de estimulação foi de $3 \mathrm{~Hz}$. Os sinais foram captados com eletrodos de superfície em indivíduo neurologicamente normal e sadio, no Laboratório de Engenharia Biomédica da EPUSP.

A literatura apresenta vários métodos para eliminação ou redução de artefatos de estímulo. Alguns deles são descritos a seguir.

\subsection{Técnicas pré-aquisição para remoção do artefato de estímulo}

Algumas técnicas de redução do artefato de estímulo podem ser aplicadas antes da aquisição. Elas são descritas a seguir. 


\subsubsection{Técnicas clínicas de minimização de artefato de estímulo}

Várias técnicas clínicas são sugeridas para minimização do artefato de estímulo: limpar a pele, esfoliar a pele com substância abrasiva e utilizar pasta eletrolítica entre os eletrodos e a pele para assegurar contatos de baixa impedância; utilizar um eletrodo de referência com grande área de superfície e colocá-lo próximo dos eletrodos de registro; manter os eletrodos de estimulação e registro na máxima distância possível e, quando possível, posicionar os eletrodos de registro sobre linhas equipotenciais, o que é difícil de fazer numa situação experimental, devido à geometria irregular do membro estimulado (braço ou perna) e à variação das linhas equipotenciais durante a captação dos sinais (McGILL at al., 1982; SCOTT; Mc LEAN; PARKER, 1997; DEL POZO; DELGADO, 1978; McLEAN; SCOTT; PARKER, 1996).

\subsubsection{Métodos de hardware para minimização do artefato de estímulo}

Além das técnicas clínicas, várias técnicas de hardware foram desenvolvidas para minimizar o problema do artefato de estímulo. Pode-se ajustar a frequência de corte do filtro passa altas do amplificador de registro para minimizar a amplitude do artefato (McGILL at al., 1982). Também se pode utilizar um circuito de sample-and-hold que mantenha fixo o valor da tensão por um intervalo de tempo e que evite a saturação do amplificador de registro, reduzindo a entrada do sinal de estimulação no amplificador de registro. Outra técnica utiliza um estimulador híbrido com corrente constante durante o pulso de estimulação e com tensão constante entre os pulsos (DEL POZO; DELGADO, 1978).

As técnicas clínicas e de hardware apresentadas anteriormente nem sempre eliminam o artefato, especialmente quando o sinal adquirido é muito fraco ou quando a distância entre os 
eletrodos de estimulação e captação é muito curta. $\mathrm{O}$ artefato de estímulo remanescente deve ser removido pelo processamento do sinal adquirido.

A eliminação de artefatos de estímulos por meio de filtros convencionais não é efetiva, porque a faixa espectral do artefato se sobrepõe à do potencial evocado. Além disso, os filtros convencionais deixam um resíduo do artefato de estímulo ou alteram o conteúdo espectral do potencial evocado (WICHMANN, 2000).

\subsubsection{Métodos baseados em estímulos adicionais}

Para a estimativa do artefato, há três outros métodos conhecidos: método sublimiar, duplo estímulo e "fora do nervo" (do inglês off-nerve) (McGILL at al., 1982).

O método sub-limiar consiste em reduzir a intensidade do estímulo abaixo do limiar de excitação do nervo. Neste caso os mesmos eletrodos usados na captação do artefato supralimiar e do potencial evocado são utilizados para registrar o artefato de estímulo gerado com um estímulo sub-limiar. Em seguida, o artefato supra-limiar é estimado a partir do artefato sub-limiar e é usado para cancelar o artefato sobreposto ao potencial evocado. Este método usa a hipótese de linearidade entre as amplitudes dos estímulos e os artefatos sub- e supralimiar.

O método de duplo estímulo consiste na aplicação de um segundo pulso de estímulo aplicado durante o período refratário. O período refratário é o período imediatamente após a geração do potencial evocado no qual um segundo pulso de estímulo não consegue gerar um segundo potencial evocado. O primeiro pulso produz potencial evocado mais o artefato de estímulo enquanto que o segundo gera apenas o artefato de estímulo. Subtrai-se o segundo artefato de estímulo do primeiro e como resultado seria esperado apenas o potencial evocado. 
O problema deste método é que os artefatos de estímulo do primeiro e do segundo pulso não são necessariamente idênticos, podendo ser consideravelmente diferentes.

O método "fora do nervo" utiliza um par adicional de eletrodos de captação, que é posicionado distante do nervo a ser examinado, e que registra um sinal contendo somente o artefato de estímulo. Porém, não há como garantir que os dois artefatos sejam linearmente dependentes. Além disso, é bastante difícil encontrar um posicionamento dos eletrodos para que o sinal registrado contenha somente o artefato de estímulo e que este tenha formato semelhante ao daquele que contamina o potencial evocado. Outra possibilidade seria aplicar um estímulo adicional numa posição próxima, porém, fora do nervo. A resposta captada teria, a princípio, somente o artefato de estímulo, sem a geração do potencial evocado. No entanto, novamente, não há como garantir a manutenção do formato do artefato com o deslocamento dos eletrodos de estimulação.

\subsection{Técnicas pós-aquisição para remoção do artefato de estímulo}

Uma vez feita a aquisição dos potenciais evocados, a eliminação do artefato de estímulo é feita por meio de métodos computacionais. Alguns deles são descritos a seguir.

\subsubsection{Métodos baseados na delimitação do trecho com artefato de estímulo}

\section{Método de O’Kleefe}

$\mathrm{O}$ artefato de estímulo pode ser eliminado por meio de um algoritmo que identifique o trecho que contém o artefato de estímulo e o remova, deixando intacto o potencial evocado (O’KEEFFE et al, 2001). A delimitação é baseada em valores específicos obtidos a partir dos picos do sinal. Esses valores específicos (limiares superior e inferior) são calculados a partir 
dos picos do sinal capturado. Em seguida, o trecho delimitado é preenchido com zeros ou substituído por trechos anteriores ao artefato.

A figura 1.3 ilustra um sinal cujo valor máximo $M$ é de $4,3 \mu \mathrm{V}$. O método de O'Kleefe foi aplicado com $H T=0,5 M$ e $L T=0,05 M$.
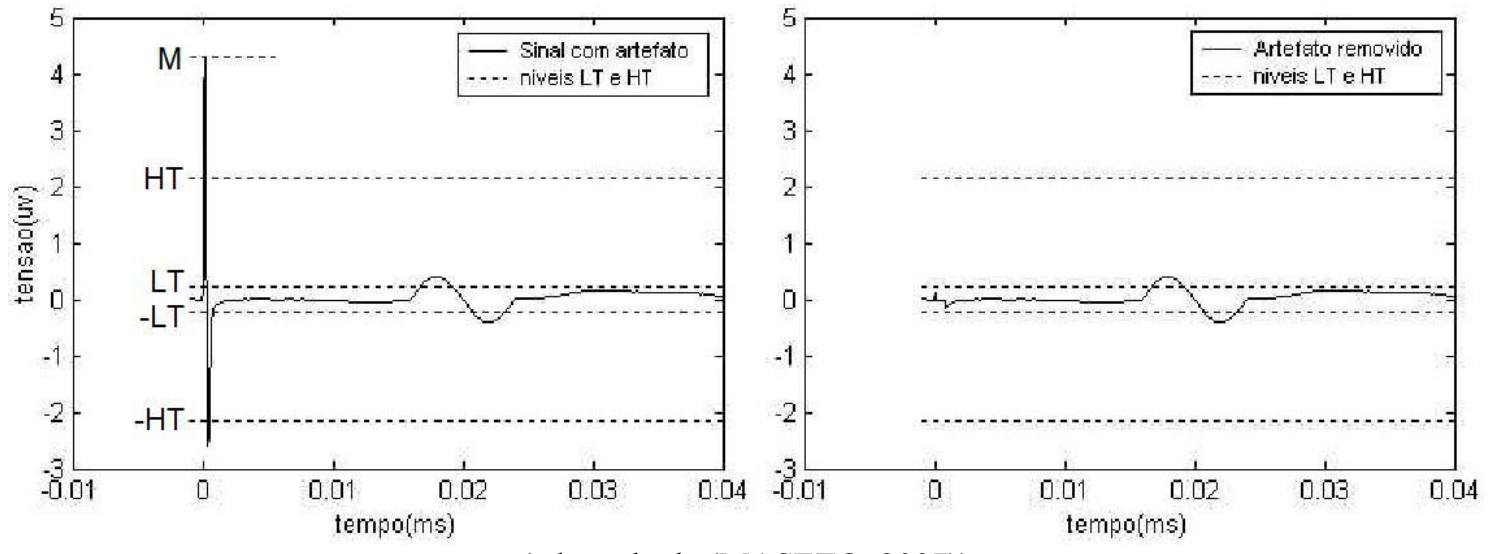

(adaptado de (MASETO, 2007))

Figura 1.3 - Remoção de artefato de estímulo de polaridade positiva pelo algoritmo de O'Kleefe.

Observa-se que o artefato foi eliminado, enquanto que a onda permaneceu intacta. Entretanto, houve uma descontinuidade, ilustrada na figura 1.4. Ela é resultante da substituição do segmento com artefato de estímulo por zeros, sem considerar a transição entre segmentos.

Como o método simplesmente delimita o artefato de estímulo e faz uma substituição por zeros, ele não pode ser aplicado quando há sobreposição entre o artefato de estímulo e o potencial evocado. 


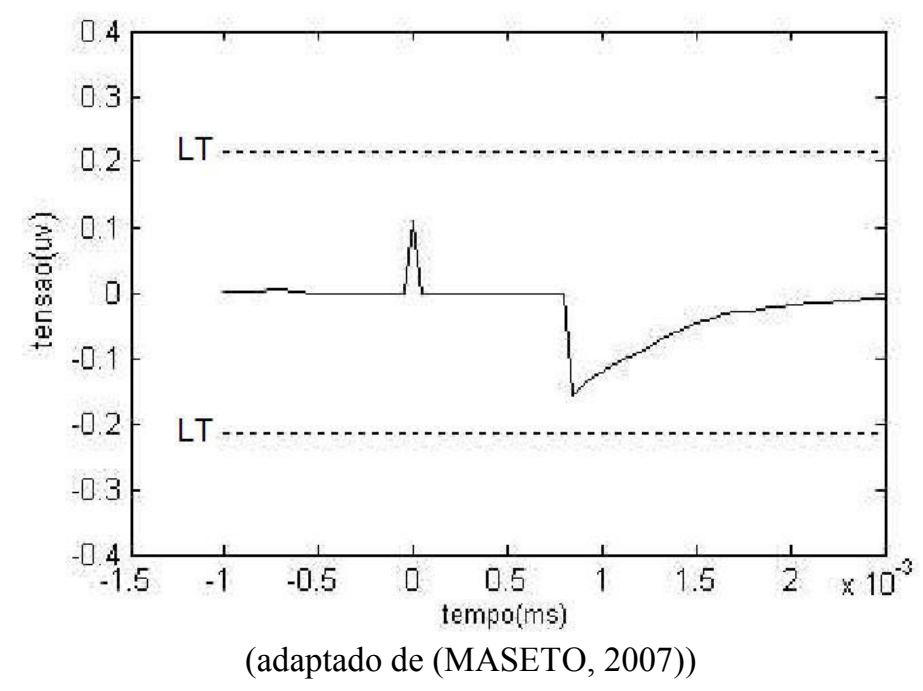

Figura 1.4 - Descontinuidade resultante do método de O'Kleefe. Sinal remanescente após a remoção do artefato de estímulo.

\subsubsection{Métodos baseados na estimação e subtração do artefato de estímulo}

\section{Método de Wichmann}

O método de Wichmann (WICHMANN, 2000) consiste na eliminação dos artefatos de estímulos baseado na hipótese de que a forma do estímulo permanece a mesma durante toda a aquisição.

Inicialmente se faz uma filtragem passa-baixas digital com frequência de corte em 2kHz. Em seguida, calcula-se o "artefato médio" entre os segmentos contendo os artefatos de estímulo. Cada artefato individual é deslocado no tempo, até que se minimize o erro quadrático em relação ao artefato médio.

Na figura 1.5 , ilustram-se deslocamentos de $0,050 \mathrm{~ms}$ e de $0,005 \mathrm{~ms}$ do artefato médio. 


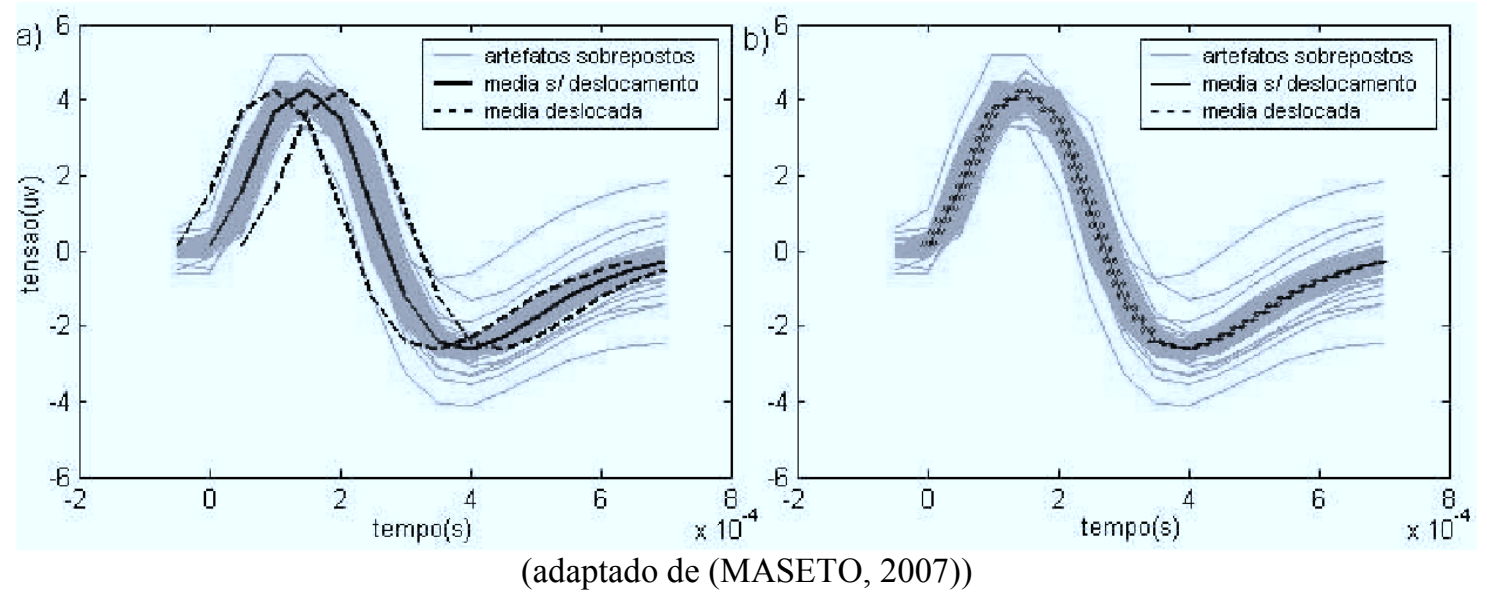

Figura 1.5 - Artefato médio deslocado a) de $0,050 \mathrm{~ms}$ e b) de $0,005 \mathrm{~ms}$.

Em seguida, cada sinal com deslocamento ótimo é normalizado em amplitude. Essa normalização também busca a minimização do erro quadrático.

Por fim, calcula-se um novo artefato médio, a partir dos artefatos deslocados e normalizados. Esse novo artefato médio é subtraído de cada sinal individual. Antes de cada subtração, o artefato médio é reajustado no tempo e na amplitude, por meio de um deslocamento inverso e de uma desnormalização que garantam a minimização do erro quadrático.

No método de Wichmann, o artefato de estímulo não pode estar sobreposto ao potencial evocado, senão este também será removido.

\section{Método de Harding}

Outras técnicas para estimação do artefato de estímulo utilizam detecção de picos, separação de trechos e aproximação exponencial (HARDING, 1991). Eventualmente, quando a aproximação exponencial não é perfeita, pode permanecer um artefato residual após a aplicação da mesma. No entanto, esta técnica produz bons resultados e não demanda um sinal auxiliar, já que os parâmetros das exponenciais são determinados a partir do próprio sinal. Por isso, constitui-se a técnica a ser implementada neste mestrado. 
A Figura 1.6 representa um artefato de estímulo por meio de três segmentos e um componente adicional (HARDING, 1991). No primeiro segmento temos uma subida rápida do sinal (Figura 1.6b) logo após a aplicação do pulso de estímulo, seguido pelo segundo segmento no qual temos um decaimento exponencial rápido (Figura 1.6c). No terceiro segmento temos um decaimento exponencial lento indicando o fim do artefato de estímulo. $\mathrm{O}$ componente adicional é um decaimento exponencial muito lento.

O potencial evocado captado juntamente com o artefato de estímulo é separado nos três segmentos descritos anteriormente. Para cada segmento o artefato é removido separadamente e o eventual resíduo é corrigido.

O primeiro segmento é removido e substituído pelo valor do sinal anterior ao estímulo, assumindo que o potencial evocado acontece após o mesmo. Pode-se manter o valor da primeira amostra do artefato para indicar o início do pulso de estímulo.

Para a remoção do segundo e terceiro segmentos, supõe-se que esses segmentos sejam resultantes das propriedades resistivas e capacitivas dos eletrodos, propriedades dos tecidos e do amplificador de registro. Portanto, os segmentos do artefato são exponenciais. Assume-se que os parâmetros dessas exponenciais não mudem durante o artefato e que o potencial evocado não tenha formato semelhante ao do artefato. Os segmentos são aproximados por exponenciais e subtraídos do sinal captado. 


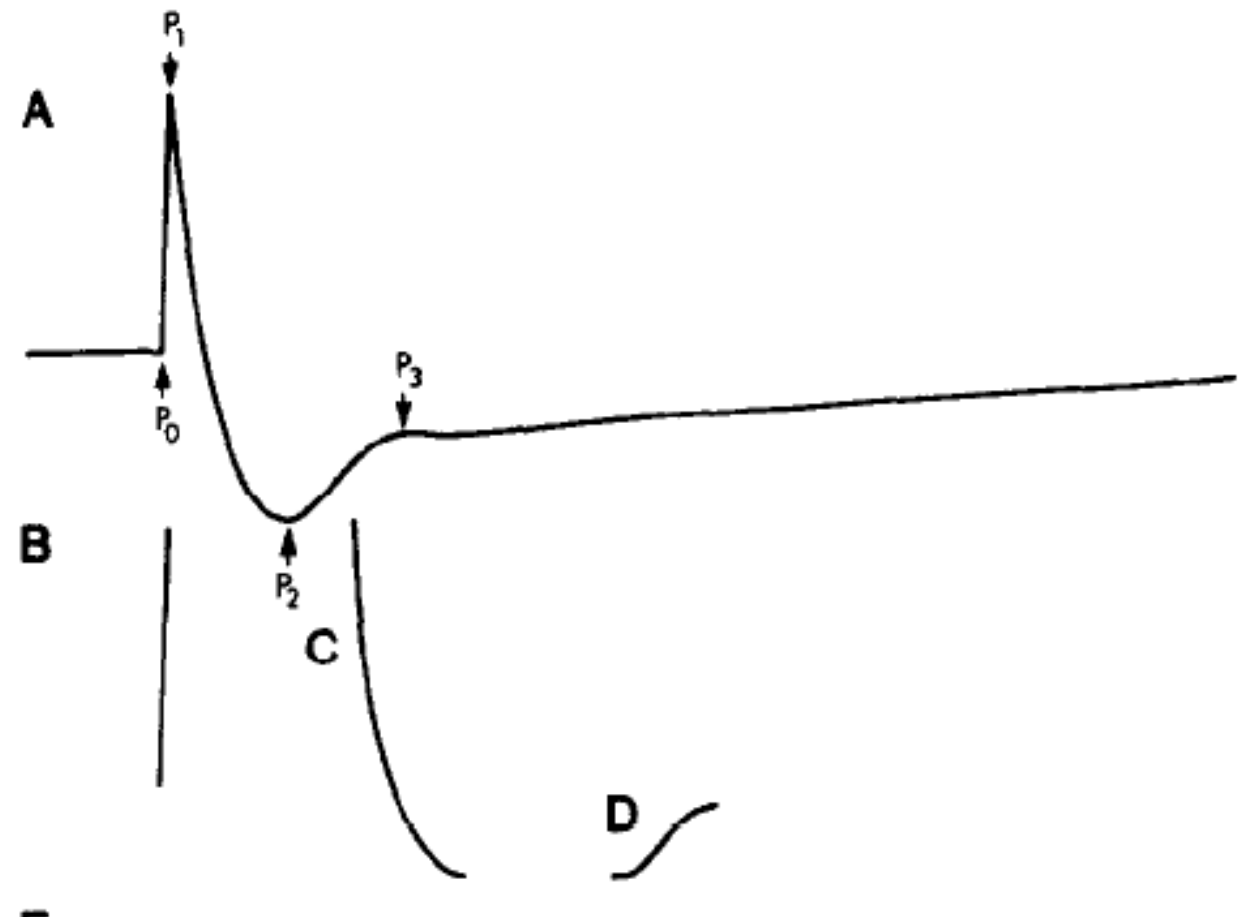

E

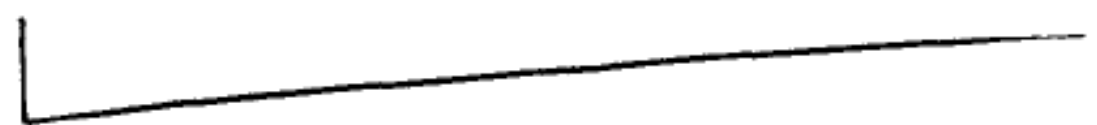

(adaptado de (HARDING, 1991))

Figura 1.6 - (A) Artefato de estímulo. As setas $\mathrm{p}_{0}, \mathrm{p}_{1}, \mathrm{p}_{2}, \mathrm{p}_{3}$ indicam a separação dos segmentos. (B) Primeiro segmento. (C) Segundo segmento. (D) Terceiro segmento. (E) Componente adicional.

A função exponencial utilizada para a aproximação do segundo e terceiro segmentos do artefato é dada por:

$$
v_{i}=b \cdot \exp \left(a / t_{i}^{c}\right)
$$

em que $v_{i}$ são as amostras do sinal (potencial evocado mais artefato de estímulo), $t_{i}$ são os instantes das amostras e os valores $a, b, c$ são constantes a serem determinadas. Aplicandose o logaritmo natural aos dois lados da equação 1.1, obtém-se uma relação na forma $y=A x+B:$

$$
\ln \left(v_{i}\right)=a t_{i}^{-c}+\ln (b) .
$$


Para um dado valor de $c$, a equação 1.2 é uma relação linear nas variáveis $a$ e $\ln (b)$. Portanto, os valores de $a$ e $\ln (b)$ podem ser determinados por meio de regressão linear com a correlação de ajuste r-quadrado $\left(r^{2}\right)$. O melhor valor de $c$ pode ser determinado otimizando $r^{2}$

Um artefato gerado computacionalmente com $a=-1700, \quad b=-8,47$ e $\quad c=-0,93$ está representado na figura 1.7a. A aplicação do algoritmo de Harding resultou na figura 1.7b. Observa-se que o artefato foi completamente eliminado, deixando intacto o sinal de interesse.

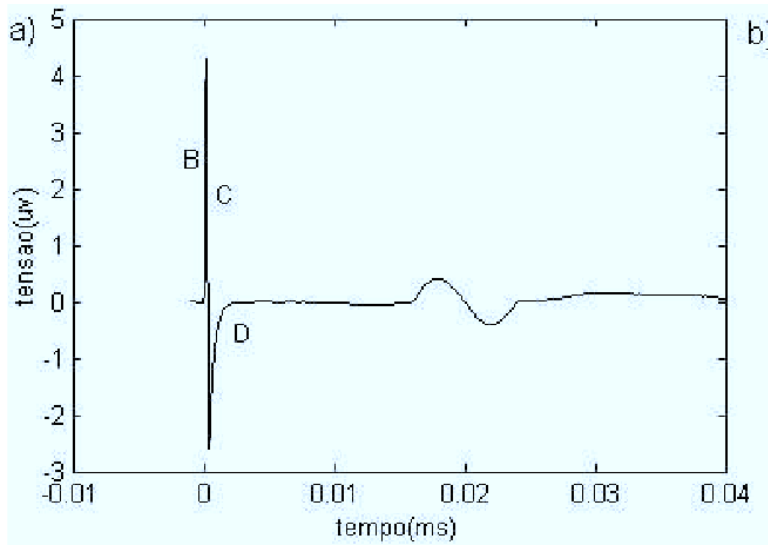

(adaptado de (MASETO, 2007))

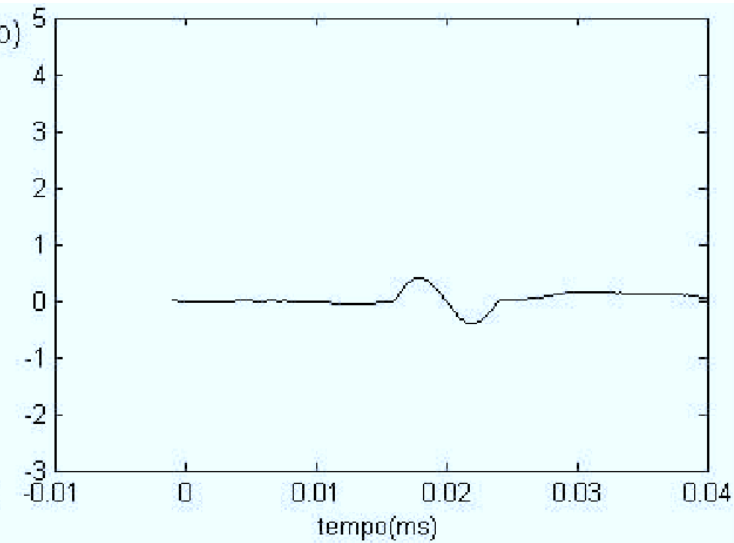

tempo(ms)

Figura 1.7 - Remoção de artefato de estímulo pelo método de Harding.

\section{Método de Dotsinsky}

Em 1999, Dotsinsky, dos Santos e Tashev (1999) aplicaram um outro método de aproximação exponencial. Um potencial evocado contaminado com artefato de estímulo $c(t)$ é mostrado na Figura 1.8. O artefato de estímulo é dividido em duas exponenciais: $a_{l}(t)$ para exponencial decorrente da aplicação do pulso de estímulo e $a_{2}(t)$ para o decaimento exponencial do artefato, após a aplicação do estímulo. 

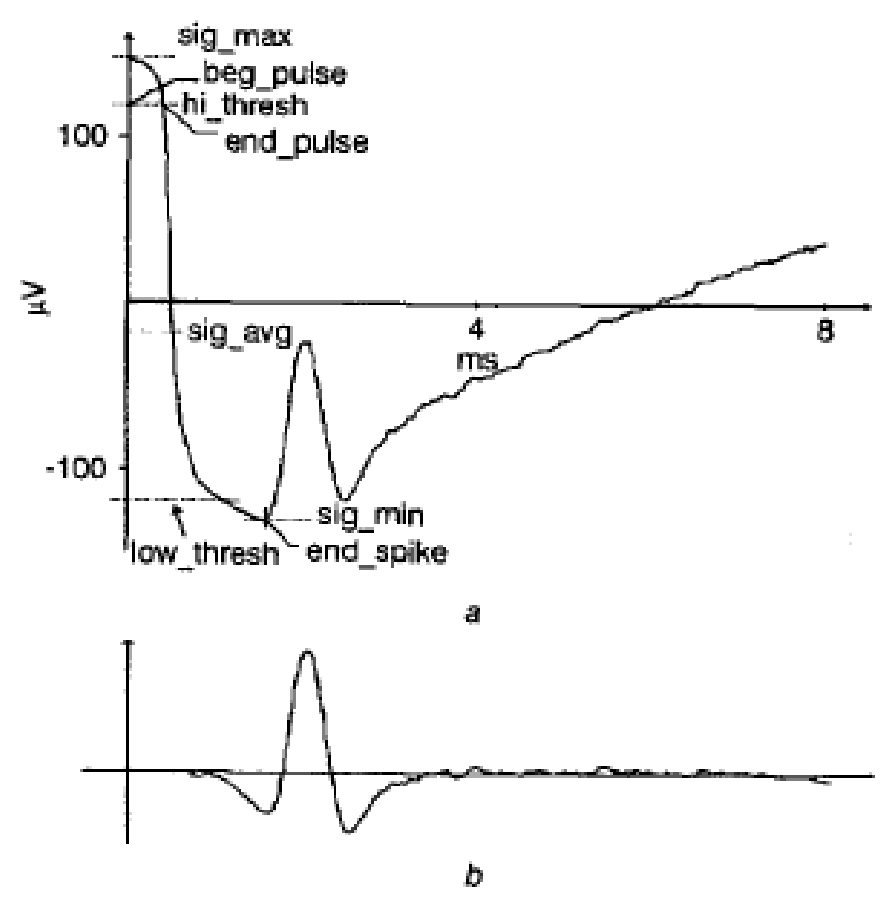

(adaptado de (DOTSINSKY; DOS SANTOS; TASHEV, 1999))

Figura 1.8 - (A) Potencial evocado contaminado com artefato de estímulo $c(t)$ e os pontos determinados para delimitação dos trechos. (B) Potencial evocado após a aplicação do algoritmo.

Os sinais aproximados $a_{1}(t)$ e $a_{2}(t)$ são subtraídos do sinal $c(t)$ e como resultado temse o potencial evocado $p(t)$.

O algoritmo começa com a detecção do valor máximo sig_max, do valor mínimo sig_min e o cálculo do valor médio sig_avg do sinal $c(t)$.

Os limiares superior (high_thresh) e inferior (low_thresh) são calculados por

$$
h i \_ \text {thresh }=s i g \_a v g+0,9\left(\text { sig_max }-s i g \_a v g\right)
$$

$\mathrm{e}$

$$
\text { low_thresh }=\text { sig_avg }+0,9\left(\operatorname{sig} \_\min -\operatorname{sig} \_a v g\right)
$$

Em seguida, é feita uma varredura no sinal $c(t)$ iniciando-se pela primeira amostra. É determinado o início do pulso (beg_pulse) para a primeira amostra cujo valor seja maior que hi_thresh (caso o estímulo seja positivo) ou menor que low_thresh (se o estímulo for negativo). 
O fim do pulso de estimulação, end_pulse, acontece para a próxima amostra cujo valor é menor que hi_thresh (para estimulação positiva) ou maior que low_thresh (para estimulação negativa). A largura do pulso é dada por (end_pulse - beg_pulse).

E finalmente o instante da amostra posterior a end pulse em que o valor atinge sig_max (para estimulação negativa) ou sig_min (para estimulação positiva) é chamado de fim da espícula (end_spike).

No caso de estimulação com pulso bifásico, um segundo pico é encontrado em um intervalo igual a duas vezes a largura do pico já detectado.

As amostras anteriores ao ponto end_pulse são descartadas e substituídas pelo valor anterior à aplicação do estímulo. No intervalo entre end_pulse e end_spike é feita uma aproximação exponencial dada por:

$$
a_{1}(t)=\alpha_{1}+\beta_{1} \cdot e^{-\left(t / \tau_{1}\right)}
$$

em que $\tau_{1}$ é a constante de tempo, $\alpha_{1}$ e $\beta_{1}$ são coeficientes, e $t$ é o tempo que inicia com beg_pulse. A exponencial é subtraída da equação $c(t)$, da seguinte forma:

$$
c_{1}(t)=c(t)-a_{1}(t)
$$

A segunda aproximação exponencial compreende o intervalo end_spike até o final do sinal $c(t)$ e utiliza equação semelhante:

$$
a_{2}(t)=\alpha_{2}+\beta_{2} \cdot e^{-\left(t / \tau_{2}\right)}
$$

Os parâmetros $\tau_{1}, \quad \alpha_{1}$ e $\beta_{1}$ (semelhantemente a $\tau_{2}, \quad \alpha_{2}$ e $\beta_{2}$ ) são determinados utilizando o algoritmo LMS (do inglês, Least Mean Square) para que as equações $a_{1}(t)$ e $\mathrm{a}_{2}(t)$ se aproximem das amostras do sinal $c(t)$.

A constante de tempo $\tau$ está presente na potência das equações 1.5 e $1.7, \log 0$ o sistema obtido é não-linear. Porém, para um determinado valor de $\tau$, são calculados os coeficientes $\alpha$ e $\beta$. A constante de tempo é modificada, a partir de um valor inicial, até que seja possível determinar um valor de erro mínimo. 
Para cada exponencial, o erro $\varepsilon$ é igual à soma dos quadrados das diferenças os valores $a\left(t_{i}\right)$ e suas respectivas amostras $s\left(t_{i}\right)$,

$$
\varepsilon=\sum_{i=0}^{n}\left[a\left(t_{i}\right)-s\left(t_{i}\right)\right]^{2}=\sum_{i=0}^{n}\left[\alpha+\beta \cdot e^{-\left(t_{i} / \tau\right)}-s\left(t_{i}\right)\right]^{2},
$$

em que $(n+1)$ é o número de amostras.

A partir das segundas derivadas parciais, obtém-se um sistema de equações para determinar os valores de $\alpha$ e $\beta$ de cada exponencial:

$$
\left[\begin{array}{cc}
n+1 & \sum_{i=0}^{n} e^{-\left(t_{i} / \tau\right)} \\
\sum_{i=0}^{n} e^{-\left(t_{i} / \tau\right)} & \sum_{i=0}^{n}\left[e^{-\left(t_{i} / \tau\right)}\right]^{2}
\end{array}\right]\left[\begin{array}{l}
\alpha \\
\beta
\end{array}\right]=\left[\begin{array}{c}
\sum_{i=0}^{n} s\left(t_{i}\right) \\
\sum_{i=0}^{n} e^{-\left(t_{i} / \tau\right)} . s\left(t_{i}\right)
\end{array}\right],
$$

em que $(n+1)$ é o número de amostras, $s\left(t_{i}\right)$ são as amostras do sinal nos instantes $t_{i}$, e os parâmetros a serem estimados são $\alpha$ e $\beta$ para um $\tau$ fixo.

Este método exige a solução da equação 1.9 para vários valores atribuídos a $\tau$ e a posterior escolha da solução que minimize o erro.

\subsubsection{Filtragem digital adaptativa}

A filtragem adaptativa é uma técnica alternativa para remoção de artefato de estímulo. O sinal auxiliar (sublimiar, duplo estímulo ou fora do nervo) deve ser então utilizado como entrada na referência do filtro adaptativo. Filtros adaptativos tanto lineares e quanto nãolineares já foram utilizados para a remoção do artefato. No entanto, os filtros não-lineares baseados em séries de Volterra de segunda ordem tiveram desempenho melhor que os filtros lineares de resposta impulsiva finita (FIR, do inglês Finite Impulse Response) (PARSA; PARKER; SCOTT, 1998a).

$\mathrm{Na}$ filtragem adaptativa além da escolha do filtro, a escolha do algoritmo de treinamento é um fator que influencia o desempenho da remoção do artefato. Os algoritmos LMS (do 
inglês Least Mean Squares) e RLS (do inglês Recursive Least Squares) já foram utilizados com filtros baseados em séries de Volterra de segunda ordem. Quando a relação artefato-ruído é alta, o algoritmo RLS é mais eficiente que o algoritmo LMS. No entanto, quando a relação artefato ruído é baixa, ambos os algoritmos exibem desempenhos parecidos, logo o algoritmo LMS é a opção preferida graças a sua simplicidade computacional (PARSA; PARKER; SCOTT, 1998b).

$\mathrm{Na}$ filtragem adaptativa também se podem utilizar redes neurais como elemento adaptativo para remoção de artefatos de estímulo. As redes neurais com configuração pisigma foram utilizadas com sucesso e tiveram desempenho melhor que filtros adaptativos lineares (GRIEVE; PARKER; HUDGINS, 1997). A configuração perceptrons de múltiplas camadas (MLP, do inglês Multi Layer Perceptron) (HAYKIN, 2001) com treinamento segmentado teve desempenho superior ao dos filtros adaptativos baseados em séries de Volterra de segunda ordem. Além disso, as redes neurais podem modelar não linearidades de ordem maior que 2, o que não acontece com os filtros adaptativos baseados em séries de Volterra de segunda ordem (GRIEVE at al, 2000).

Apesar dos bons resultados apresentados na literatura, a utilização dos filtros adaptativos em aplicações de tempo real é dificultada pela necessidade de um treinamento.

\subsection{Justificativa e Objetivo}

Os métodos descritos acima funcionam bem tanto para sinais simulados quanto para casos específicos de sinais adquiridos.

No entanto, os SEPs são captados desde o cotovelo ipsilateral até o escalpo contralateral. Dependendo do local de captação, há diferenças na relação entre o artefato de estímulo e os parâmetros (amplitude e latência) do sinal relevante. 
A influência da relação de amplitudes do SEP e do artefato na remoção das funções exponenciais ainda não foi descrito na literatura, nem o efeito da latência.

Por isso, este trabalho visa estudar a relação entre os parâmetros dos SEPs (amplitude e latência) e os erros associados, para várias relações de amplitude e atrasos entre os artefatos de estímulo e os SEPs. Para fazer isso, os SEPs e os artefatos de estímulo são representados por funções matemáticas. O método de ajuste de exponenciais, proposto na literatura, é implementado e testado neste mestrado para sinais gerados no computador. Também são feitas adaptações ao método para ajustá-lo a SEPs captados no cotovelo e no escalpo.

Por fim, é avaliado o efeito da amplitude e latência do potencial evocado nos erros inseridos pelo método proposto. 


\section{Potenciais Evocados}

Como esta dissertação de mestrado está sendo apresentada na Escola Politécnica da Universidade de São Paulo, não se espera que o leitor tenha conhecimentos prévios sobre potenciais evocados. Por isso, será feita uma breve apresentação dos potenciais evocados.

Neste trabalho será usada a seguinte nomenclatura. O termo "resposta individual" será usado para a resposta gerada por um único estímulo. O termo "potencial evocado" será usado para a estimativa obtida pela média síncrona de várias respostas individuais.

O potencial evocado é a resposta elétrica do sistema nervoso à estimulação sensitiva. Os potenciais evocados testam a condução nos sistemas visual, auditivo, somatossentivo e motor. São mais sensíveis para a detecção de lesões na medula espinhal e no cérebro e menos úteis para a detecção de lesões nos nervos periféricos (MISULIS, 2003).

Dependendo do método de estimulação e registro, os potenciais evocados podem ser classificados (MISULIS, 2003) em:

- $\quad$ potenciais evocados visuais (VEPs, do inglês Visual Evoked Potential), produzidos pela estimulação com flashes de luz difusa ou por tabuleiro de padrões, que podem ser gerados por uma tela de televisão, por um conjunto de diodos emissores de luz (LED, do inglês Light Emitting Diode) ou por projeção usando um espelho móvel.

- $\quad$ potenciais evocados auditivos (AEPs, do inglês Auditory Evoked Potential), o estímulo é liberado por meio de fone de ouvido, utilizando estalidos ou sinais sonoros.

- $\quad$ potenciais evocados somatossensitivos (SEPs, do inglês Sensory Evoked Potentials), produzidos por pulsos de corrente elétrica aplicados aos nervos dos membros superiores ou inferiores. 


\subsection{Aplicações}

As lesões geralmente atrasam, reduzem ou abolem os potenciais evocados. A latência aumentada geralmente indica uma diminuição na velocidade de condução e é frequentemente causada por lesões que provocam lentificação na condução axonal. Uma diminuição da amplitude tem um valor limitado como um indicador de condução comprometido, porque a redução da amplitude não indica necessariamente defeitos na condução, já que pode ser causada por outros problemas, inclusive falhas na captação do sinal. De um modo geral, as alterações de amplitude são menos úteis clinicamente do que alterações de latência (MISULIS, 2003).

Historicamente, a principal aplicação dos potenciais evocados era a detecção de lesões na suspeita de esclerose múltipla, disfunção da medula espinhal e lesões no nervo óptico. Os recentes avanços nas técnicas de imagem tornaram os potenciais evocados menos úteis para algumas destas anormalidades. Porém eles continuarão a ser usados, por exemplo, na esclerose múltipla (MISULIS, 2003).

Na cirurgia da medula espinhal o cirurgião conta com os SEPs para alertá-lo sobre uma eventual tração da medula. Os SEPs são também utilizados para monitorar a endarterectomia carotídea, tratamento de tromboembolismo. Os AEPs são frequentemente utilizados durantes cirurgias de fossa superior. Mais recentemente, AEPs têm sido usados na avaliação da função do tronco cerebral em recém nascidos e em pacientes recebendo quimioterapia audiotóxica. Os VEPs são frequentemente monitorados durante cirurgias da órbita ocular (MISULIS, 2003). 


\subsection{Os picos do potencial evocado}

Os potenciais evocados consistem de uma série de picos ou ondas em resposta a um estímulo. Cada onda tem as seguintes características: polaridade positiva ou negativa, número sequencial de picos, amplitude e latência.

\subsection{1 $\underline{\text { Polaridade }}$}

A resposta evocada corresponde à diferença entre os potenciais captados pelo eletrodo ativo e o eletrodo de referência, que são fornecidos às entradas do sistema de registro. A polaridade refere-se à positividade ou à negatividade dessa resposta (MISULIS, 2003).

A polaridade pode ser invertida caso se troque a posição do eletrodo ativo com aquela do eletrodo de referência. Ou então, pode-se invertê-la caso se troque a posição dos conectores de entrada do equipamento de aquisição. A Figura 2.1.a mostra um potencial evocado com picos de ambas as polaridades. À direita dos gráficos encontram-se as indicações + e - de que os picos negativos são representados para cima e de que os picos positivos, para baixo. Esta é a forma usual de apresentação dos picos. Na figura 2.1.b, ilustrase o efeito da inversão dos eletrodos. Os picos negativos seriam representados para baixo. 
a)

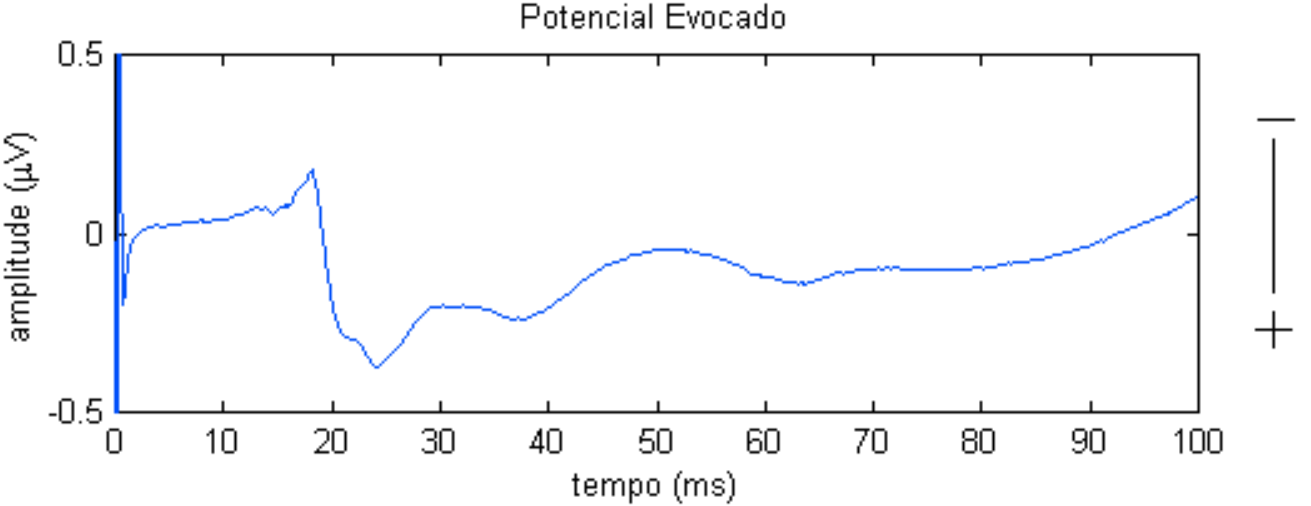

b)

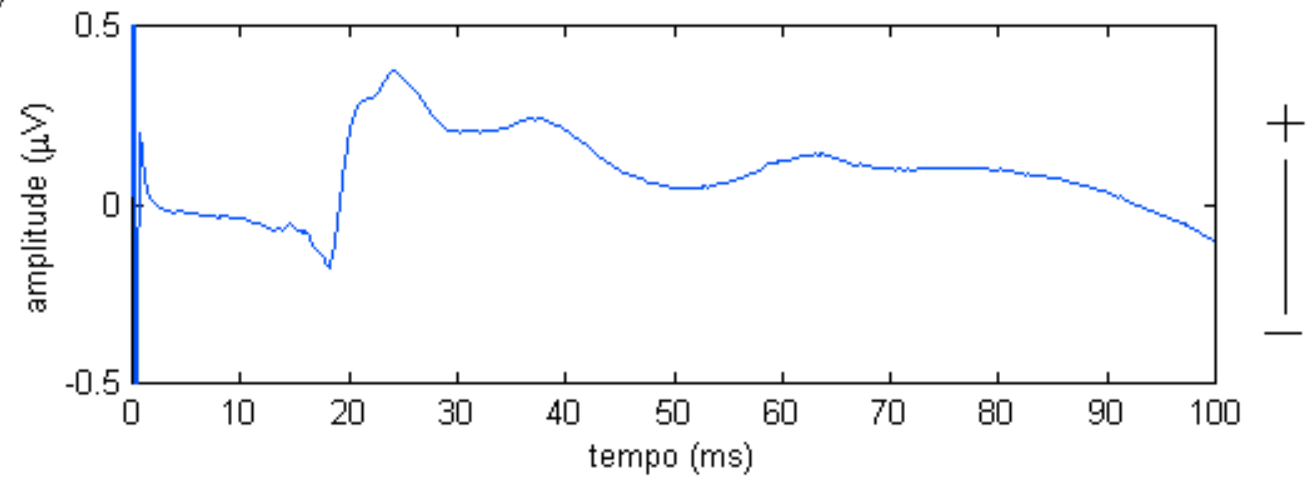

(adaptado de (SHIMIZU, 2005))

Figura 2.1 - Efeito da inversão da posição dos eletrodos de captação em um EP.

\subsubsection{Latência}

A latência de pico se refere ao tempo decorrido entre o instante de aplicação do estímulo e o pico da resposta. Juntamente com a polaridade, ela identifica o pico. Por exemplo, na figura 2.2, indica-se o primeiro pico como N19, ou seja, um pico negativo (para cima) com latência de 19ms. A latência de pico está indicada na figura pelo símbolo L1.

Por outro lado, a latência entre picos é o intervalo de tempo entre dois picos, sejam eles captados por um mesmo par de eletrodos ou não. A latência entre picos indica o tempo de condução entre os geradores de cada pico e costuma ter uma variabilidade menor que a latência de pico. No caso da figura 2.2, ambos os picos foram captados por um mesmo par de eletrodos e a latência entre os picos N19 e P25 é indicada por L2. 
Para ambas as latências, é importante que haja uma medida precisa do instante de ocorrência dos picos. Essa medição pode ser afetada pela presença de ruído, interferência e artefatos. Um dos objetivos deste trabalho é quantificar o erro introduzido pelo artefato de estímulo na medição da latência e a influência da remoção de artefato de estímulo na redução desse erro.

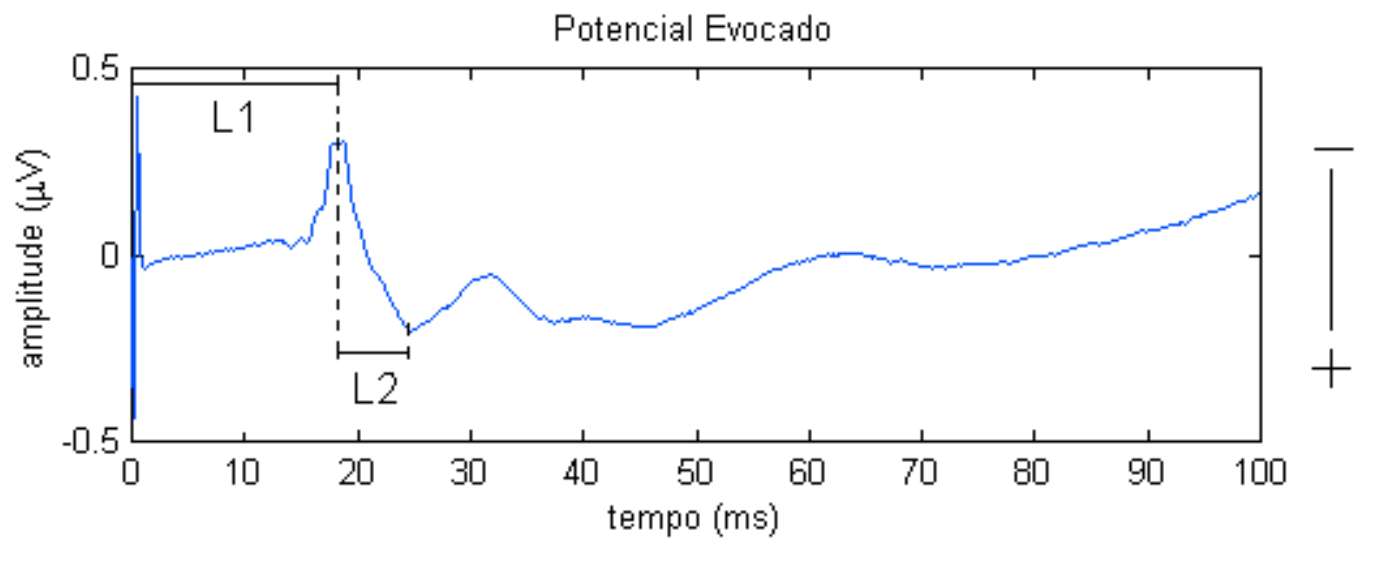

(adaptado de (SHIMIZU, 2005))

Figura 2.2 - Latência de pico (L1) e latência entre picos (L2).

\subsubsection{Amplitude}

A amplitude de pico é medida entre o pico e a linha de base, que pode ser o valor médio do trecho pré-estímulo, do trecho entre o estímulo e o início do primeiro pico, ou então, de todo o potencial evocado (CHIAPPA, 1997). Na Figura 2.3, a amplitude do pico N19 é indicada por A1, para uma linha de base igual ao valor médio do trecho pré-estímulo (não ilustrado na figura).

A amplitude pico-a-pico é a diferença entre as amplitudes de picos consecutivos e de polaridades opostas. Na figura 2.3, a amplitude pico-a-pico entre N19 e P25 é ilustrada por A2. 


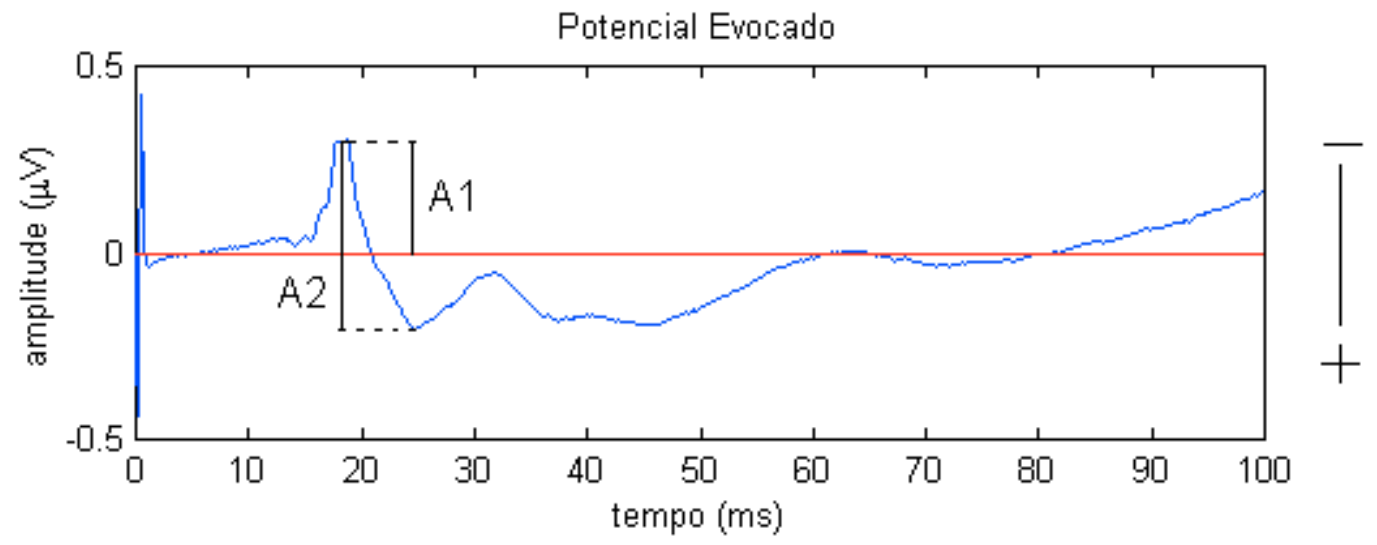

(adaptado de (SHIMIZU, 2005))

Figura 2.3 - Amplitude de pico (A1) e amplitude pico a pico (A2).

A determinação do pico pode ser dificultada por uma baixa relação sinal-ruído. Além disso, cada pico pode ter duas ou mais deflexões de amplitude semelhante. A figura 2.4 ilustra a presença de um pico duplo e as possíveis medidas da amplitude: o valor do maior pico, o valor do primeiro pico, o valor médio dos dois picos ou a intersecção das tangentes.

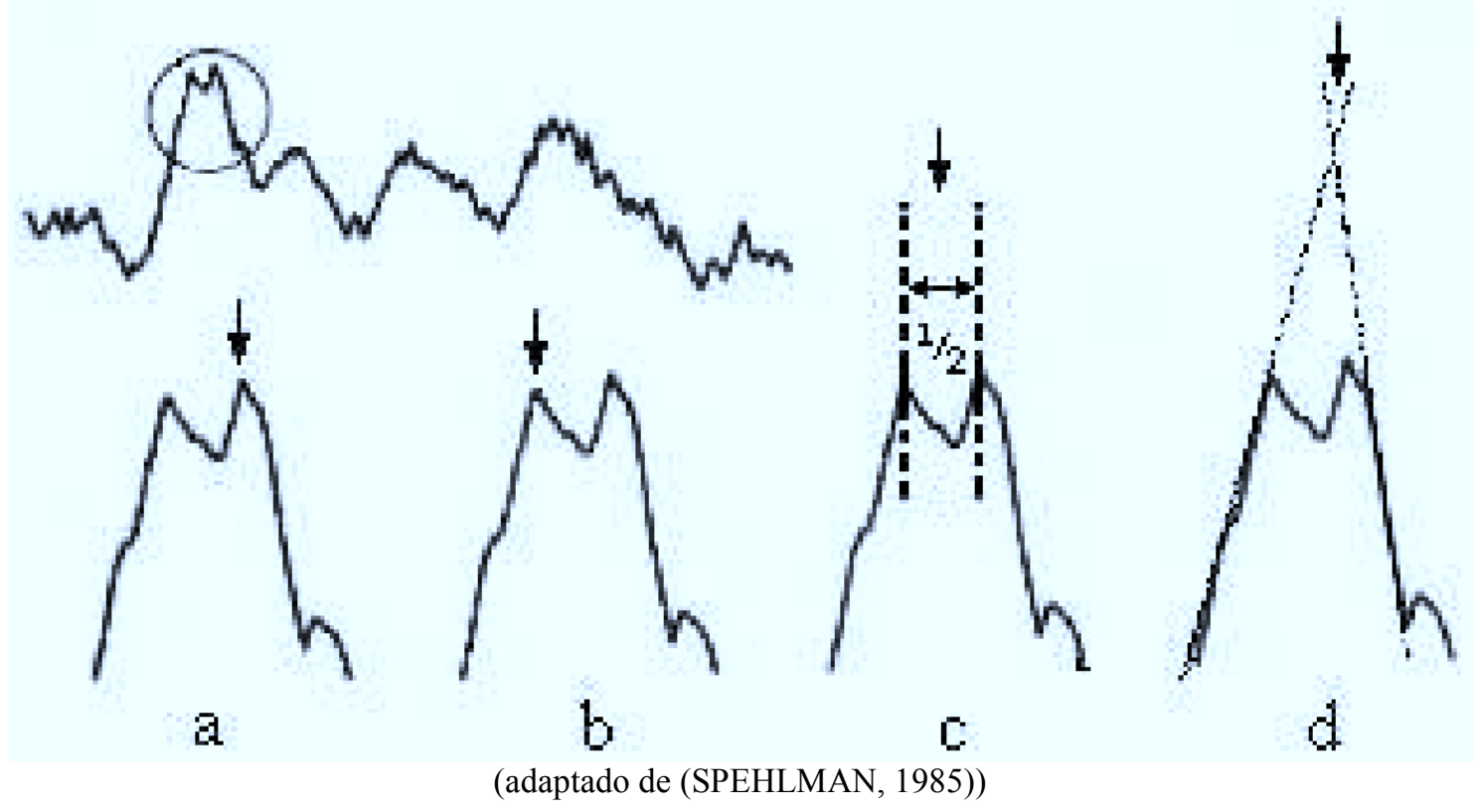

Figura 2.4 - Possíveis medições de amplitude na presença de pico duplo: a) amplitude do pico mais proeminente, b) amplitude do primeiro pico, c) média entre os picos, d) intersecção das retas tangenciais. 


\subsection{O potencial evocado somatossensitivo}

Os SEPs podem ser gerados pela estimulação de membros inferiores e superiores. No caso de membros superiores, a estimulação dos nervos ulnar, radial e mediano pode ser aplicada nos dedos ou no punho.

\subsubsection{Estimulação}

Para o nervo mediano, pode-se usar um par de eletrodos de anel para estimulação do dedo médio, ou então, um par de eletrodos de superfície com o anodo na dobra distal do punho, entre os tendões do flexor carpi radialis e do palmaris longus. O catodo fica localizado a $2 \mathrm{~cm}$ proximais do anodo. O estímulo é um pulso de corrente, de $100 \mu \mathrm{s}$ a $1 \mathrm{~ms}$ de duração, intensidade equivalente a uma vez e meia o limiar motor, e taxa de estimulação de 1Hz a 5Hz (SPEHLMAN, 1985; DeLISA; MACKENZIE; BARAN, 1987).

A figura 2.5 ilustra uma estimulação no punho.

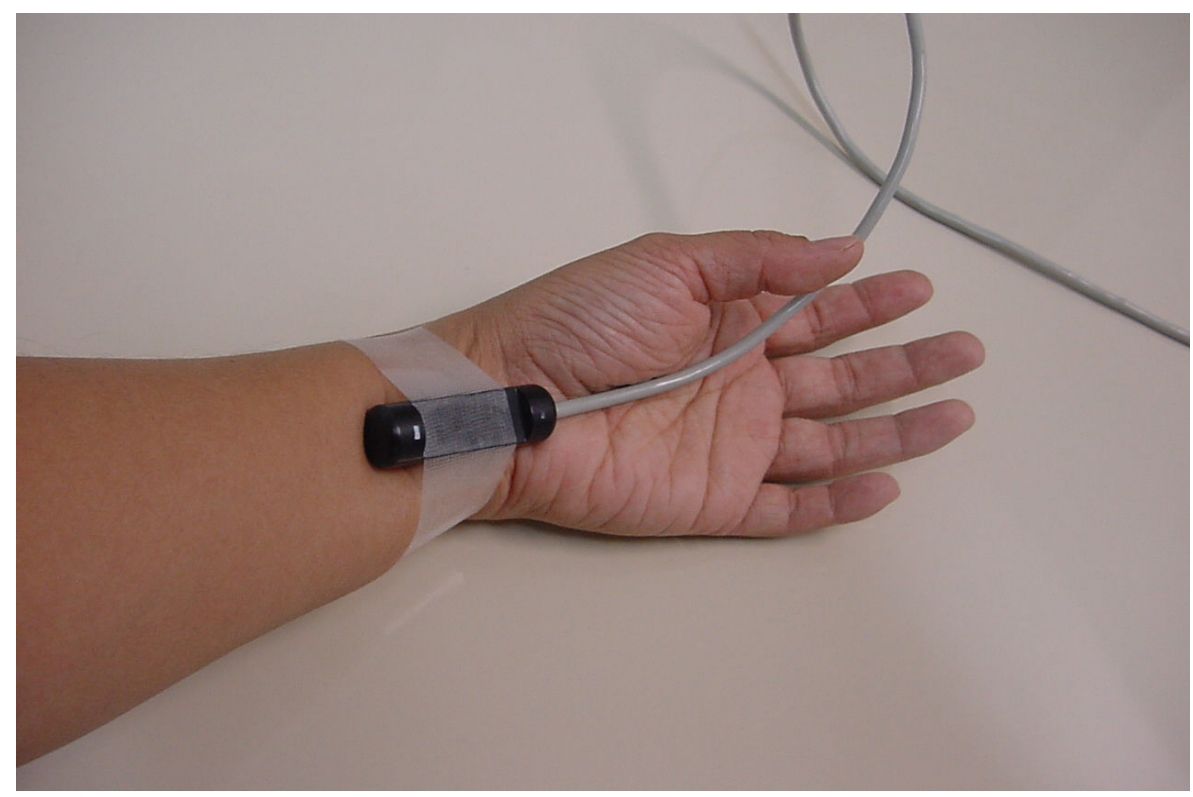

(extraído de (SHIMIZU, 2005))

Figura 2.5 - Eletrodos de estimulação fixados ao pulso de um voluntário. Ambos os eletrodos (o catodo e o anodo) estão fixos à peça plástica preta. 


\subsubsection{Captação}

A propagação do potencial evocado ocorre ao longo do nervo mediano, passa pelo plexo braquial, pela medula espinhal e chega ao córtex sensorial.

A figura 2.6 ilustra a localização do nervo mediano e do plexo braquial.

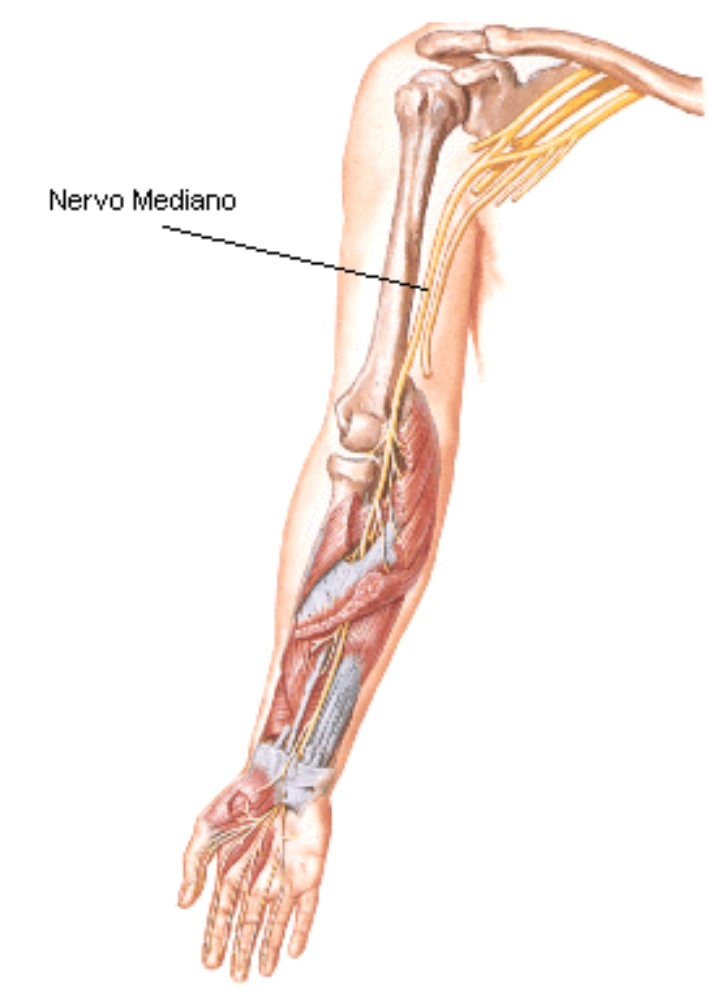

(adaptado de (NETTER; DALLEY; MYERS, 1995))

Figura 2.6 - Localização do nervo mediano nos membros superiores.

A captação é feita ao longo desse trajeto. Os registros são feitos por eletrodos de superfície colocados sobre os membros, a medula espinhal ou o encéfalo. Às vezes, são usados eletrodos de agulha e eletrodos de profundidade em pesquisas, porém, esses tipos de eletrodo não são usados na prática clínica de rotina.

Para os eletrodos de superfície posicionados no cotovelo, ombro e pescoço, anteriormente à fixação dos eletrodos com fita adesiva, é feita a abrasão da pele com pasta abrasiva e o preenchimento dos eletrodos com gel eletrolítico. No caso dos eletrodos fixados 
no escalpo, é usada uma pasta que melhora o contato do eletrodo com a pele e que simultaneamente fixa o eletrodo ao escalpo.

Os eletrodos de captação são posicionados no cotovelo (eletrodo ativo na fossa antecubital, no ponto médio entre os epicôndilos lateral e medial do úmero; eletrodo de referência no sulco ulnar), no ombro (ativo no ponto de Erb de $2 \mathrm{~cm}$ a $3 \mathrm{~cm}$ do ponto de intersecção entre a borda posterior da cabeça clavicular do músculo esternocleidomastóideo e a clavícula; referência comum no escalpo), pescoço (ativo na cervical II; referência comum no escalpo) e escalpo (ativo em C3' ou C4'; referência comum). O eletrodo comum de referência é posicionado no escalpo, em Fz'. As posições C3', C4' e Fz' estão localizadas a 2cm caudais dos pontos C3, C4 e Fpz do sistema 10-20 de posicionamento de eletrodos (figuras 2.7 e 2.8). O eletrodo de terra sempre deve ser colocado entre o par de eletrodos de estimulação e o primeiro par de eletrodos de captação, que neste caso é o par de eletrodos no cotovelo. Portanto, o eletrodo de terra é colocado a $2 \mathrm{~cm}$ distais do eletrodo ativo no cotovelo (DeLISA; MACKENZIE; BARAN, 1987).

A

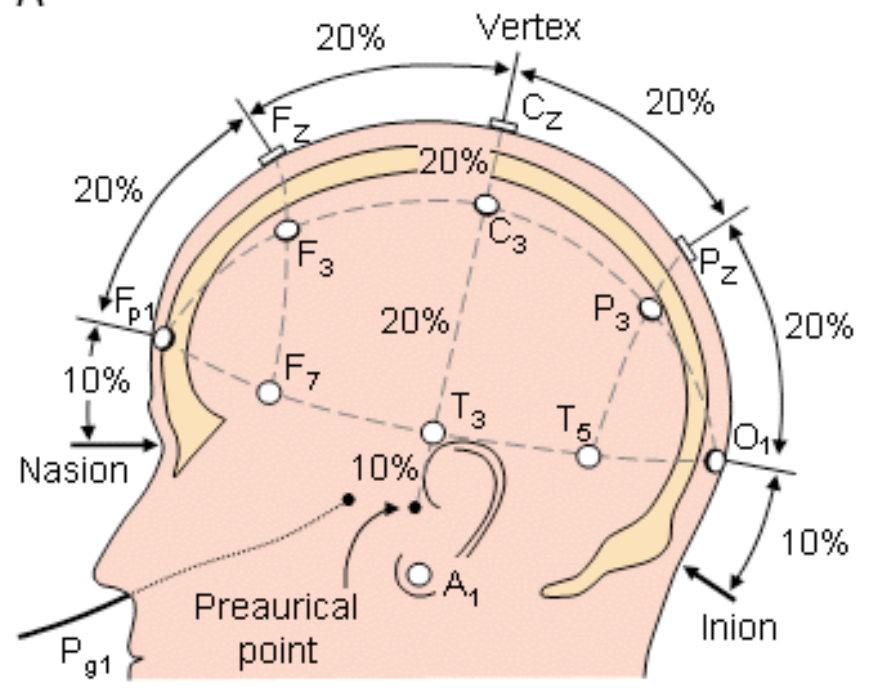

B Nasion

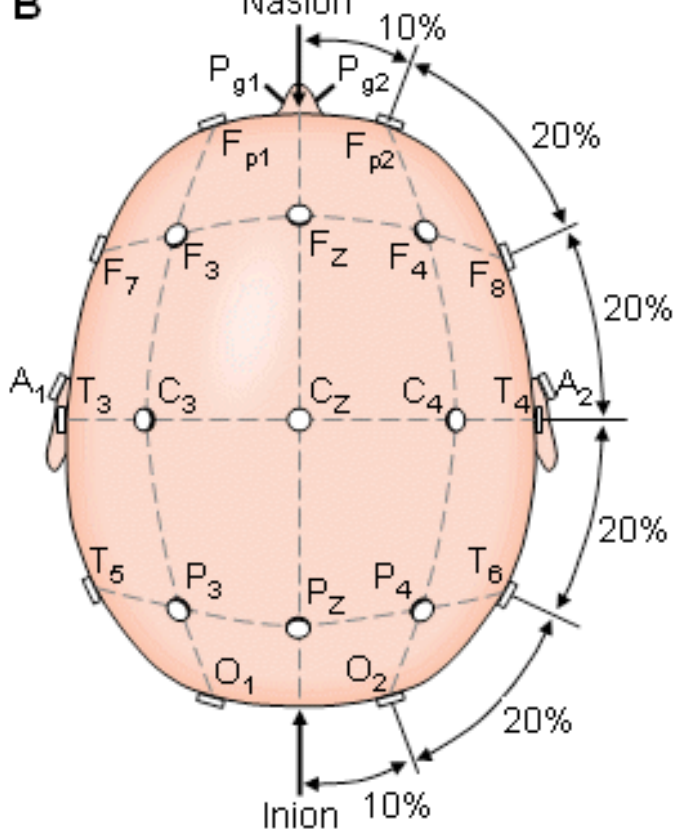

(adaptado de (SHARBROUGH et al., 1991))

Figura 2.7 -O sistema internacional 10-20 nas vistas a) lateral esquerda e b) superior da cabeça. Os símbolos indicam $\mathrm{A}=$ lóbulo auricular, $\mathrm{C}=$ central, $\mathrm{Pg}=$ nasofaríngeo, $\mathrm{P}=$ parietal, $\mathrm{F}=$ frontal, $\mathrm{Fp}=$ frontal polar, $\mathrm{O}=$ occipital. 


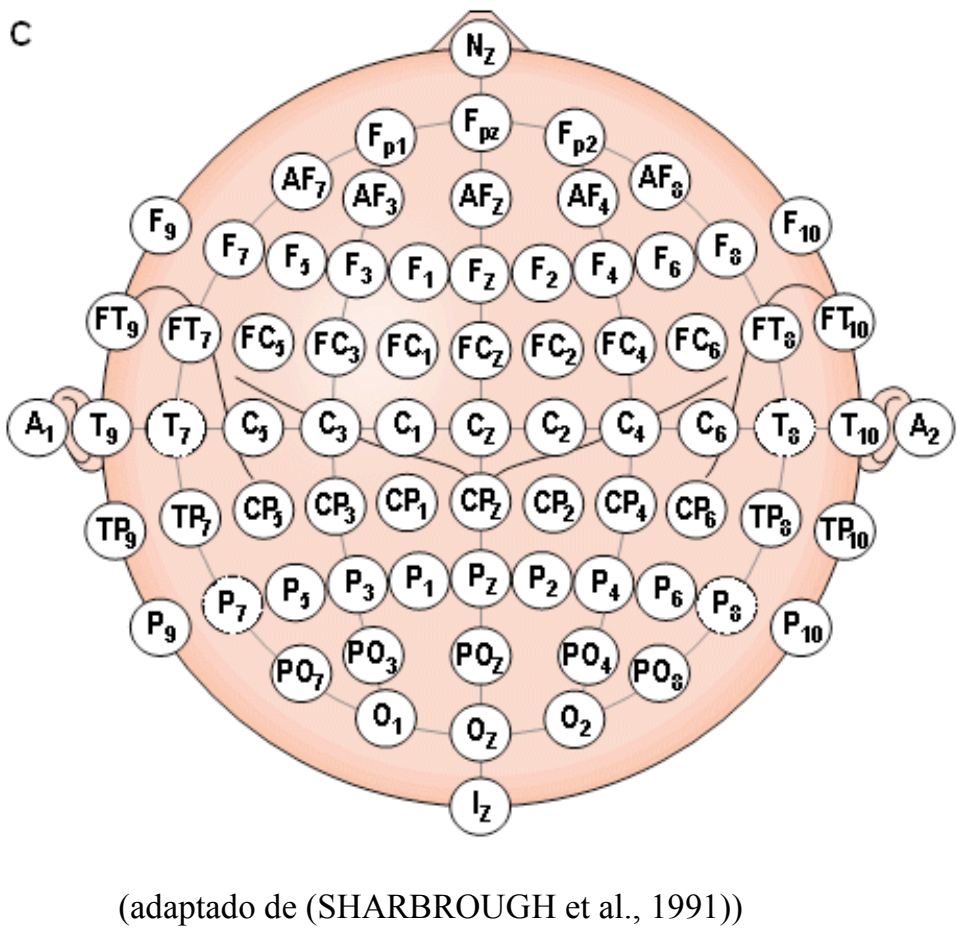

Figura 2.8 - Localização e nomenclatura dos eletrodos intermediários (10\%).

\subsubsection{Pré condicionamento}

O condicionamento é independente para cada canal, ou seja, a amplificação do sinal de cada par de eletrodos é ajustada de forma independente para cada canal. Esse ajuste depende da amplitude do sinal captado (SEP + EEG) e da faixa de entrada do conversor. Semelhantemente, a banda dos filtros associados a cada par de eletrodos é específica para cada canal (de $10 \mathrm{~Hz}$ até $3 \mathrm{kHz}$ para os eletrodos no cotovelo, ombro e pescoço; e de $0 \mathrm{~Hz}$ até 2kHz para os eletrodos no escalpo). (DeLISA; MACKENZIE; BARAN, 1987). 


\subsubsection{Aquisição}

A taxa de amostragem é ajustada para respeitar o critério de Nyquist para todos os canais. Como a máxima frequência de corte superior é de $3 \mathrm{kHz}$, a frequência de amostragem deve ser estritamente maior que $6 \mathrm{kHz}$. Uma taxa de amostragem de 20.000 amostras por segundo, como a usada nas aquisições e simulações deste trabalho, atende ao critério de Nyquist.

\subsection{Os artefatos de estímulo}
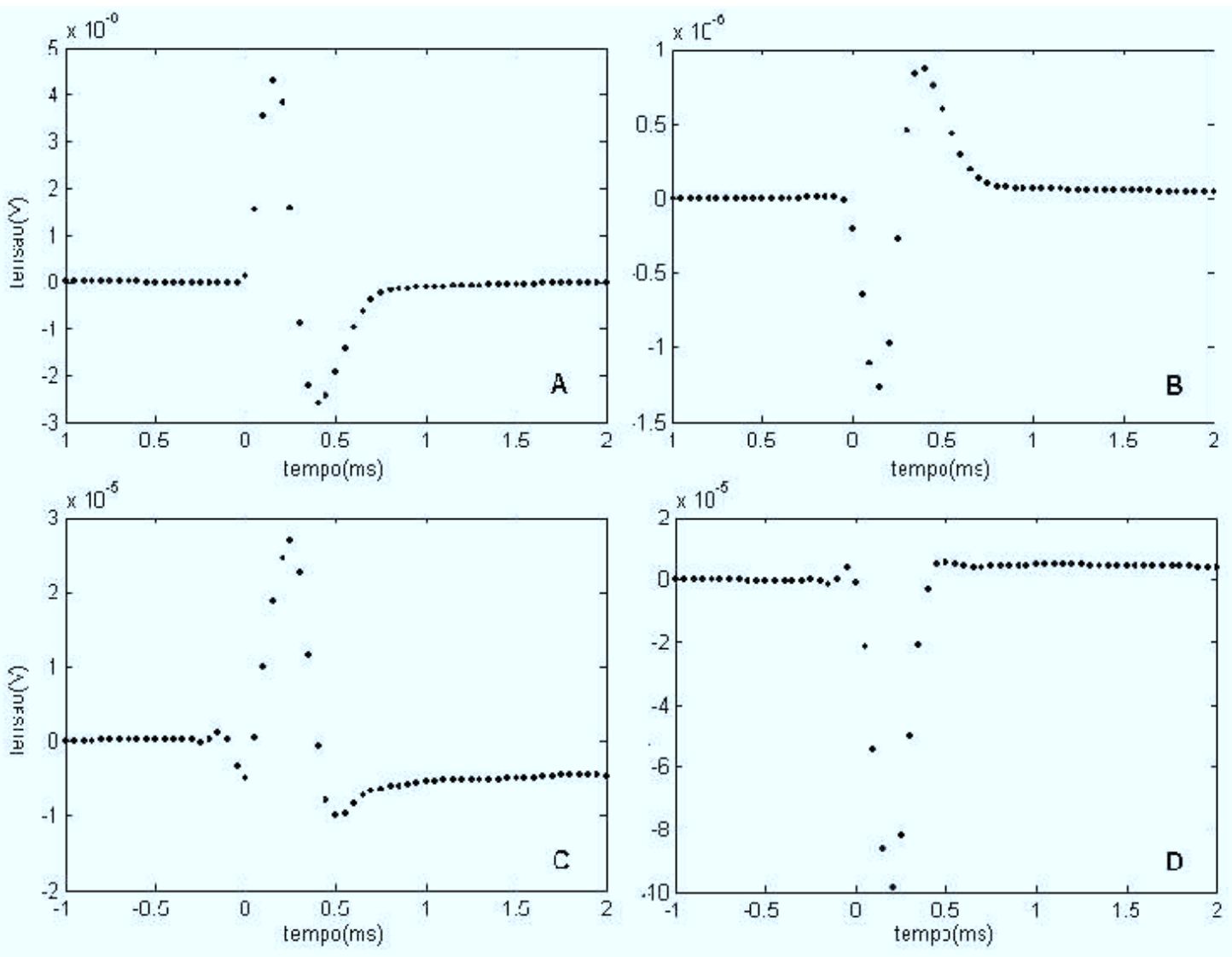

(adaptado de (MASETO, 2007))

Figura 2.9 - Tipos de artefatos de estímulo: a) bifásico de polaridade negativa; b) bifásico de polaridade positiva; c) monofásico de polaridade negativa; d) monofásico de polaridade positiva. Os picos negativos são indicados para cima. 
Os artefatos de estímulo podem ter vários formatos. Ressaltam-se os artefatos bifásicos (com dois picos de polaridade oposta) e os monofásicos (um únco pico proeminente). Os artefatos considerados positivos são aqueles cujo primeiro pico é positivo. A figura 2.9 ilustra alguns artefatos de estímulo com formatos variados: bifásicos de polaridades negativa e positiva assim como monofásicos de ambas as polaridades. 


\section{Materiais e métodos}

Neste capítulo, inicialmente serão apresentadas as descrições dos modelos de potencial evocado, de artefato de estímulo e de ruído. Em seguida serão apresentados os métodos de eliminação do artefato de estímulo. Também serão descritos os métodos para o estudo da relação entre parâmetros de SEP e erros associados, ou seja, serão mostradas as formas de cálculo dos erros e de medição de amplitude pico a pico e de latência.

\subsection{Descrição do modelo de potencial evocado}

Para representar o modelo do potencial evocado, um sinal com dois ciclos de senóide completos é multiplicado por um co-seno levantado. A Figura 3.1 mostra o modelo do potencial evocado. Dois ciclos completos de senóide de amplitude unitária $(A=1)$ e freqüência de $666,67 \mathrm{~Hz}$ com início em $D=6 \mathrm{~ms}$ (figura 3.1a) são multiplicados por um co-seno levantado (figura 3.1b) de amplitude 0,5 , freqüência de $333,33 \mathrm{~Hz}$ e valor médio 0,5 , resultando no modelo de SEP da figura 3.1c.

A função que representa o potencial evocado tem a seguinte fórmula:

$$
x(t)=A \sin (4 \pi(t-D) / 3)[1+\cos (2 \pi(t-D) / 3)] / 2,
$$

para $D \leq t \leq(D+3 \mathrm{~ms})$ em ms e:

$$
x(t)=0,
$$

para $t<D$ e $t>(D+3 \mathrm{~ms})$. O parâmetro $D$ é o atraso variável em ms entre o disparo do estímulo e o início do potencial evocado. O parâmetro $A$ é proporcional à amplitude do potencial evocado. Um valor unitário do parâmetro $A$ representa uma razão de amplitude de 83\% entre o SEP e o artefato de estímulo. A duração do SEP é fixada em 3ms (60 amostras), que é um valor próximo ao encontrado na literatura (DeLISA; MACKENZIE; BARAN, 1987) 
para estimulação do nervo mediano no punho com captação na fossa antecubital. Essa duração correspondeu a uma onda senoidal de $666,7 \mathrm{~Hz}$ multiplicada por um co-seno levantado de 333,3Hz. Como ilustração, a Figura 3.1 mostra o SEP produzido com um atraso $D$ de $6 \mathrm{~ms}$ e um parâmetro $A$ unitário.
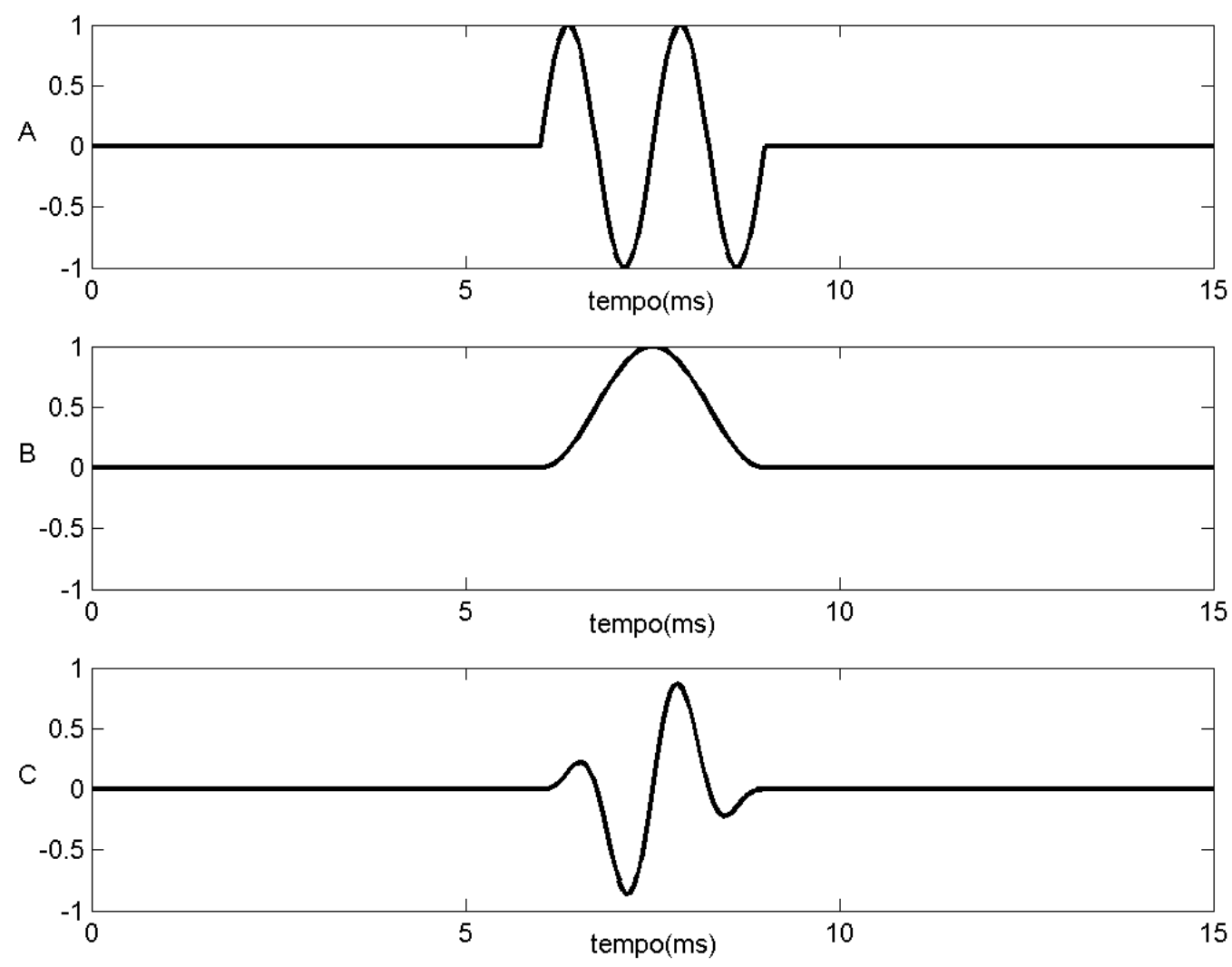

Figura 3.1 - (A) Dois ciclos completos de senóide de amplitude unitária e freqüência de $666,67 \mathrm{~Hz}$ com início em 6ms. (B) Co-seno de amplitude 0,5 e freqüência de $333,33 \mathrm{~Hz}$ somado a um nível DC (offset) de 0,5. (C) Modelo do SEP, resultante da multiplicação dos sinais anteriores.

Neste modelo os parâmetros relevantes, amplitude e latência, estão bem representados na Figura 3.2. O primeiro pico de baixa amplitude define a latência $(L)$ do potencial evocado, enquanto que os picos de grande amplitude bipolares definem a amplitude pico a pico (App). $\mathrm{O}$ atraso (D) define o início do primeiro pico de baixa amplitude. 


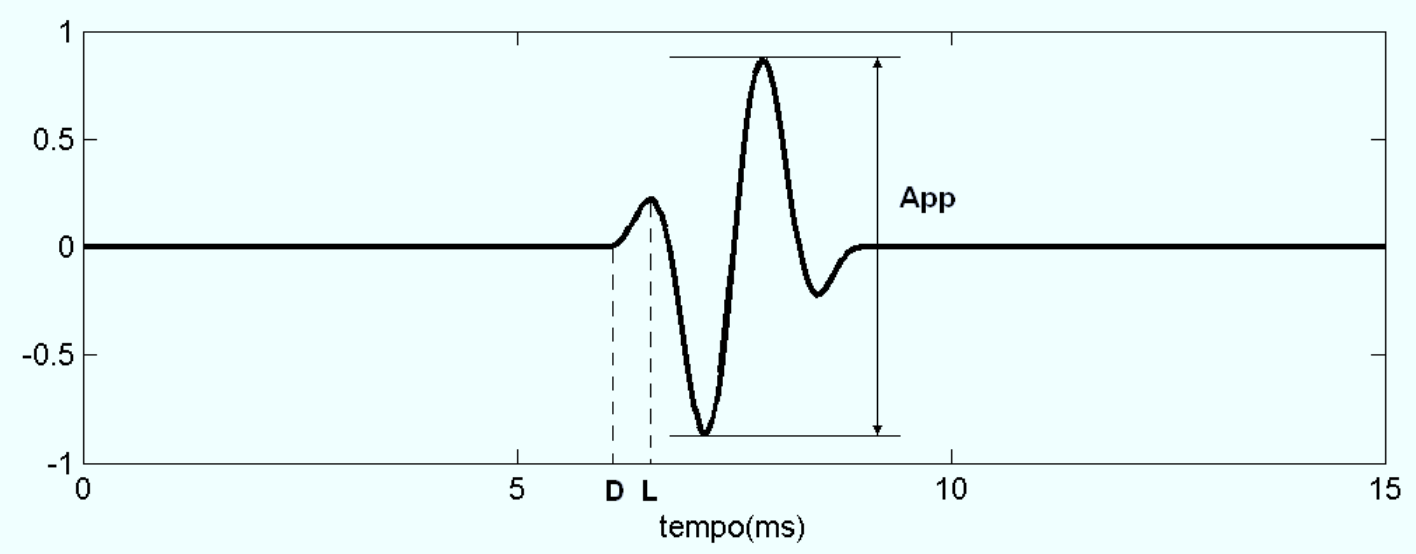

Figura 3.2 - Modelo de potencial evocado com os parâmetros atraso $(D)$, latência $(L)$ e amplitude pico a pico (App).

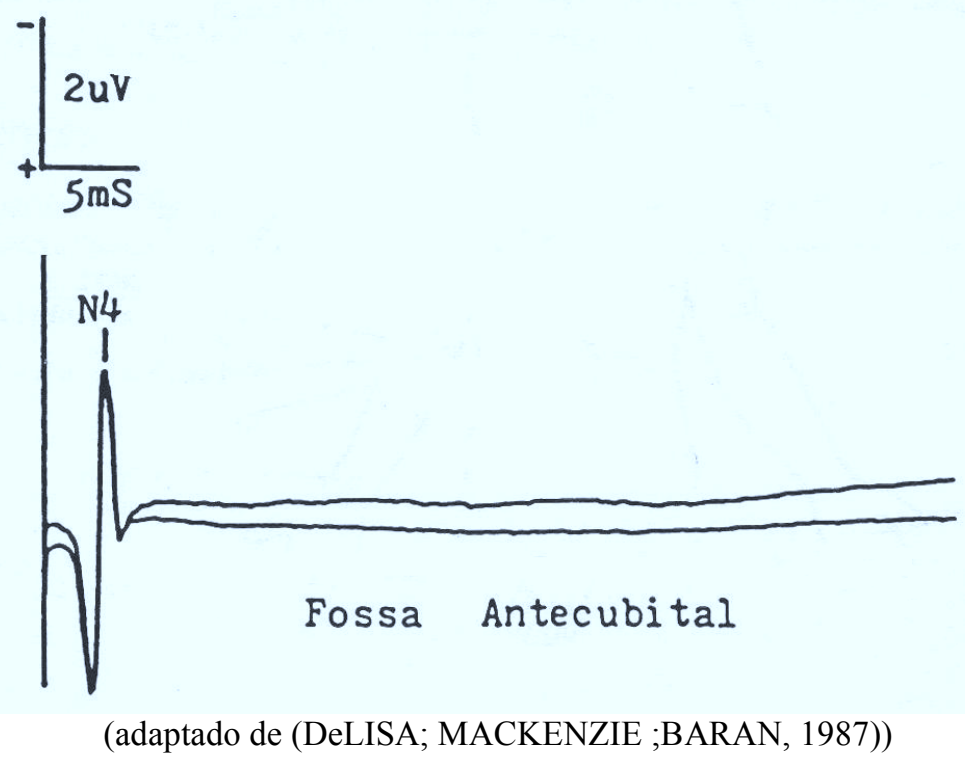

Figura 3.3 - Potencial evocado somato-sensitivo captado na fossa antecubital em resposta à estimulação do nervo mediano (punho).

O modelo de SEP é simples, porém, com o ajuste da frequência e do atraso pode-se representar muito bem o potencial evocado captado na fossa antecubital. Podemos comparar visualmente os potenciais nas Figuras 3.3 e 3.4. Na Figura 3.3 é ilustrado o potencial evocado para estimulação do nervo mediano no punho com captação na fossa antecubital e na Figura 3.4, o modelo de potencial evocado utilizando as fórmulas (1) e (2) com parâmetros tais que o modelo se ajuste ao potencial evocado da Figura 3.3. Pode-se observar a semelhança das 
formas de onda. O modelo de SEP com duração de $3 \mathrm{~ms}$ será utilizado em todas as simulações deste trabalho.

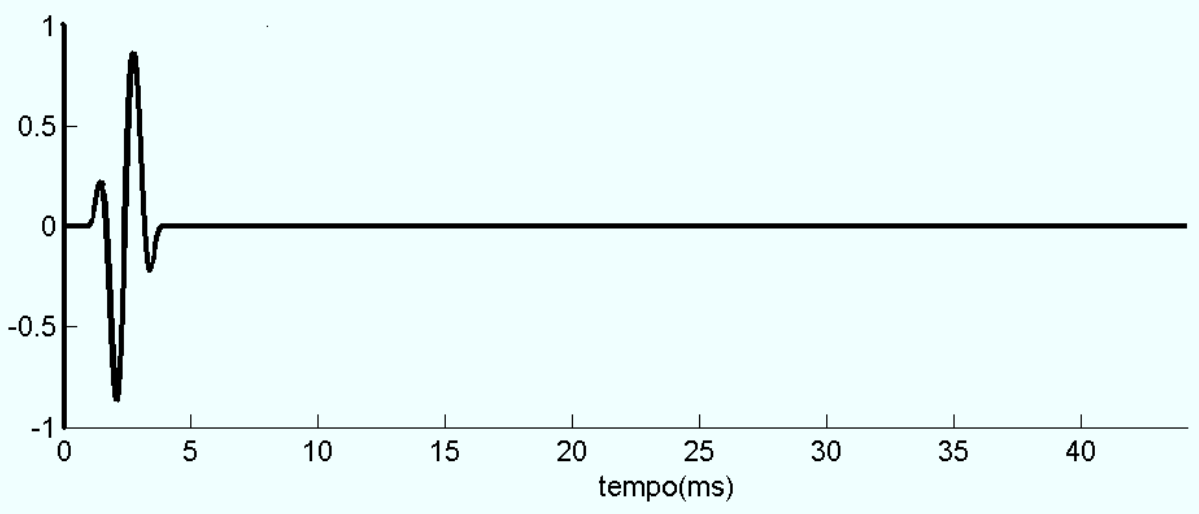

Figura 3.4 - Modelo do potencial evocado com duração de $3 \mathrm{~ms}$, atraso $D$ de $1 \mathrm{~ms}$ e parâmetro $A$ unitário (amplitude de pico de 0,83 ) que foi ajustado para uma comparação visual com o potencial evocado da Figura 3.3.

\subsection{Descrição do modelo de artefato de estímulo}

Os artefatos de estímulo foram modelados como trechos de exponenciais concatenados de maneira a se ajustar ao formato dos artefatos.

O artefato de estímulo foi modelado pela concatenação de um pulso bipolar retangular inicial e três segmentos exponenciais. O pulso definiu o instante em que o estímulo foi aplicado: $0 \leq t \leq 0,2 m s$. Ele foi seguido por três segmentos exponenciais, como em Harding (1991). O valor inicial do primeiro segmento foi fixado sempre em 1. Isso não impôs nenhuma restrição adicional, já que as amplitudes podem ser interpretadas como normalizadas. Na Figura 3.5, os segmentos estão desconexos, visando somente ilustrar os segmentos de forma clara. No modelo do artefato de estímulo, todos os segmentos foram posicionados de forma a manter a continuidade entre os segmentos sucessivos. 


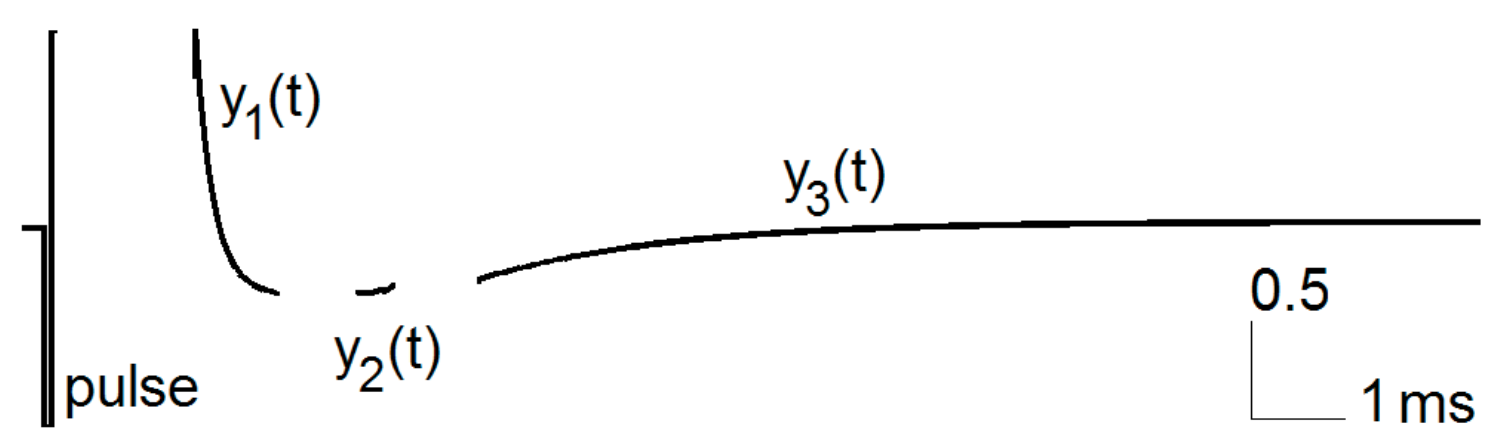

Figura 3.5 - Um pulso bipolar retangular e três segmentos exponenciais do modelo de artefato de estímulo.

A função ajustada ao primeiro segmento exponencial tem a forma

$$
y_{1}(t)=a_{1}\left[\exp \left(-\left(\left(t-t_{0}\right) / 1000\right)^{b_{1}} / c_{1}\right)-1\right]+d_{1}
$$

para $t_{0} \leq t \leq t_{1}$; em que $t$ representa os instantes amostrados (ms), $t_{0}$ é a duração do estímulo $(0,2 \mathrm{~ms})$ e os valores de $a_{1}, \quad b_{1}$, e $c_{1}$ devem ser determinados. O segundo segmento é dado por

$$
y_{2}(t)=a_{2}\left[\exp \left(+\left(\left(t-t_{1}\right) / 1000\right)^{b_{2}} / c_{2}\right)-1\right]+d_{2},
$$

para $t_{1} \leq t \leq t_{2}$. E o terceiro segmento é

$$
y_{3}(t)=a_{3}\left[\exp \left(-\left(\left(t-t_{2}\right) / 1000\right)^{b_{3}} / c_{3}\right)\right],
$$

para $t_{2} \leq t \leq 100 \mathrm{~ms}$. Os valores constantes usados em todas as simulações foram $a_{1}=1,35$; $a_{2}=1,35 ; \quad a_{3}=y_{2}\left(t_{2}\right) ; \quad b_{1}=1,0 ; \quad b_{2}=2,3 ; \quad b_{3}=1,0 ; \quad c_{1}=0,2 \mathrm{~ms} ; \quad c_{2}=0,0006 \mathrm{~ms} ; \quad c_{3}=2,0 \mathrm{~ms} ; \quad d_{1}=1$; $d_{2}=y_{1}\left(t_{1}\right) ; t_{0}=0,2 \mathrm{~ms} ; t_{1}=1,2 \mathrm{~ms} ; t_{2}=1,6 \mathrm{~ms}$ 


\subsection{Descrição do sinal com ruído}

Foi acrescentado um ruído $w(t)$ gaussiano de média nula e variância $4 \times 10^{-6}$ à soma da resposta evocada com o artefato de estímulo. O sinal resultante é dado por

$$
s(t)=x(t)+y(t)+w(t)
$$

em que a resposta evocada é dada por $x(t)$; o artefato de estímulo $y(t)$ é obtido pela concatenação dos segmentos $y_{1}(t), y_{2}(t)$, e $y_{3}(t)$ ao pulso bipolar retangular; e o ruído aditivo é $w(t)$. A Figura 3.6 mostra um exemplo do sinal $s(t)$.

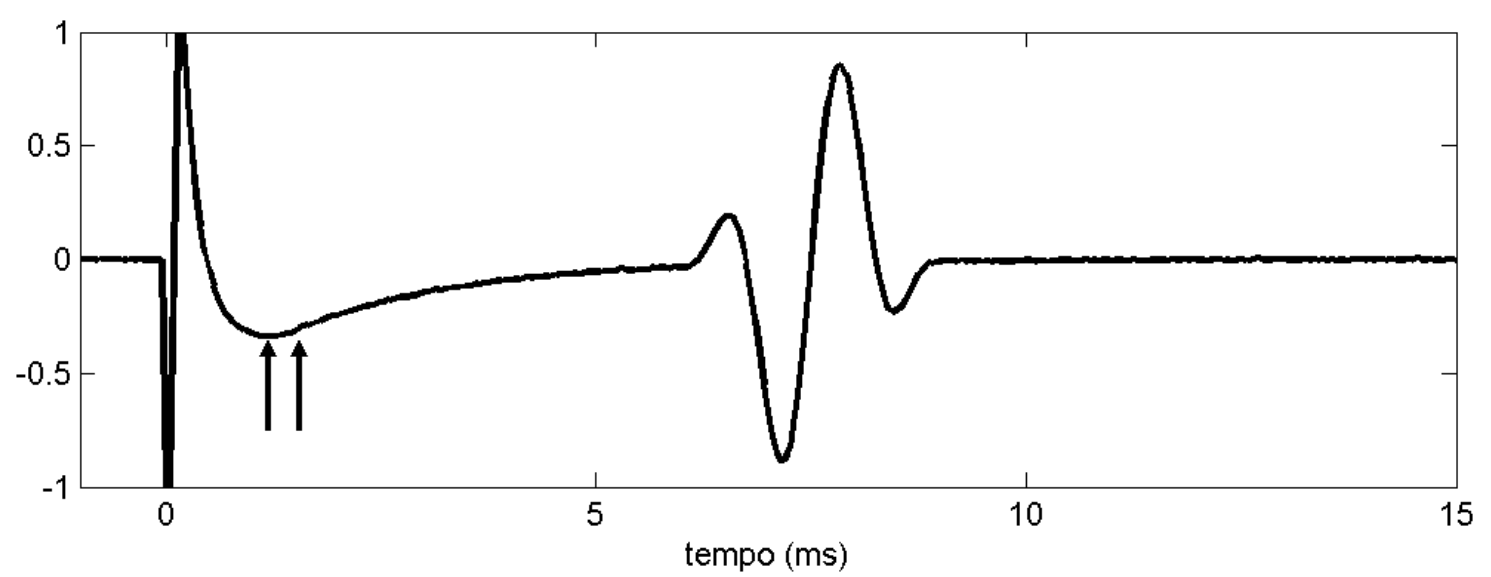

Figura 3.6 - Sinal composto pelo artefato de estímulo, resposta evocada e ruído. As flechas indicam os pontos que demarcam o início e o fim do segundo segmento exponencial.

Para estudar a relação entre os parâmetros do SEP (amplitude e latência) e os erros associados, foram gerados sinais computacionais no ambiente Matlab (versão 6). Cada sinal tinha 2048 amostras e a frequência de amostragem $\left(f_{a}\right)$ foi de $20 \mathrm{kHz}$. Eles foram gerados pela soma do modelo de potencial evocado, do modelo de artefato de estímulo e do ruído branco gaussiano.

Os sinais biológicos utilizados neste trabalho foram obtidos de um banco de dados préexistente no Laboratório de Engenharia Biomédica da Escola Politécnica da Universidade de São Paulo (LEB-EPUSP). Foram obtidos com estimulação do nervo mediano no punho esquerdo e captados no cotovelo esquerdo (fossa antecubital - sulco ulnar) e no escalpo 
direito (C4' - FPz'). Esses sinais haviam sido captados de indivíduos normais, amplificados e filtrados por um passa-faixa, com freqüências de corte em $5 \mathrm{~Hz}$ e $3 \mathrm{kHz}$. Os sinais haviam sido digitalizados por um conversor A/D de 12 bits, adquiridos à taxa de 20.000 amostras por segundo e salvos em arquivos.

\subsection{Remoção do Artefato}

Inicialmente, o sinal combinado foi particionado em seu pulso retangular bipolar e três segmentos exponenciais, baseado no conhecimento dos comprimentos de cada segmento. Para sinais adquiridos, a separação entre a primeira e segunda exponenciais poderia ser delimitada pelo primeiro pico negativo. A segunda e terceira exponenciais poderiam ser separadas pelo ponto em que a derivada atinge seu máximo valor.

O pulso retangular bipolar foi removido por template matching (ajuste a modelo). Neste trabalho o modelo é um pulso retangular bipolar, com duas amostras iguais a -1, uma amostra igual a 0 e duas amostras iguais a +1 .

Em seguida, cada segmento exponencial foi removido separadamente, baseado no ajuste de curva pelo método de Gauss-Newton. O método foi implementado pela função nlinfit.m, do Toolbox de Estatística do Matlab. Ela forneceu as estimativas dos coeficientes $\hat{a}_{1}, \hat{a}_{2}, \hat{b}_{1}$, $\hat{b}_{2}, \hat{b}_{3}, \hat{c}_{1}, \hat{c}_{2}, \hat{c}_{3}$ que minimizavam o erro médio quadrático entre o sinal $s(t)$ e a estimativa do segmento do artefato $\hat{y}_{i}(t)$, para $i=1,2,3$. Então, as estimativas dos segmentos $\hat{y}_{1}(t), \quad \hat{y}_{2}(t)$ e $\hat{y}_{3}(t)$ foram calculadas com base nas estimativas dos coeficientes. Posteriormente, as estimativas dos segmentos foram removidas do sinal $s(t)$. Após a remoção da estimativa do artefato, o resíduo constituía uma estimativa do SEP:

$$
\hat{x}(t)=s(t)-\hat{y}(t) .
$$


Para estimar os coeficientes de cada trecho exponencial, pode-se usar o método iterativo de Gauss-Newton, que pode ser aplicado ao seguinte problema de minimização

$$
\min _{a, b, c}\{E\}=\min _{a, b, c}\left\{\sum_{t=t_{0}}^{t_{f}}\left[e_{N}(t)\right]^{2}\right\} .
$$

A variável $e_{N}(t)$ é a diferença entre as amostras do sinal $s(t)$ e uma função analítica $y(t, a, b, c)$ que descreve o trecho de exponencial específico, ou seja,

$$
e_{N}(t)=s(t)-y(t, a, b, c)
$$

em que os coeficientes a serem estimados são dados por $a, b, c$.

As estimativas dos coeficientes são atualizadas iterativamente. Os coeficientes da iteração $(m+1)$ são calculados a partir dos coeficientes da iteração $(m)$ e das derivadas de primeira e segunda ordem calculadas na iteração $(m)$, da seguinte forma

$$
\left[\begin{array}{l}
a^{(m+1)} \\
b^{(m+1)} \\
c^{(m+1)}
\end{array}\right]=\left[\begin{array}{l}
a^{(m)} \\
b^{(m)} \\
c^{(m)}
\end{array}\right]-\left[\begin{array}{ccc}
\frac{\partial^{2} E}{\partial a \partial a^{T}} & \frac{\partial^{2} E}{\partial a \partial b^{T}} & \frac{\partial^{2} E}{\partial a \partial c^{T}} \\
\frac{\partial^{2} E}{\partial b \partial a^{T}} & \frac{\partial^{2} E}{\partial b \partial b^{T}} & \frac{\partial^{2} E}{\partial b \partial c^{T}} \\
\frac{\partial^{2} E}{\partial c \partial a^{T}} & \frac{\partial^{2} E}{\partial c \partial b^{T}} & \frac{\partial^{2} E}{\partial c \partial c^{T}}
\end{array}\right]_{\substack{a=a^{(m)} \\
b=b^{(m)} \\
c=c^{(m)}}}^{-1}\left[\begin{array}{c}
\frac{\partial E}{\partial a} \\
\frac{\partial E}{\partial c}
\end{array}\right]_{\substack{a=a^{(m)} \\
c=b^{(m)} \\
c=c^{(m)}}}
$$

\subsection{Medição da amplitude pico-a-pico}

A amplitude pico-a-pico da resposta evocada foi calculada pela diferença entre os valores máximo e mínimo dos picos mais proeminentes. Essa medida de amplitude foi aplicada tanto ao sinal original $s(t)$ quando à estimativa da SEP $\hat{x}(t)$. Posteriormente, as medidas foram comparadas com a amplitude pico-a-pico do modelo da resposta evocada $x(t)$. 


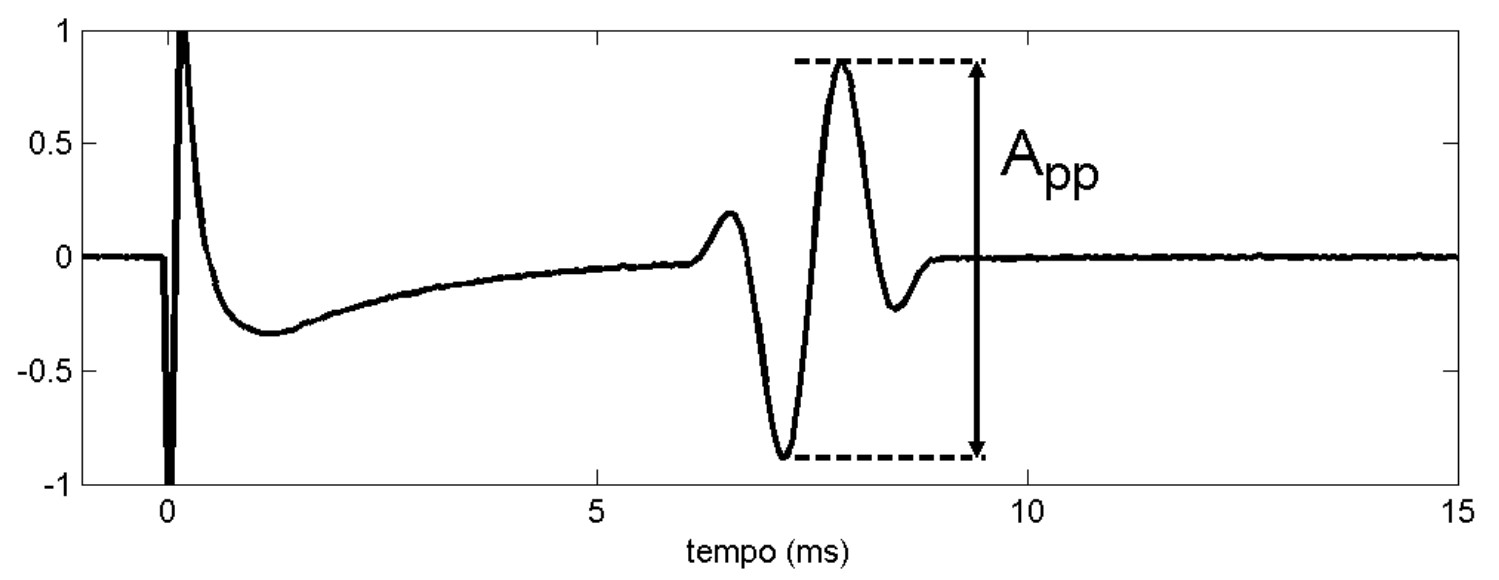

Figura 3.7 - Medição da amplitude pico-a-pico $\left(A_{p p}\right)$ no sinal original $s(t)$.

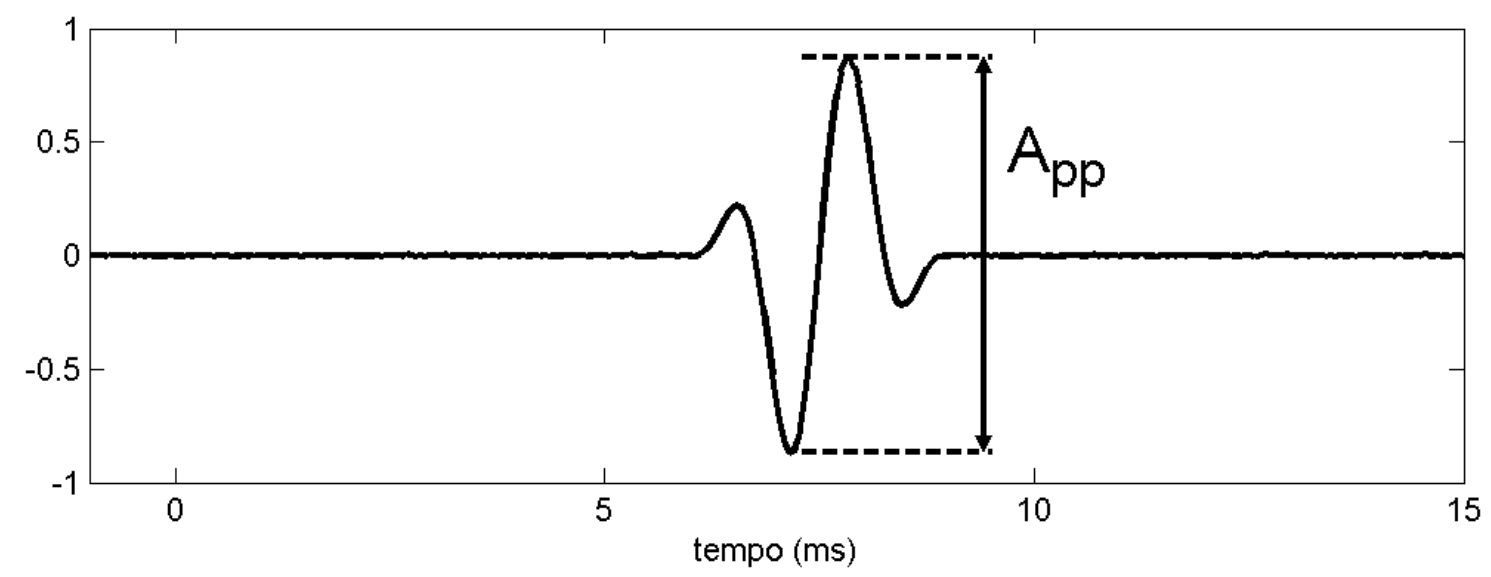

Figura 3.8 - Medição da amplitude pico-a-pico $\left(A_{p p}\right)$ na estimativa do potencial evocado $\hat{x}(t)$.

\subsection{Medição da latência}

O padrão (template) do pulso retangular bipolar foi removido do potencial evocado, no intervalo de 0 a $0,2 \mathrm{~ms}$ (período de aplicação do estímulo).

Após a remoção do pulso retangular bipolar, o potencial evocado foi filtrado em ambas as direções por um filtro passa-baixas de Butterworth com frequência de corte em $2 \mathrm{kHz}$, usando a função do Matlab filtfilt.m. Para promediações com um número grande de respostas, a filtragem pode ser desnecessária, desde que a relação sinal-ruído seja suficientemente alta. 
Em seguida, a operação de diferença foi aplicada ao sinal filtrado: $g(t)=f(t)-f(t-0,05 \mathrm{~ms})$. Os cruzamentos de zero do sinal diferencial $g\left(t_{p}\right)$ definiram a localização dos picos do potencial evocado $f\left(t_{p 1}\right), f\left(t_{p 2}\right), f\left(t_{p 3}\right), f\left(t_{p 4}\right)$. Escolheu-se o primeiro pico pequeno $f\left(t_{p 1}\right)$,. E se definiu que esse instante de tempo $t_{p 1}=L$ seria a latência da resposta evocada.

A figura 3.9 ilustra o potencial evocado (linha contínua) após a remoção do pulso retangular bipolar e o sinal diferencial (linha tracejada). Os círculos marcam o cruzamento do zero para o sinal diferencial e o pico pequeno do potencial evocado. Escolheu-se o pico pequeno para definir a latência, para se trabalhar com o "pior caso", ou seja, com a medição que poderia inserir os maiores erros, já que os picos maiores são, a princípio, mais fáceis de serem detectados corretamente.

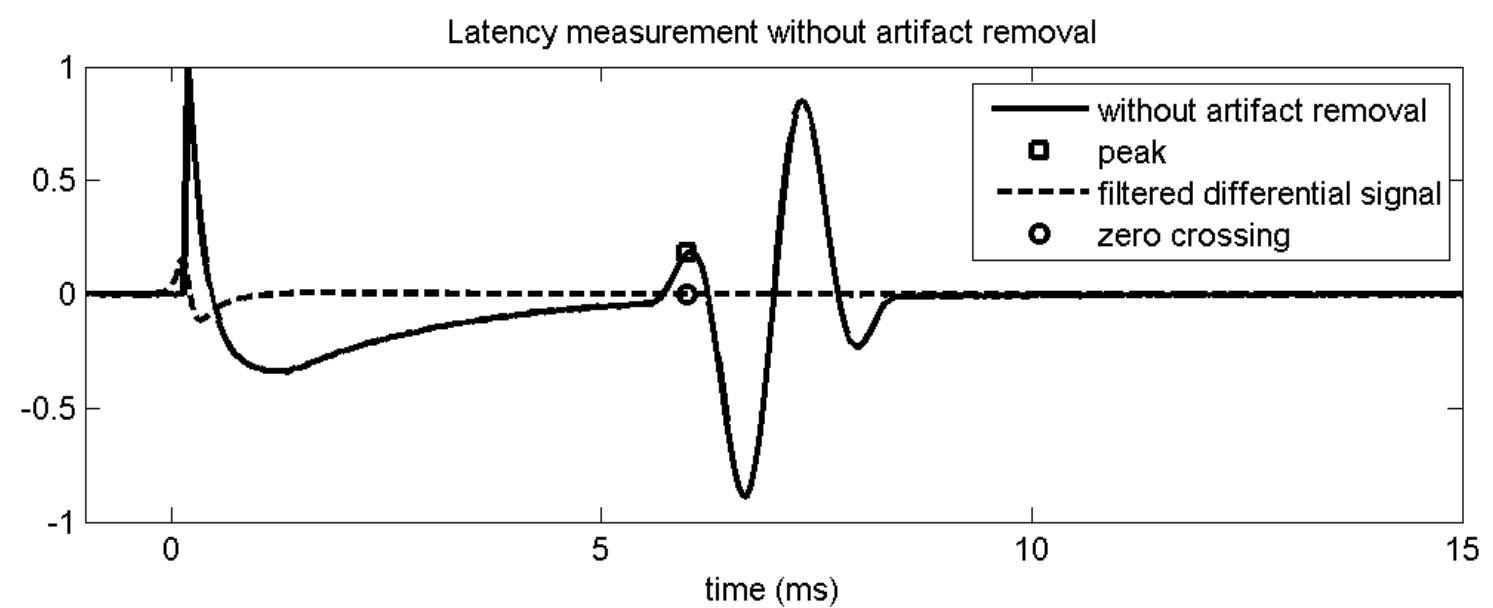

Figura 3.9 - Medida de latência. O cruzamento do zero do sinal diferencial define o pico pequeno da estimativa da resposta evocada (antes da remoção do artefato).

O mesmo procedimento foi aplicado ao sinal após a remoção das exponenciais que mimetizam o artefato de estímulo. $\mathrm{O}$ sinal sem artefato de estímulo, que corresponde à estimativa da resposta evocada, foi filtrado e diferenciado.

A Figura 3.10 mostra a estimativa da resposta evocada $\hat{x}(t)$ em linha contínua e o sinal diferencial $g(t)$ em linha tracejada, assim como os pontos que definem as estimativas de latência (círculos). 


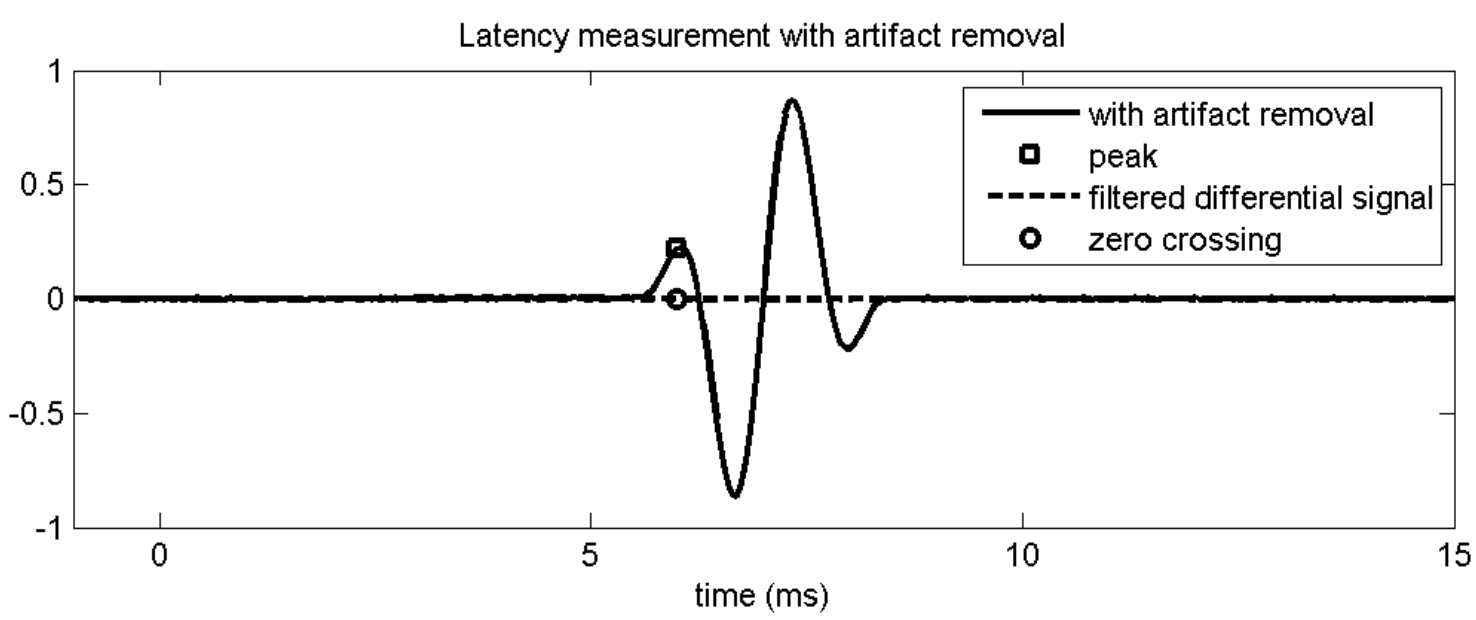

Figura 3.10 - Medida de latência. O cruzamento do zero do sinal diferencial define o pico da estimativa da resposta evocada (depois da remoção do artefato).

\subsection{Erro médio quadrático}

A diferença entre o modelo da resposta evocada e sua estimativa forneceu o erro médio quadrático (MSE, do inglês Mean Square Error):

$$
\operatorname{MSE}(t)=E\left\{[x(t)-\hat{x}(t)]^{2}\right\} .
$$

Em estatística, o erro médio quadrático de um estimador é uma das muitas maneiras de se quantificar a diferença entre o estimador (estimativa do SEP) e o verdadeiro valor a ser estimado (modelo de potencial evocado). O MSE calcula a esperança $E\{$.$\} (ou valor médio)$ do quadrado do erro.

Outra medida utilizada frequentemente para quantificar a diferença entre o estimador e o verdadeiro valor a ser estimado é a raiz quadrada do erro médio quadrático (RMSE, do inglês Root Mean Square Error):

$$
\operatorname{RMSE}(t)=\sqrt{E\left\{[x(t)-\hat{x}(t)]^{2}\right\}}
$$




\section{Resultados}

Neste capítulo são apresentados os resultados obtidos. Inicialmente é ilustrado o efeito da remoção do artefato de estímulo. Em seguida, são apresentados os resultados referentes ao erro médio quadrático. E por fim, são mostrados os erros de medição de amplitude e latência.

\subsection{Remoção do artefato de estímulo}

A Figura 4.1 mostra a estimativa da resposta evocada, obtida ao se remover a estimativa do artefato de estímulo do sinal mostrado na Figura 3.6.

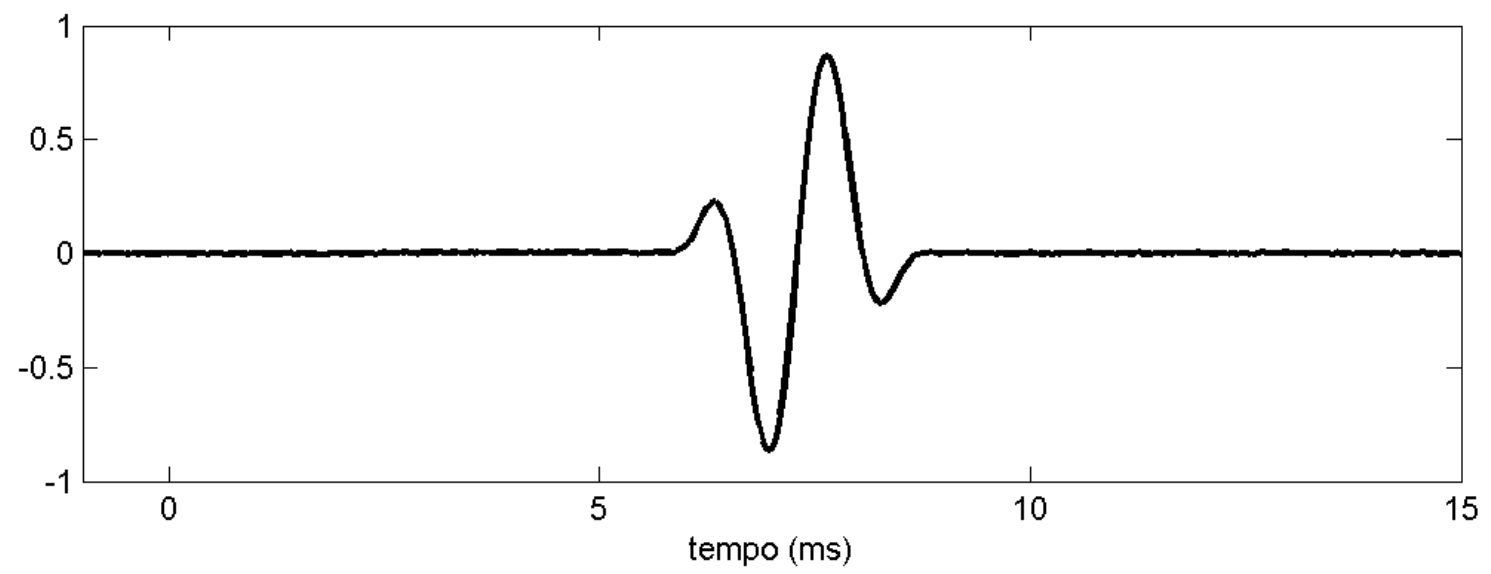

Figura 4.1 - Estimativa da resposta evocada.

\subsection{Erro médio quadrático}

A raiz quadrada do MSE foi calculada para valores diferentes de $D$ e $A$. O parâmetro $A$ variou de 0,00 a 1,00 em passos de 0,05 . O atraso $D$ variou de $2,0 \mathrm{~ms}$ a $20,0 \mathrm{~ms}$ em passos de $0,5 \mathrm{~ms}$. A faixa do atraso foi escolhida para englobar as latências dos SEPs do nervo 
mediano captados no cotovelo, ombro, pescoço e escalpo, considerando tanto a estimulação no punho quanto na mão (DeLISA; MACKENZIE; BARAN, 1987).

\subsection{1 $\underline{\text { O erro médio quadrático como função do parâmetro } A}$}

A raiz quadrada do MSE aumentou quando a razão entre as amplitudes do sinal e do artefato aumentou. A Figura 4.2 mostra os resultados para atrasos fixos em função do parâmetro $A$.

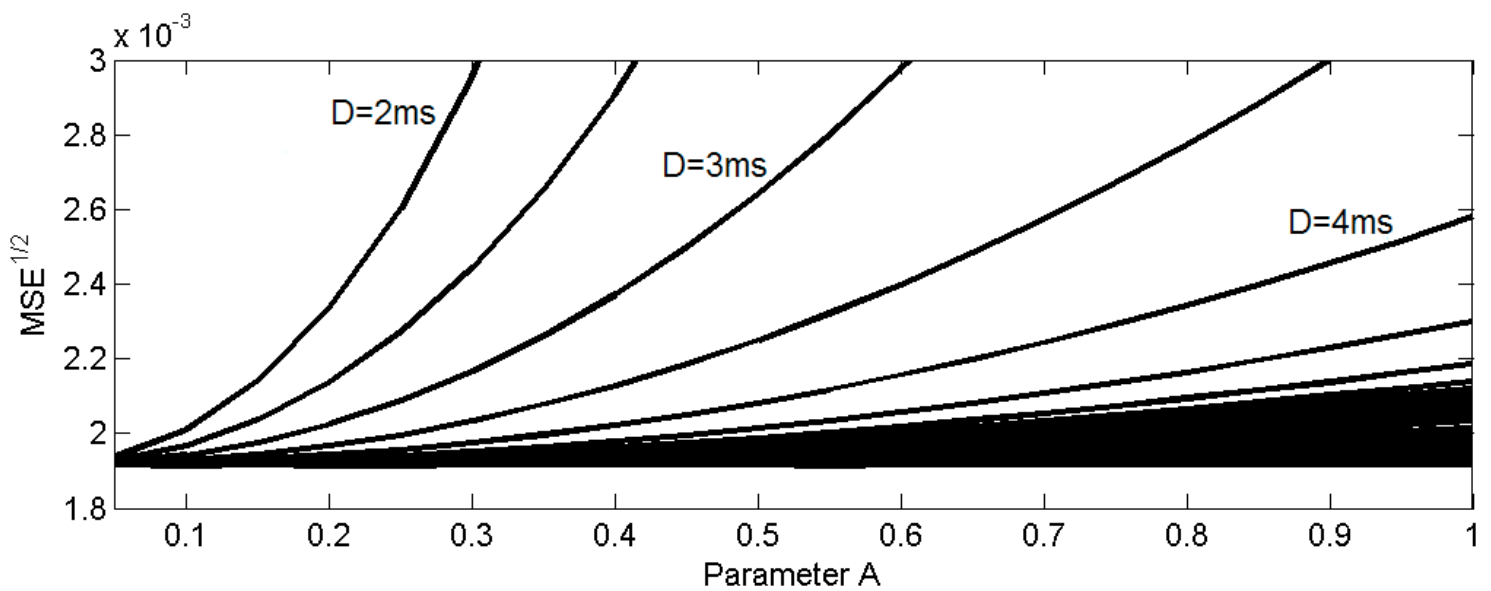

Figura 4.2 - Raiz quadrada do erro médio quadrático para diversos atrasos fixos, como função do parâmetro $A$.

\subsection{2 $\underline{\text { O erro médio quadrático como função do atraso } D}$}

Por outro lado, a raiz quadrada do MSE diminuiu quando o atraso entre o estímulo e o SEP aumentou. A Figura 4.3 mostra os resultados para diversas amplitudes de artefato para o atraso $D$ variando de $2 \mathrm{~ms}$ a $4 \mathrm{~ms}$. 


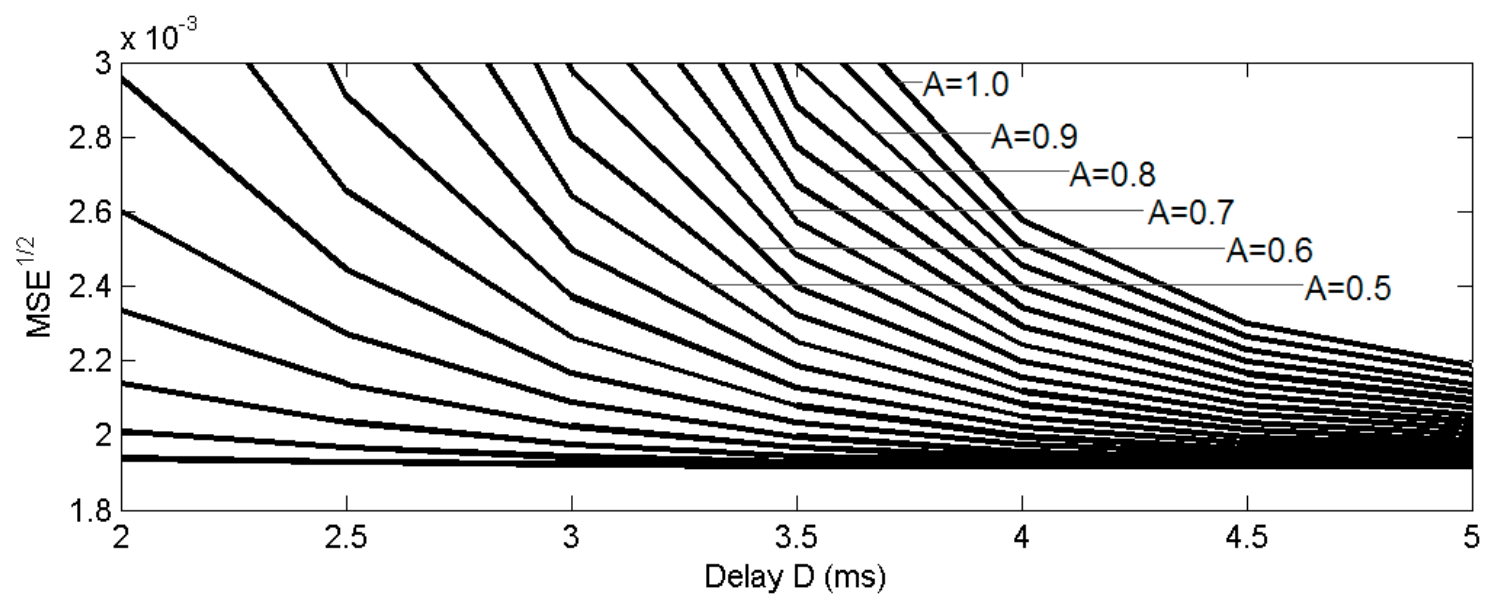

Figura 4.3 - Raiz quadrada do erro médio quadrático para diversas amplitudes fixas, como função do atraso $D$ variando de $2 \mathrm{~ms}$ a $4 \mathrm{~ms}$.

\subsubsection{0 erro médio quadrático como função do atraso $D$ e do parâmetro $A$}

Foi calculada a raiz quadrada do erro médio quadrático entre o sinal antes da remoção do artefato de estímulo e o potencial-evocado padrão. Também foi calculada entre o sinal após a remoção do artefato de estímulo e o potencial-evocado padrão. Após a remoção do artefato de estímulo, os erros ficaram pequenos, conforme ilustrado na figura 4.4. Observa-se que, para o parâmetro $A$ maior que 0,5 e atrasos $D$ menores que $3 \mathrm{~ms}$, há um aumento na raiz quadrada do erro médio quadrático. 


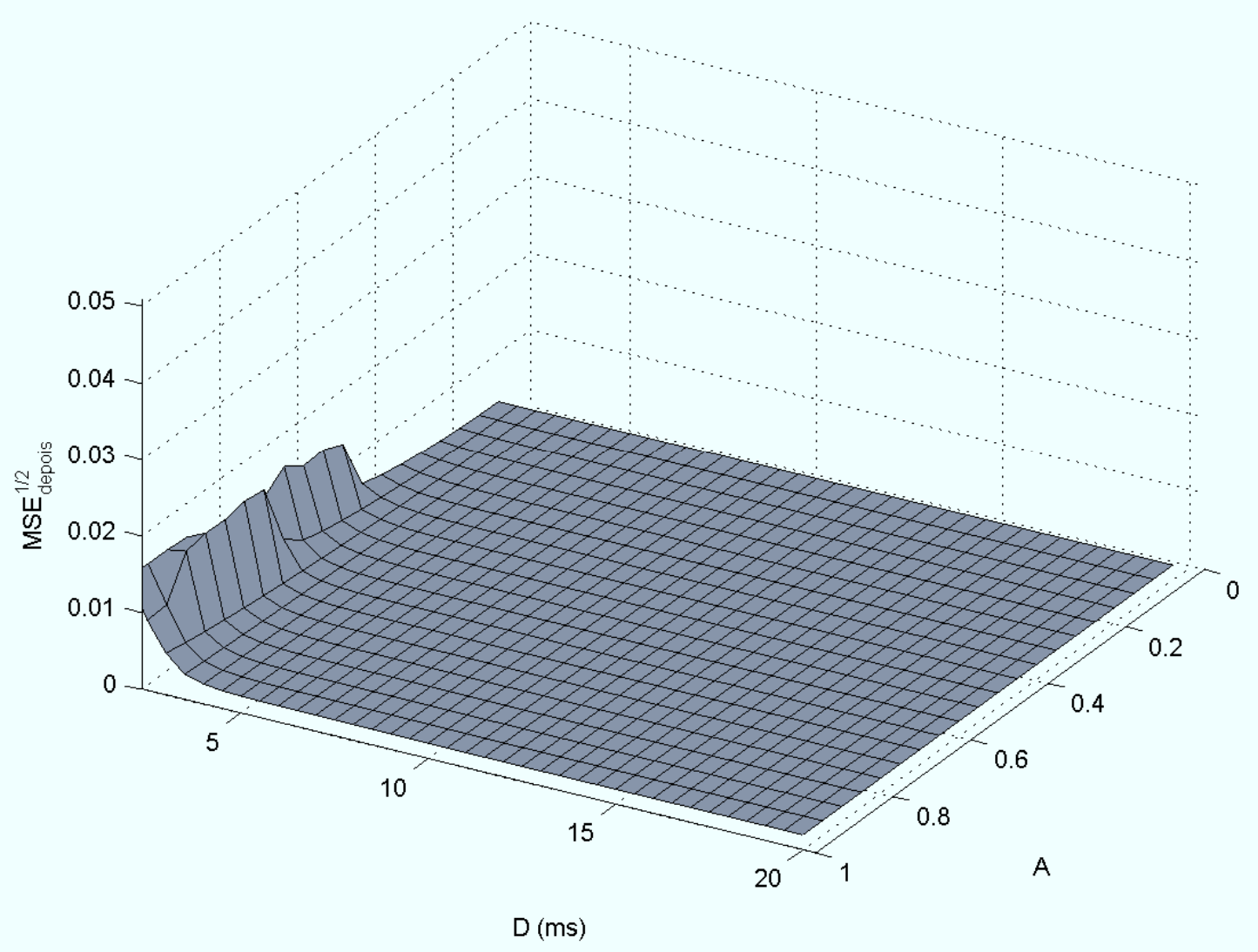

Figura 4.4 - Raiz quadrada do erro médio quadrático, em função do parâmetro $A$ (de 0,00 a $1,00)$ e do atraso $D$ (de $2 \mathrm{~ms}$ a $20 \mathrm{~ms}$ ), após remoção do artefato de estímulo.

\subsection{4 $\underline{A}$ influência da remoção do artefato de estímulo no erro médio quadrático}

Subtraindo-se as raízes quadradas dos erros médios quadráticos obtidos antes e depois da remoção de artefato, obtém se a Figura 4.5. Os valores positivos indicam que o erro antes da remoção do artefato era maior que o erro após a remoção do artefato de estímulo e os valores negativos indicariam erros maiores após a remoção do artefato. Os valores indicam que, em termos de erro médio quadrático, o sinal após a remoção do artefato de estímulo se aproxima mais do potencial evocado padrão do que o sinal antes da remoção do artefato. 


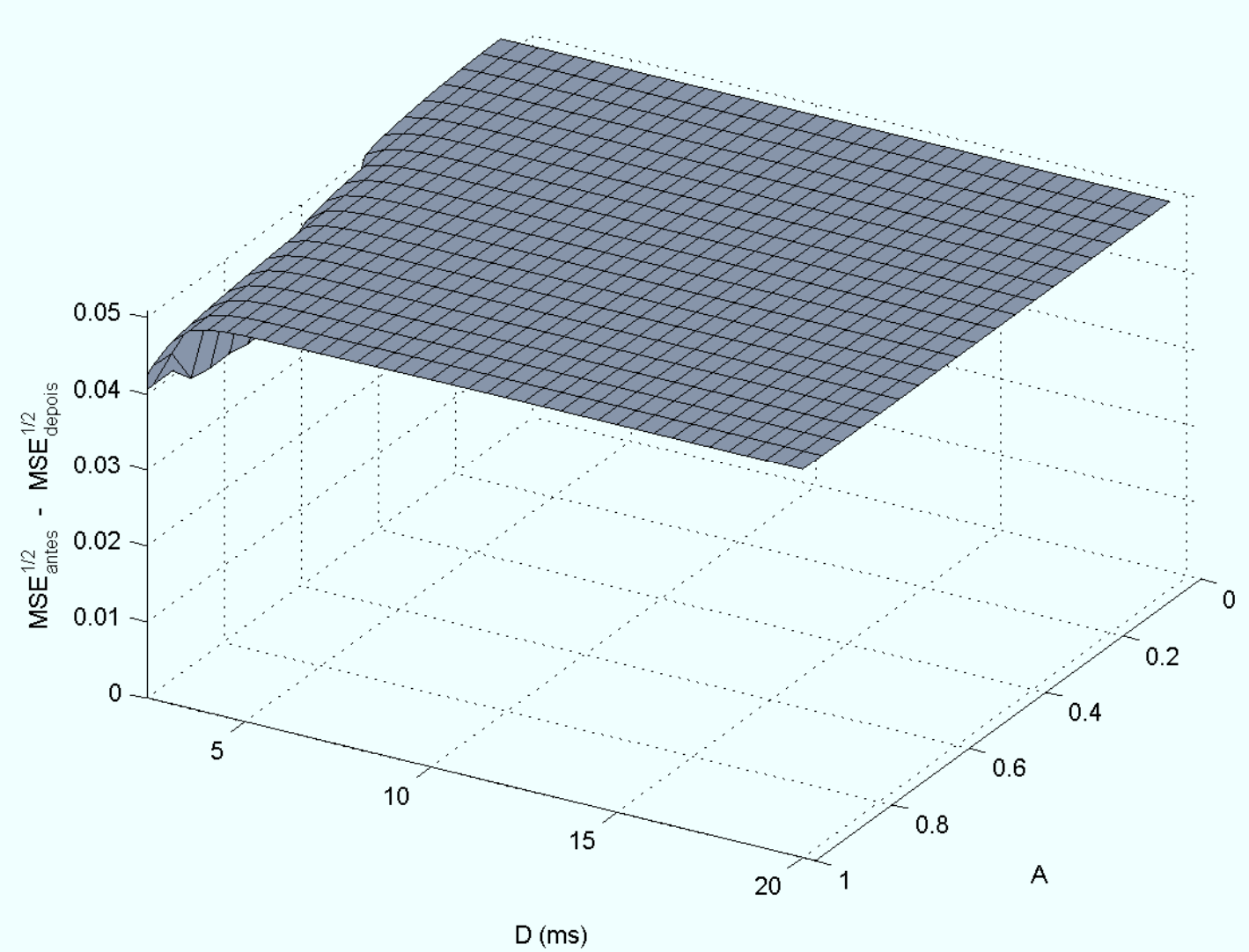

Figura 4.5 - Diferença entre os erros médios quadráticos antes e depois da remoção do artefato de estímulo, em função do parâmetro $A$ (de 0,00 a 1,00$)$ e do atraso $D$ (de $2 \mathrm{~ms}$ a 20ms).

\subsection{O erro da amplitude pico-a-pico}

A amplitude pico-a-pico da resposta evocada foi medida para o sinal $s(t)$ antes da remoção do artefato e para a estimativa da resposta evocada $\hat{x}(t)$ após a remoção do artefato.

\subsubsection{0 erro da amplitude pico-a-pico como função do parâmetro $A$}

A Figura 4.6 mostra os resultados para um atraso fixo de $4 \mathrm{~ms}$. Observa-se que a remoção de artefato melhora a medida da amplitude pico-a-pico da resposta evocada. 


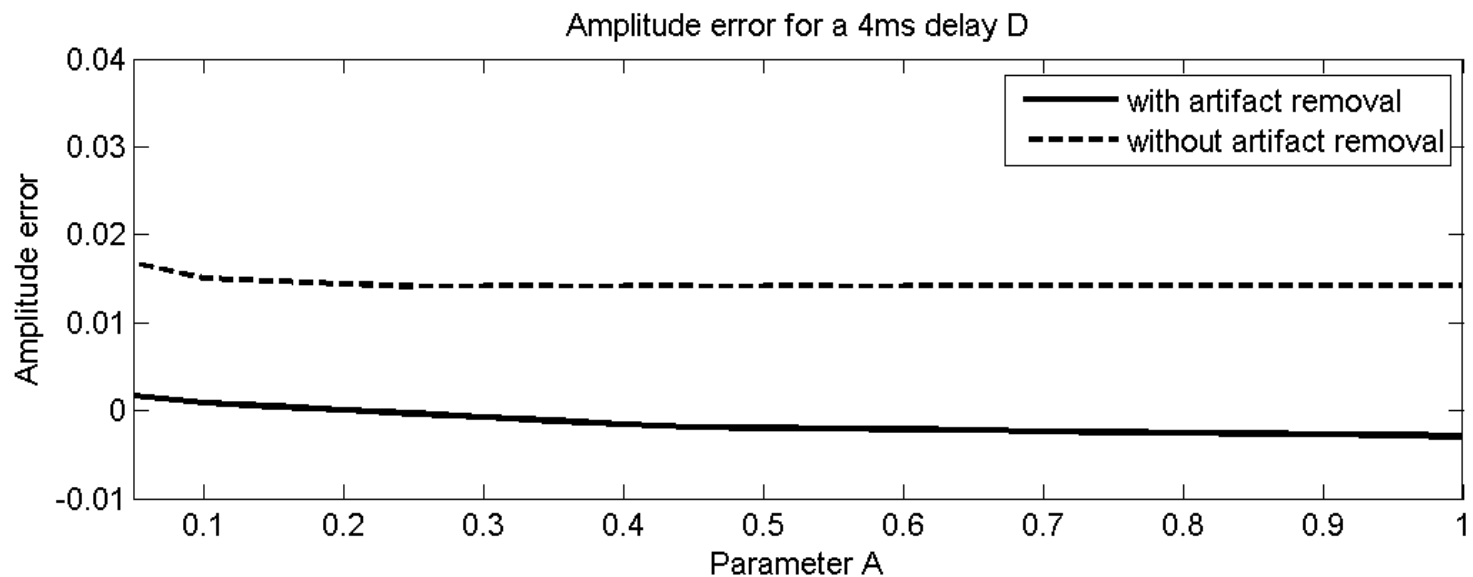

Figura 4.6 - Erro de amplitude calculado antes (linha tracejada) e após remoção de artefato (linha contínua), representado como função do parâmetro $A$, para o atraso $D$ de $4 \mathrm{~ms}$.

\subsubsection{0 erro da amplitude pico-a-pico como função do atraso $D$}

A Figura 4.7 mostra os resultados para um parâmetro $A$ igual a 0,15 . Ela mostra que, para pequenos valores de atraso (8ms ou menos), a remoção de artefato melhora a medida da amplitude pico-a-pico da resposta evocada

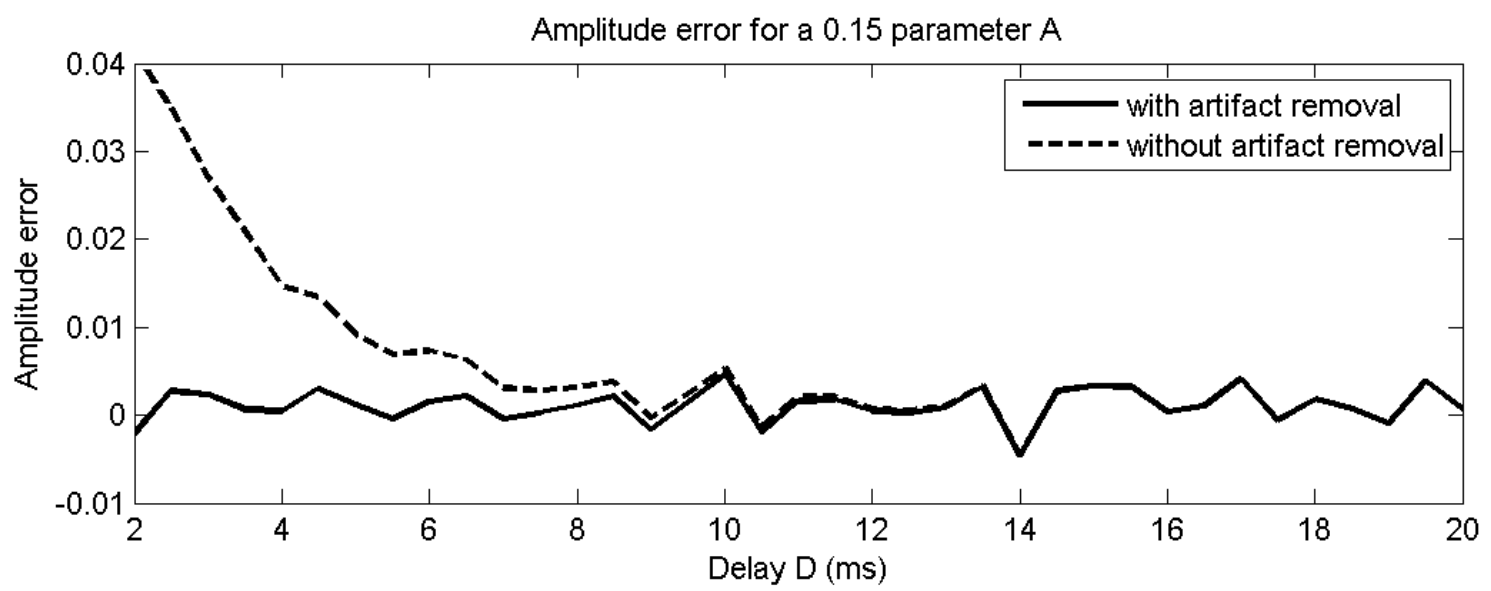

Figura 4.7 - Erro de amplitude calculado antes (linha tracejada) e após remoção de artefato (linha contínua), representado como função do atraso $D$, para o parâmetro $A$ de 0,15 . 


\subsubsection{0 erro da amplitude pico-a-pico como função do atraso $D$ e do parâmetro $A$}

Ao se considerar o erro na medição da amplitude pico-a-pico, após a remoção do artefato de estímulo, observa-se que os erros são negativos na figura 4.8. Isso significa que a remoção do artefato de estímulo causa uma diminuição da amplitude pico-a-pico, em relação ao valor verdadeiro, ou seja, uma subestimação do valor da amplitude.

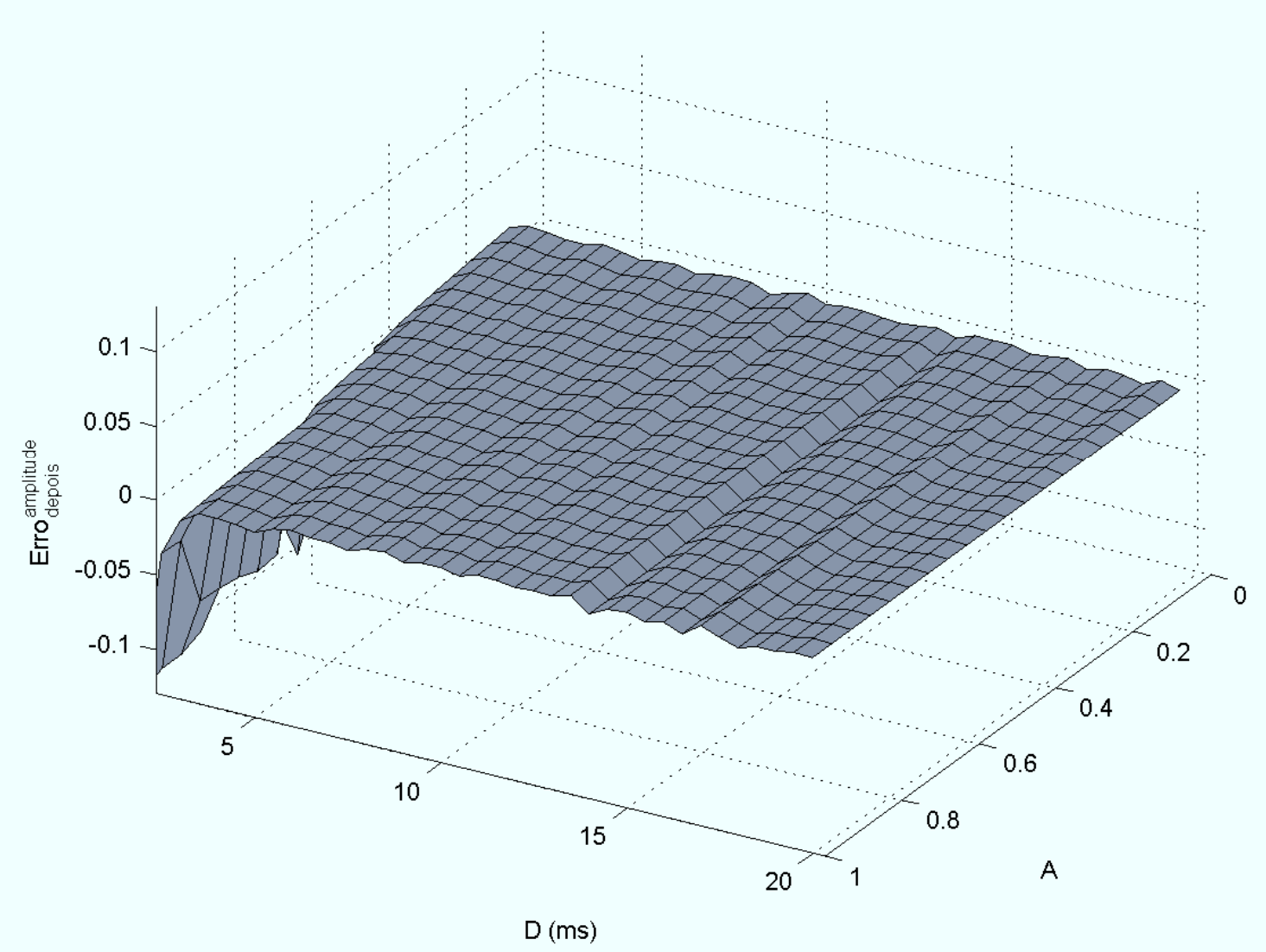

Figura 4.8 - Erro da amplitude pico-a-pico, em função do parâmetro $A$ (de 0,00 a 1,00) e do atraso $D$ (de $2 \mathrm{~ms}$ a $20 \mathrm{~ms}$ ), após remoção do artefato de estímulo. 


\subsubsection{A influência da remoção do artefato de estímulo no erro da amplitude pico-a-} pico

Ao se comparar o erro na estimação da amplitude antes e depois da remoção do artefato de estímulo observa-se que, para atrasos menores que $7,5 \mathrm{~ms}$, a remoção melhora a estimativa da amplitude. Esse resultado só não ocorre para atrasos menores que 2,5ms, quando o valor do parâmetro $A$ é maior que 0,4 .

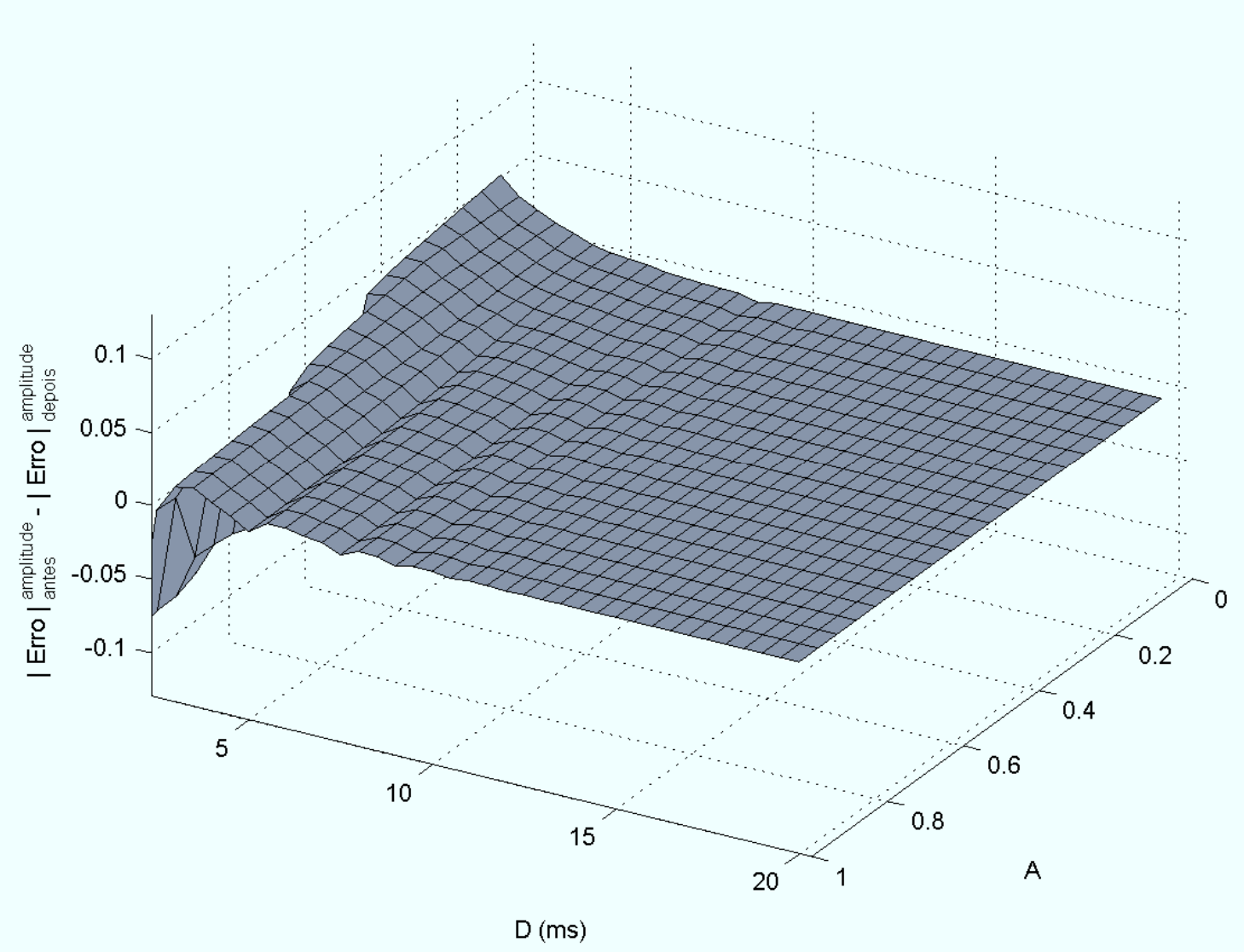

Figura 4.9 - Diferença entre os erros absolutos da amplitude pico-a-pico medida antes e depois da remoção do artefato de estímulo, em função do parâmetro $A$ (de 0,00 a 1,00 ) e do atraso $D$ (de $2 \mathrm{~ms}$ a $20 \mathrm{~ms}$ ). 


\subsection{O erro da latência}

\subsection{1 $\underline{0}$ erro da latência como função do parâmetro $A$}

A latência da resposta evocada foi calculada para o sinal $s(t)$ antes da remoção de artefato e para a estimativa da resposta evocada após a remoção de artefato $\hat{x}(t)$.

A Figura 4.10 mostra os erros de latência para um atraso fixo de 4ms. Ela mostra que, para um parâmetro $A$ menor que 0,5 , a remoção do artefato melhorou a medida da latência da resposta evocada.

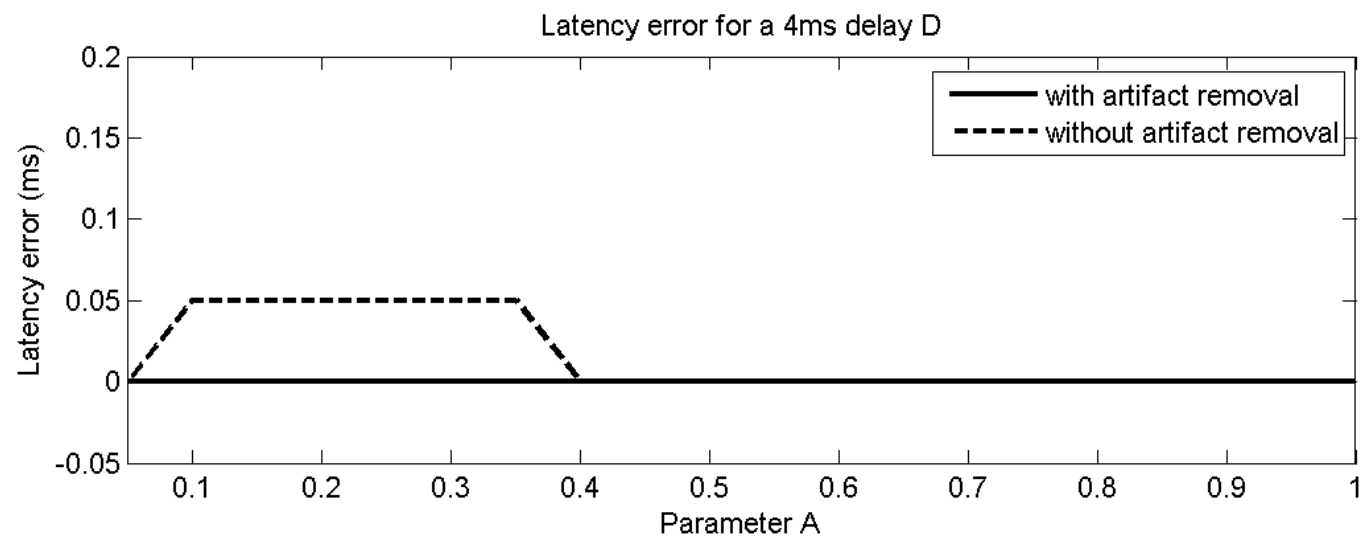

Figura 4.10 - Erro de latência (em ms) calculado antes (linha tracejada) e depois (linha contínua) da remoção do artefato, como função do parâmetro $A$, para um atraso $D$ de $4 \mathrm{~ms}$.

\subsection{2 $\underline{0 \text { erro da latência como função do atraso } D}$}

A Figura 4.11 mostra os erros para um parâmetro $A$ igual a 0,15 . Semelhantemente à figura anterior, a Figura 4.11 mostra que, para atrasos menores que 8ms, a remoção do artefato melhorou a estimativa da latência da resposta evocada. 


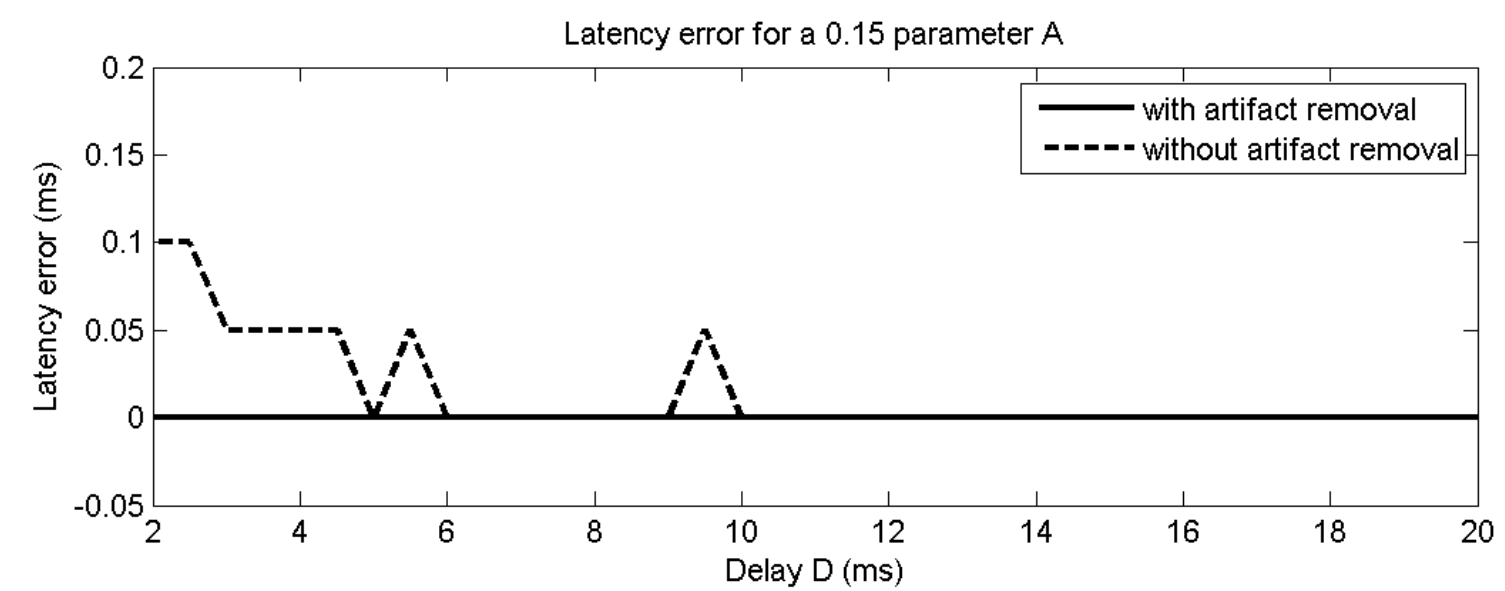

Figura 4.11 - Erro de latência (em ms) calculado antes (linha tracejada) e depois (linha contínua) da remoção do artefato como função do atraso $D$, para um parâmetro $A$ de 0,15 .

\subsubsection{0 erro da latência como função do atraso $D$ e do parâmetro $A$}

Após a remoção do artefato de estímulo, a medida da latência é muito próxima do valor verdadeiro. A figura 4.12 indica que o erro é praticamente nulo para quase todas combinações de valores do parâmetro $A$ e do atraso $D$. 


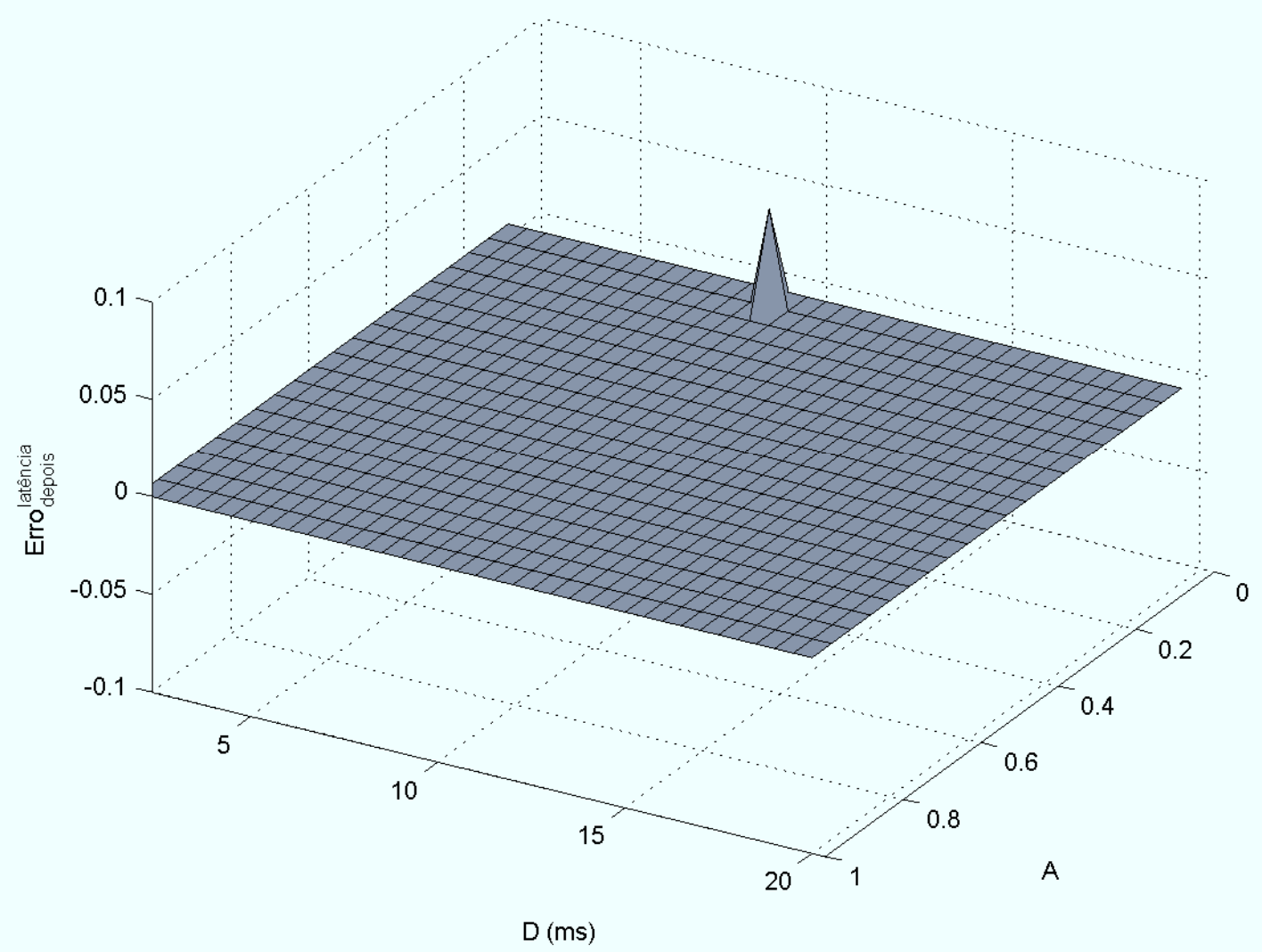

Figura 4.12 - Erro da latência (em ms), em função do parâmetro $A$ (de 0,00 a 1,00) e do atraso $D$ (de $2 \mathrm{~ms}$ a $20 \mathrm{~ms}$ ), após remoção do artefato de estímulo.

\subsubsection{A influência da remoção do artefato de estímulo no erro da latência}

Quanto se faz a comparação com a medida de latência antes da remoção do artefato de estímulo, verifica-se que o método contribui para melhorar a medição da latência. A figura 4.13 mostra que a maior contribuição ocorre para latências pequenas e amplitudes pequenas. 


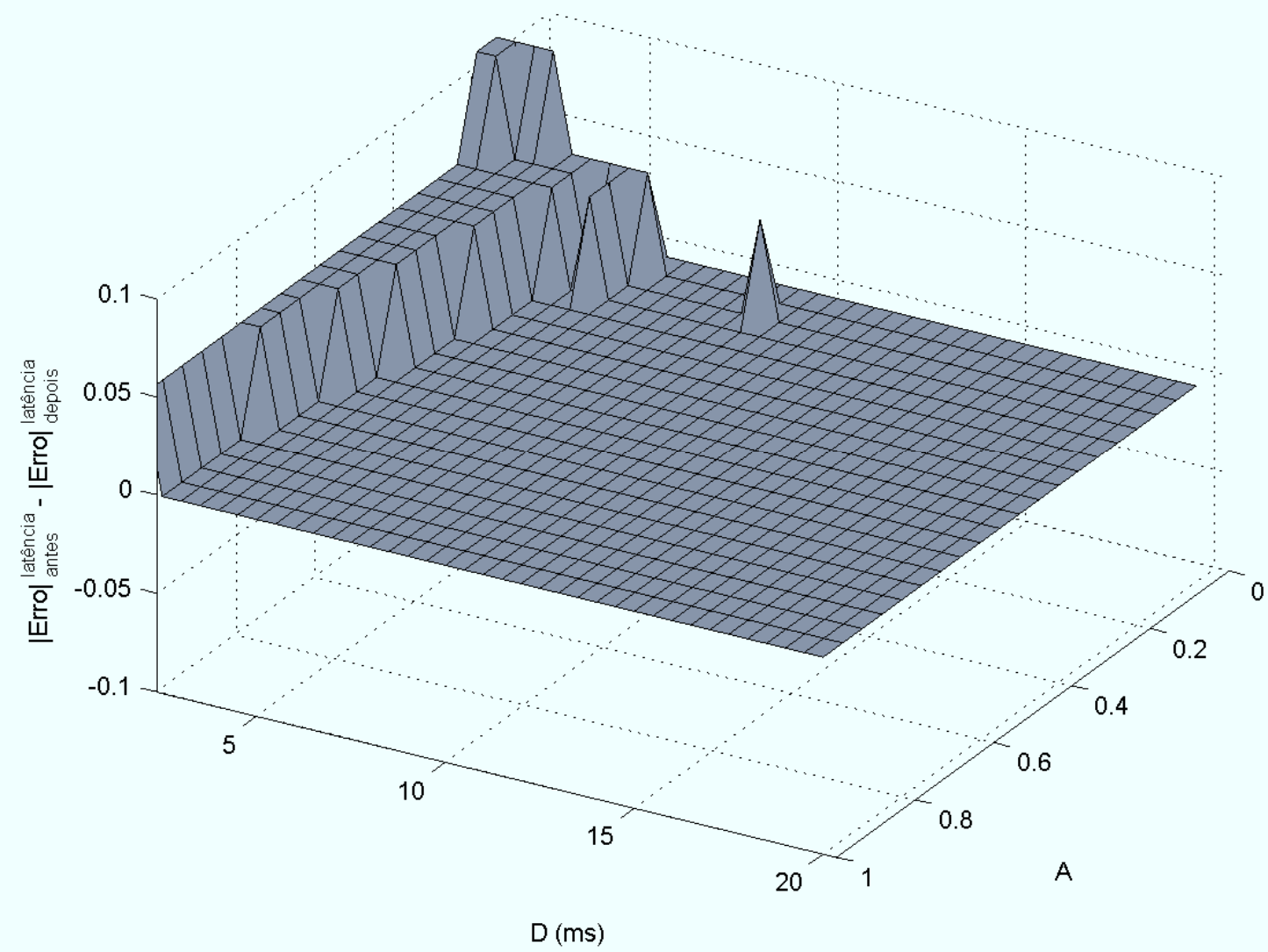

Figura 4.13 - Diferença (em ms) entre os erros absolutos da latência medida antes e depois da remoção do artefato de estímulo, em função do parâmetro $A$ (de 0,00 a 1,00 ) e do atraso $D$ (de $2 \mathrm{~ms}$ a $20 \mathrm{~ms})$.

\subsection{Aplicação da técnica de remocão do artefato de estímulo em potenciais evocados somatossensitivos adquiridos}

A técnica de remoção do artefato de estímulo foi aplicada a um potencial evocado previamente adquirido e integrante do banco de dados do laboratório. O sinal foi obtido de uma voluntária de 40 anos de idade, neurologicamente normal, após seu consentimento escrito. Foram aplicados estímulos ao nervo mediano no punho esquerdo. A captação foi efetuada no cotovelo. No condicionamento do sinal, foi utilizado um filtro passa-banda de $5 \mathrm{~Hz}$ a $3 \mathrm{kHz}$. A taxa de amostragem foi de 20.000 amostras por segundo. 
A figura 4.14 ilustra o sinal adquirido. As setas indicam o potencial evocado somatossensitivo e o artefato de estímulo.

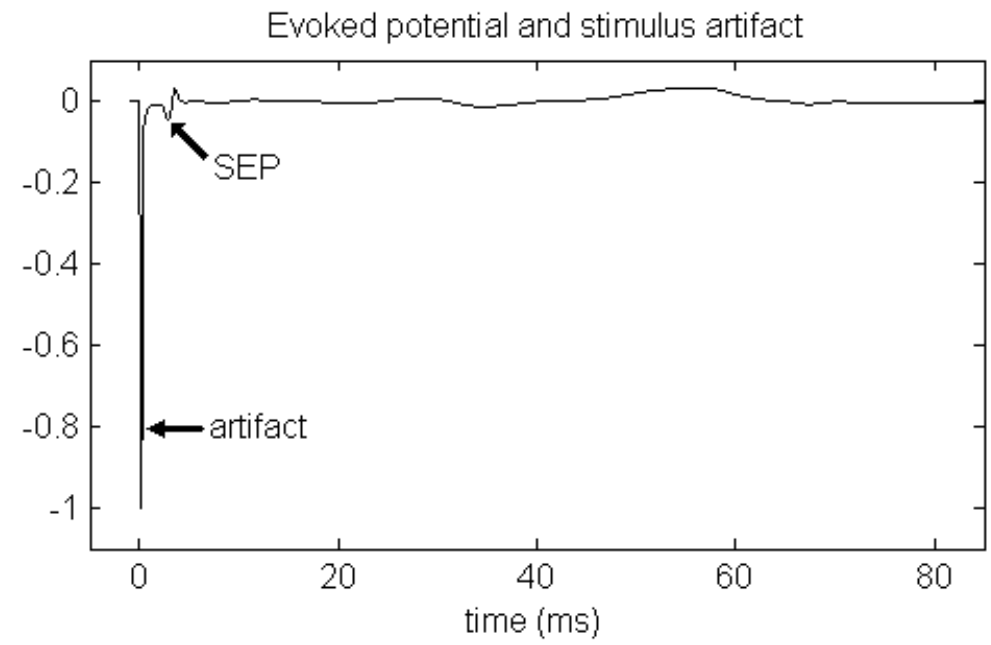

Figura 4.14 - Potencial evocado somatossensitivo captado no cotovelo de uma voluntária neurologicamente normal e artefato de estímulo.

A técnica de remoção de artefato de estímulo foi adaptada ao sinal captado. O modelo de artefato consistia de um pulso bipolar retangular (durante a aplicação do estímulo) seguido de três exponenciais. No entanto, o sinal adquirido não saturava e, portanto não apresentava o pulso bipolar retangular.

Durante o primeiro trecho de aplicação do estímulo $(-0,05 s \leq t \leq 0,10 s)$ o sinal normalizado apresentava uma rápida transição entre 0 e -1 . Esse primeiro trecho não poderia ser ajustado à primeira exponencial da equação 3.3 do modelo computacional, $y_{1}(t)=a_{1}\left[\exp \left(-\left(\left(t-t_{0}\right) / 1000\right)^{b_{1}} / c_{1}\right)-1\right]+1$, que se inicia em +1 e decai em direção a zero. Por isso, a primeira exponencial foi ajustada a uma fórmula que considerasse uma curva que começasse em 0 e seguisse até um valor negativo $d_{1}$ de forma instável, ou seja,

$$
y_{1}(t)=a_{1}\left[\exp \left(+\left(\left(t-t_{0}\right) / 1000\right)^{b_{1}} / c_{1}\right)\right]+d_{1},
$$

em que $a_{1}+d_{1} \cong 0$.

O segundo trecho $0,10 s \leq t \leq 0,20 s$ ainda correspondia ao intervalo de aplicação do estímulo e foi ajustado à exponencial estável 


$$
y_{2}(t)=a_{2}\left[\exp \left(-\left(\left(t-t_{1}\right) / 1000\right)^{b_{2}} / c_{2}\right)\right\rfloor+d_{2} .
$$

A exponencial $y_{3}(t)=a_{3}\left[\exp \left(+\left(\left(t-t_{2}\right) / 1000\right)^{b_{3}} / c_{3}\right)\right]+d_{3}$ da equação 3.4 foi ajustada ao terceiro trecho do artefato de estímulo $0,20 s \leq t \leq 0,60 s$.

A exponencial $y_{4}(t)=a_{4}\left[\exp \left(-\left(\left(t-t_{3}\right) / 1000\right)^{b_{4}} / c_{4}\right)\right]$ correspondente à equação 3.5 foi ajustada ao último trecho do artefato de estímulo, para $0,60 s \leq t \leq 1,50 s$.

A Tabela 4.1 apresenta as estimativas dos parâmetros das exponenciais ajustadas ao artefato de estímulo.

Tabela 4.1 - Estimativas dos parâmetros das exponenciais para SEP captado no cotovelo.

\begin{tabular}{|c|c|c|c|c|}
\hline Trecho $i$ & $a_{i}$ & $b_{i}$ & $c_{i}$ & $d_{i}$ \\
\hline 1 & 0,7929 & 2,3196 & $6,8304 \times 10^{-7}$ & $-0,8014$ \\
\hline 2 & $-2,3690 \times 10^{-5}$ & 0,8318 & 0,0293 & $-0,8014$ \\
\hline 3 & $-0,9124$ & 1,5027 & 0,0011 & $-0,0400$ \\
\hline 4 & $-0,0410$ & 0,7640 & $-2,8677$ & ------ \\
\hline
\end{tabular}

A figura 4.15 ilustra a estimativa do potencial evocado, obtida pela remoção do artefato de estímulo.

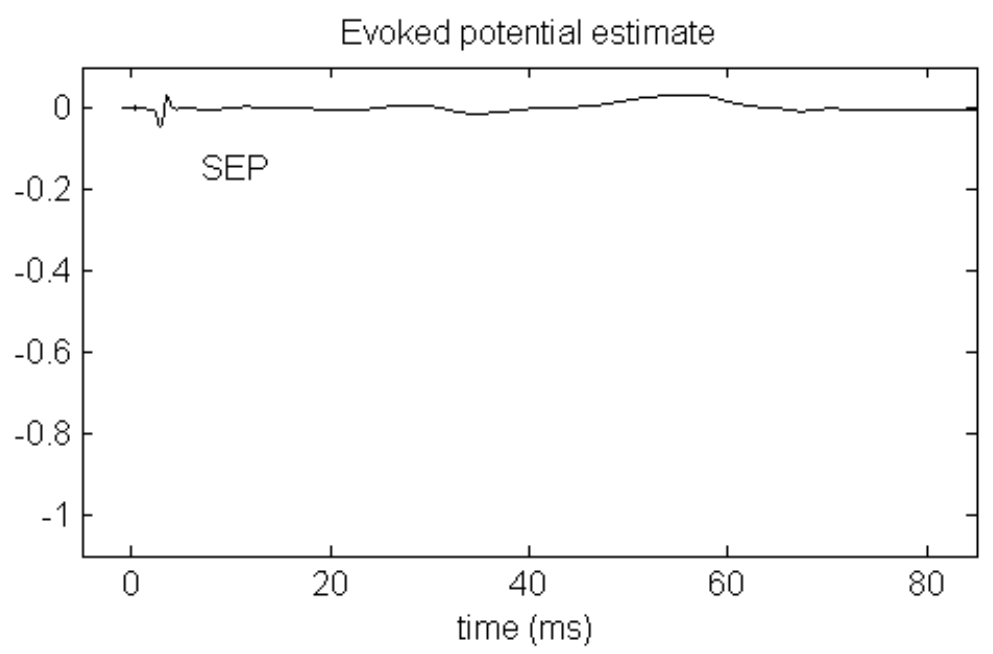

Figura 4.15 - Estimativa do potencial evocado, após remoção do artefato de estímulo. 
A figura 4.16 apresenta uma ampliação do trecho em que o artefato de estímulo está presente. O SEP encontra-se fora da figura, pois está à direita do trecho ampliado. Observa-se que o artefato de estímulo (linha tracejada) foi removido, resultando no sinal em linha contínua.

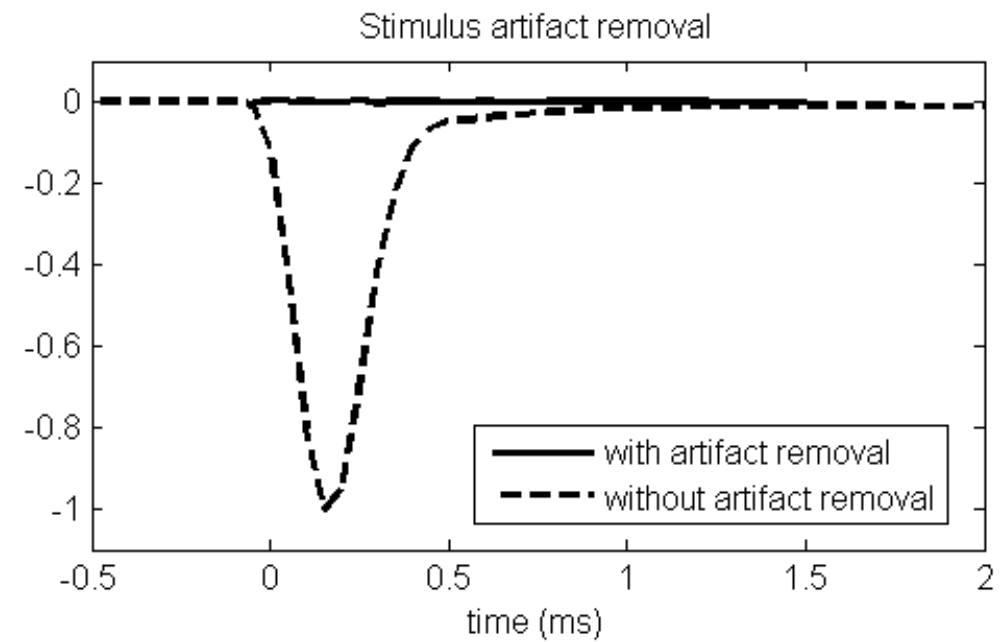

Figura 4.16 - Sinais antes da remoção (em linha tracejada) e após a remoção (em linha contínua) do artefato de estímulo.

O método também foi aplicado a outro potencial evocado previamente adquirido e integrante do banco de dados do laboratório. O sinal foi captado de um voluntário de 24 anos de idade, neurologicamente normal, após seu consentimento escrito. O nervo mediano foi estimulado à taxa de 3 estímulos por segundo, no punho esquerdo. A captação foi efetuada no escalpo. No condicionamento do sinal, foi utilizado um filtro passa-banda de $5 \mathrm{~Hz}$ a $2 \mathrm{kHz}$. A taxa de amostragem foi de 20.000 amostras por segundo.

A figura 4.17 ilustra o sinal adquirido, com indicações do potencial evocado somatossensitivo e do artefato de estímulo. 


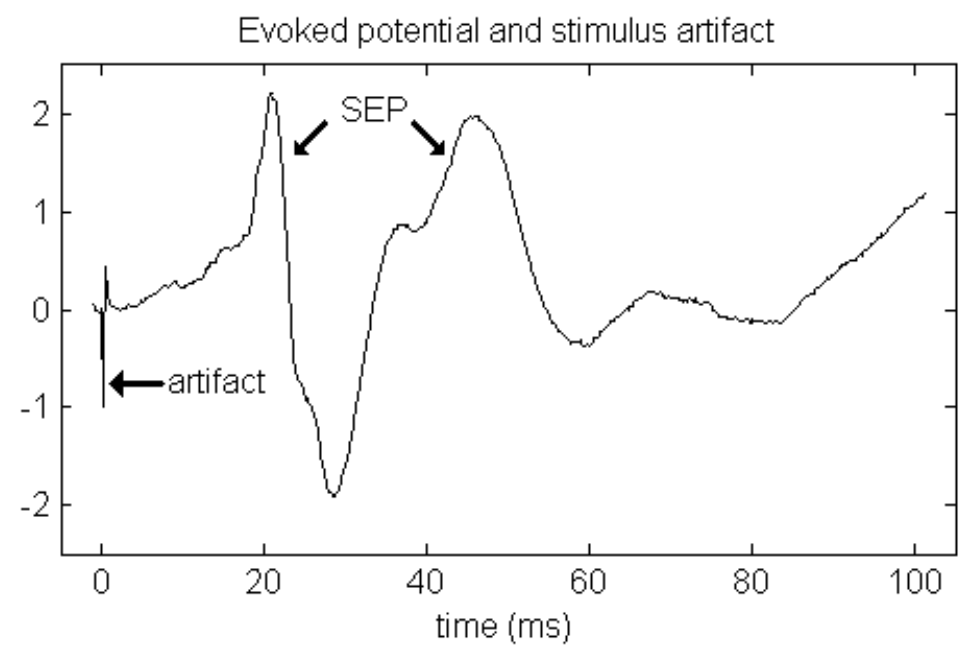

Figura 4.17 - Potencial evocado somatossensitivo captado no escalpo de um voluntário neurologicamente normal e artefato de estímulo.

A técnica de remoção de artefato de estímulo foi novamente adaptada ao sinal captado. Como o sinal adquirido não apresentava saturação, o pulso bipolar retangular do modelo de artefato de estímulo foi desconsiderado. Durante a aplicação do estímulo, o sinal normalizado apresentava uma rápida transição entre 0 e -1 .

Esse primeiro trecho foi ajustado à exponencial da equação 3.3: $y_{1}(t)=a_{1}\left[\exp \left(-\left(\left(t-t_{0}\right) / 1000\right)^{b_{1}} / c_{1}\right)\right]+d_{1}$, para $0,00 s \leq t \leq 0,20 s$.

O segundo trecho foi ajustado à exponencial da equação 3.4: $y_{2}(t)=a_{2}\left[\exp \left(+\left(\left(t-t_{1}\right) / 1000\right)^{b_{2}} / c_{2}\right)\right]+d_{2}$, para $0,20 s \leq t \leq 0,35 s$.

O terceiro trecho foi novamente ajustado a uma exponencial equivalente àquela da equação 3.3: $y_{3}(t)=a_{3}\left[\exp \left(-\left(\left(t-t_{2}\right) / 1000\right)^{b_{3}} / c_{3}\right)\right]+d_{3}$, para $0,35 s \leq t \leq 0,50 s$.

$\mathrm{O}$ quarto trecho foi ajustado à equação 3.5 , com os devidos ajustes: $y_{4}(t)=a_{4}\left[\exp \left(-\left(\left(t-t_{3}\right) / 1000\right)^{b_{4}} / c_{4}\right)\right]$, para $0,50 s \leq t \leq 2,35 s$.

As estimativas dos parâmetros das exponenciais são apresentadas na tabela 4.2. 
Tabela 4.2 - Estimativas dos parâmetros das exponenciais para SEP captado no escalpo.

\begin{tabular}{|c|c|c|c|c|}
\hline Trecho $i$ & $a_{i}$ & $b_{i}$ & $c_{i}$ & $d_{i}$ \\
\hline 1 & 0,3687 & 2,1545 & $1,7357 \times 10^{-6}$ & $-0,3658$ \\
\hline 2 & 0,4288 & 0,1644 & 25,2055 & $-0,3658$ \\
\hline 3 & $-0,0898$ & 2,9349 & $1,2275 \times 10^{-10}$ & 0,1528 \\
\hline 4 & 0,1528 & 0,7199 & 2,4632 & ------ \\
\hline
\end{tabular}

Para os parâmetros da tabela 4.2, obteve-se uma estimativa do artefato de estímulo. Após sua subtração do sinal original, obteve-se uma estimativa do potencial evocado, ilustrada na figura 4.18 .

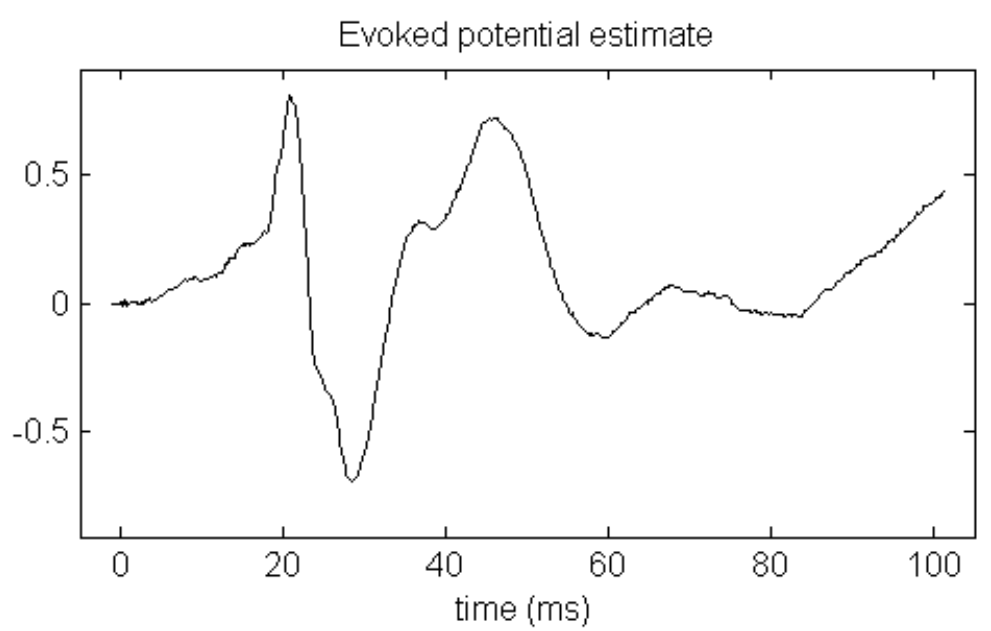

Figura 4.18 - Estimativa do potencial evocado, após remoção do artefato de estímulo.

A figura 4.19 apresenta uma ampliação do trecho em que o artefato de estímulo está presente. O SEP encontra-se à direita do trecho ampliado e não é visualizado na figura. Observa-se que o artefato de estímulo (linha tracejada) foi removido, resultando no sinal em linha contínua. 


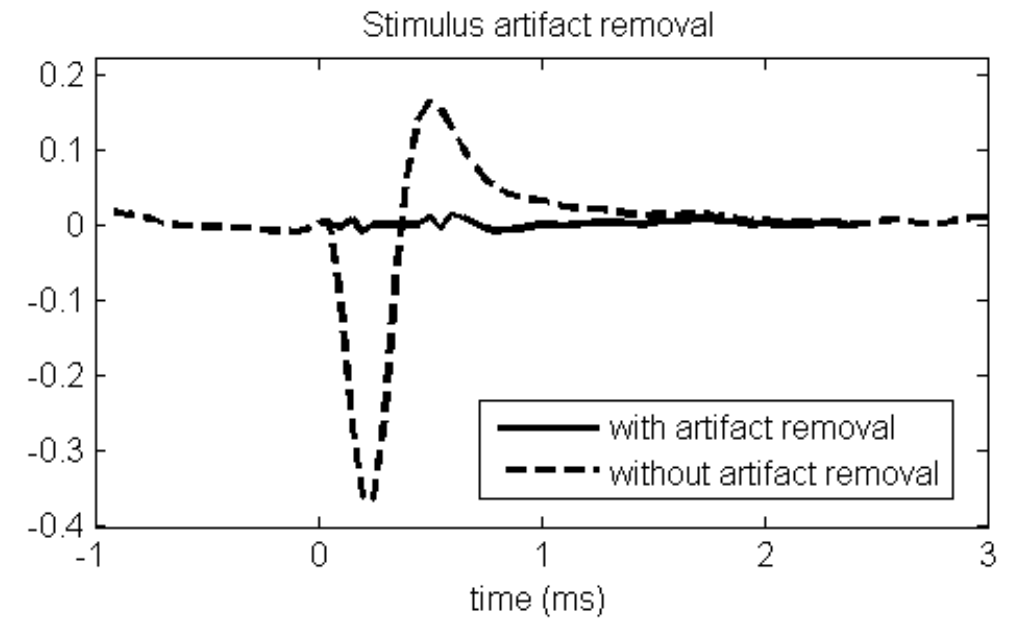

Figura 4.19 - Sinais antes da remoção (em linha tracejada) e após a remoção (em linha contínua) do artefato de estímulo. 


\section{Análise e conclusão}

\subsection{Remoção do artefato de estímulo}

Neste trabalho, estudou-se a influência da amplitude e latência da resposta evocada na remoção de artefato de estímulo, por meio de simulações computacionais. Representou-se o potencial evocado somatossensitivo captado no cotovelo, ombro, pescoço e escalpo pela variação da amplitude da resposta de $0 \%$ a $83 \%$ da amplitude do artefato e do atraso de $2 \mathrm{~ms}$ a $20 \mathrm{~ms}$

Supôs-se que um pulso de estimulação de corrente de alta intensidade saturava o amplificador e gerava um artefato de estímulo composto por um pulso retangular bipolar seguido de três segmentos exponenciais.

A estimação e remoção do pulso retangular bipolar foram feitas por ajuste a um padrão (template matching). A estimação dos primeiros segmentos exponenciais definiu o valor inicial do terceiro segmento exponencial, já que a concatenação de todos os segmentos deveria resultar em uma função sem descontinuidades. O terceiro segmento foi modelado por uma função exponencial com um tempo de decaimento c3 de $2 \mathrm{~ms}$, começando no instante t2 igual a 1,6ms. A remoção dos segmentos exponenciais resultou na estimativa do potencial evocado somatossensitivo, com ruído remanescente.

\subsection{Erro médio quadrático}

Analisando-se o efeito da remoção do artefato de estímulo, o erro médio quadrático entre o sinal e o potencial evocado padrão após a remoção foi menor do que aquele antes da remoção. 
Após a remoção do artefato de estímulo, o erro médio quadrático foi maior para atrasos menores e amplitudes maiores do potencial evocado somatossensitivo.

Esse aumento do erro médio quadrático quando há redução do atraso é justificável, já que isso indica um deslocamento do potencial evocado em direção ao artefato de estímulo, causando uma maior sobreposição entre eles e dificultando a remoção do artefato sem interferir no potencial evocado.

Por outro lado, o aumento do erro médio quadrático com a amplitude do potencial evocado é causado pelo fato de o trecho que contém o potencial evocado ter sido usado na estimação da exponencial a ser removida. É compreensível que a estimativa da exponencial seja mais afetada quando a amplitude do potencial evocado é maior.

Uma forma de eliminar essa dependência do método em relação à amplitude do potencial evocado seria a de excluir o trecho contendo o potencial evocado do ajuste de exponencial. No caso dos sinais sintéticos, essa exclusão provavelmente forneceria resultados bons, já que o curto trecho de exponencial antes do potencial evocado e o longo trecho de exponencial depois o potencial evocado são provenientes de uma função exponencial gerada computacionalmente e, portanto, perfeitamente ajustável. Para os sinais biológicos adquiridos, esse ajuste foi visualmente satisfatório.

\subsection{O erro da amplitude pico-a-pico}

Após a remoção do artefato de estímulo, para atrasos pequenos, o erro de estimação da amplitude pico-a-pico do potencial evocado (figura 4.8) foi negativo para amplitudes grandes e positivo para amplitudes pequenas. Isso indica que, para atrasos pequenos, a remoção do artefato reduziu a amplitude estimada dos potenciais evocados grandes. 
Mas comparando-se o erro de estimação da amplitude antes e depois da remoção do artefato (figura 4.9), verificou-se que, ainda para atrasos pequenos, o erro antes da remoção era muito maior (em módulo) para amplitudes pequenas.

Para atrasos médios e grandes, o erro da amplitude é negligível, oscilando em torno do zero.

Esses resultados indicam que a remoção do artefato de estímulo auxilia a medição da amplitude pico-a-pico para potenciais evocados de curta latência e pequena amplitude.

\subsection{O erro da latência}

Após a remoção do artefato de estímulo, o erro de estimação da latência foi nulo, para quase todas as combinações de atrasos e amplitudes (figura 4.12),

Comparando-se a estimativa de latência antes e depois da remoção (figura 4.13), o erro era maior antes da remoção. As regiões que correspondem à maior contribuição da remoção, diminuindo o erro, correspondem aos atrasos pequenos e às amplitudes grandes.

Esses resultados indicam que o método deve ser usado para melhorar a medição das latências de potenciais evocados de curta latência e grande amplitude.

\subsection{Aplicação da técnica de remoção do artefato de estímulo em potenciais evocados somatossensitivos adquiridos}

A aplicação da técnica de remoção do artefato de estímulo foi adaptada especificamente para cada potencial evocado somatossensitivo. 
A técnica, após as devidas adaptações, foi aplicada a potenciais evocados estimulados no punho esquerdo e captados no cotovelo ipsilateral e no escalpo contralateral.

Nos sinais adquiridos não havia um pulso bipolar retangular, já que o ganho havia sido ajustado para que não houvesse saturação. Por isso, cada borda de subida ou descida foi ajustada a uma ou duas exponenciais, conforme o caso específico.

Além disso, como o potencial evocado poderia alterar a exponencial a ser ajustada, então o potencial evocado foi delimitado no tempo e o ajuste de exponencial foi efetuado até o início do potencial evocado delimitado.

Os resultados obtidos foram satisfatórios, do aspecto de inspeção visual. No entanto, a metodologia deverá ser aplicada a um banco de dados com um número grande de sinais de morfologias diversas para que a técnica possa ser melhorada. Estudos futuros deverão automatizar a definição dos trechos exponenciais e testar o uso de outras formas de onda.

No caso de potenciais adquiridos não se sabe qual é o potencial evocado padrão, principalmente quando há sobreposição entre o artefato de estímulo e o potencial evocado. Portanto, não é possível calcular o erro médio quadrático e analisar a influência da remoção do artefato de estímulo no erro da amplitude pico-a-pico e no erro da latência. Estudos futuros deverão validar as medidas de amplitude pico-a-pico e latência, antes e depois da remoção do artefato, com a ajuda de um médico especialista em potenciais evocados. O médico fornecerá as medidas para diferentes sinais de morfologias diversas, antes e depois da remoção do artefato, e possibilitará uma validação da técnica de remoção de artefato comparando com os resultados obtidos através de simulação computacional. 


\subsection{Considerações gerais}

Foram obtidos bons resultados para o modelo de artefato de estímulo, quando a razão das amplitudes da resposta evocada e do artefato foi maior que 5\% e menor que $40 \%$, simultaneamente a uma latência da resposta evocada dentro da faixa de $3 \mathrm{~ms}$ a $8 \mathrm{~ms}$.

O conjunto de resultados indica que, para potenciais evocados de curta latência em que há sobreposição com o artefato, o método de remoção de artefato de estímulo deve ser usado. O erro médio quadrático sempre foi reduzido, com a remoção do artefato de estímulo. O erro de medição da latência pode ser reduzido a praticamente zero, independentemente da amplitude do potencial evocado. Por outro lado, o método insere erro na medição da amplitude de potenciais grandes. Por isso, nesse caso específico de atraso pequeno e amplitude grande, a medição da amplitude deve ser feita diretamente no sinal antes da remoção do artefato de estímulo.

Para potenciais evocados de longa latência, quando não há mais sobreposição significativa entre o artefato de estímulo e o potencial evocado, não há necessidade de se usar o método de remoção de artefato, já que o rápido decaimento do artefato garante que não haja interferência na medição da amplitude e latência da resposta evocada.

Comparando os valores de latência com os locais de captação do potencial evocado, pode-se afirmar que, para o modelo de artefato de estímulo usado neste trabalho, a necessidade de se aplicar o procedimento de remoção de artefato se restringe aos potenciais evocados captados no cotovelo, para estimulação do nervo mediano tanto no punho quanto na mão. 


\section{Referências Bibliográficas}

CHIAPPA, K. H. Evoked Potentials in Clinical Medicine, 3.ed, Philadelphia: LippincottRaven, 1997.

DeLISA, J.A.; MACKENZIE, K.; BARAN, E.M. Manual of Nerve Conduction Velocity and Somatosensory Evoked Potentials, 2.ed., New York: Raven Press, 1987.

DEL POZO F., DELGADO M. R. Hybrid stimulator for chronic experiments, IEEE Trans. Biomed. Eng., v.25, p.92-94, 1978.

DOTSINSKY, I., DOS SANTOS, A., TASHEV., I. Artefact cancellation in motor-sensory evoked potentials: two approaches using adaptive filtration and exponential approximation, Med. Biol. Eng. Comput., 37, p.87-92, 1999.

GRIEVE, R.; PARKER, P., HUDGINS, B. Adaptive stimulus artifact cancellation in biological signals using neural networks, IEEE-EMBC and CMBEC, 1997.

GRIEVE, R.; PARKER, P., HUDGINS, B., ENGLEHART, K. Nonlinear adaptive filtering of stimulus artifact, IEEE Trans. Biomed. Eng., v.47, n.3, p.389-395, 2000.

HARDING, G. W. A method for eliminating the stimulus artifact from digital recordings of the direct cortical response. Comp. Biomed. Res., v.24, p.183-195, 1991.

HAYKIN, S. Redes Neurais: Princípios e Prática. Bookman, 2.ed., 2001.

HUA, Y., LOVELY, D. F., DORAISWAMI, R. Factors affecting the stimulus artifact tail in surface-recorded somatosensory-evoked potentials. Med. Biol. Eng. Comput., 44, p.226-214, 2006.

MASETO, B.D. Eliminação de Artefatos de Estímulo em Potenciais Evocados Somatossensitivos. Relatório Parcial de Iniciação Científica da FAPESP, São Paulo, 2007.

McGILL, K. C., CUMMINS, K. L., DORFMAN, L. J., BERLIZOT, B. B., LUETKEMEYER, K., NISHIMURA, D. G. On the nature and elimination of stimulus artifact in nerve signals evoked and recorded using surface electrodes, IEEE Trans. Bioned. Eng., v.BME-29, n.2, p.129-137, 1982.

McLEAN, L., SCOTT, R. N., PARKER, P. A. Stimulus artifact reduction in evoked potential measurements, Arch. Phys. Med. Rehabil., v. 77, p.1286-1292, 1996.

MISULIS, K. E. Potencial Evocado de Spehlmann. Revinter, 2ª edição, 2003.

NETTER, F.H.; DALLEY II, A.F.; MYERS, J.H. Interactive Atlas of Human Anatomy, Ciba Medical Education \& Publications, 1995. 
O'KEEFFE, D. T., LYONS, G. M., DONNELLY, A. E., BYRNE C. A. Stimulus artifact removal using a software-based two-stage peak detection algorithm, J. Neurosci. Meth., 109, p.137-145, 2001.

PARSA, V., R.; PARKER, P., SCOTT, R. N. Adaptive stimulus artifact reduction in noncortical somatosensory evoked potential studies, IEEE Trans. Biomed. Eng., v.45, n.2, p.165-178, 1998a.

PARSA, V., R.; PARKER, P., SCOTT, R. N. Convergence characteristics of two algorithms in non-linear stimulus artifact cancellation for electrically evoked potential enhancement, Med. Biol. Eng. Comput., v.36, p.202-214, 1998 b.

SCOTT, R. N., McLEAN, L., PARKER, P. A. Stimulus artefact in somatosensory evoked potencial measurement. Med. Biol. Eng. Comput., 35, p.211-215, 1997.

SHARBROUGH, F.; CHATRIAN, G.-E.; LESSER, R.P.; LÜDERS, H.; NUWER, M.; PICTON, T.W, figuras adaptadas. Disponível em http:/www.bem.fi/book/13/13.htm\#03 site acessado em 20 de julho de 2010. American Electroencephalographic Society guidelines for standard electrode position nomenclature. J. Clin. Neurophysiol, 8: p.200-202, 1991.

SHIMIZU, D.M. Análise Auto-Regressiva de Tempo-Freqüência de Potenciais Evocados Somatossensitivos. Relatório Final de Iniciação Científica da FAPESP, São Paulo, 2005

SPEHLMAN, R. Evoked Potential Primer: Visual, Auditory and Somatosensory Evoked Potentials in Clinical Diagnosis, Seven Oaks: Butterworth, 1985.

WICHMANN, T. A digital averaging method for removal of stimulus artifacts in neurophysiologic experiments. J. Neurosci. Meth., v.98, p.57-62, 2000. 